TRUBBNERS BIBLIOTHEK

2.

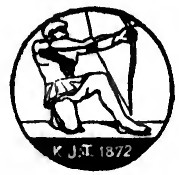




\section{.}



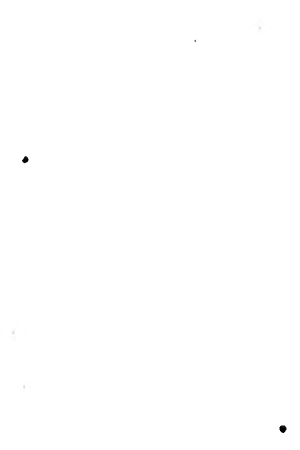


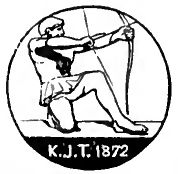


N2994k

TRÜBNERS PHILOLOGISCHE BIBLIOTHEK

BAND 2

\section{KURZE HISTORISCHE SYNTAX}

DER

\section{DEUTSCHEN SPRACHE}

VON

\section{HANS NAUMANN}

PRIVATDOZENT AN DER UNIVERSITAT STRASSBURG.

STRASSBURG

VERLAG VON KARL J. TRÜBNER 1915

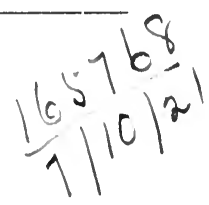


Alle Rechte, insbesondere das der Übersetzung, vorbehalten.

Druck von M. DuMont Schauberg, Straßburg. 


\section{Inhalt.}

Einleitung $\cdot \cdot \cdot \cdot \cdot \cdot \cdot \cdot \cdot \cdot \cdot \cdot \cdot \cdot \cdot \cdot 0^{\circ}$

1. Begriff der Syntax. 2. Grenzgebiete. 3. Die wichtigste syntaktische Literatur.

\section{Satzlehre.}

Subjekt und Prädikat ........... dikat.

4. Subjekt. 5. Subjektlose Sätze. 6. Impersonalia. 7. Prä-

Wortgruppen .............

8. Gruppenglieder und ihre Distanzstellung.

Gruppen mit Verbum ............

9. Verbum mit Infinitiv. 10. Accusativus cum Infinitivo. 11. Verbum mit Participium. 12. Dativus absolutus. 13. Erweiterung des Verbums. 14. Verbum mit Substantiv.

Gruppen mit Substantivum . . . . . . .

15. Substantiv mit Substantiv. 16. Attributiver Genitiv. 17. Ein adnominaler Dativ. 18. Attributives Adjektivum. 19. Substantiv mit Adverb. 20. Erweiterung des Substantivs.

Gruppen mit Adjektivum . . . . . . . .

21. Adjektivum mit Substantivum. 22. Adjektivum mit Adverb. 23. Erweiterung des Adjektivs.

Gruppen mit Adverbium . . . . . . . .

24. Bestimmung und Erweiterung des Adverbs.

Kongruenz und Inkongruenz . . . . . . . .

25. Kongruenz. 26. Inkongruenz der Person. 27. Inkongruenz des Numerus. 28. Inkongruenz im Genus. 29. Inkongruenz im Kasus. 30. Inkongruenz im Modus.

Hauptsätze ..............

31. Einfacher und zusammengesetzter Satz. 32. Aufforderungs- und Aussagesätze. 33. Negierte Sätze. 34. Fragesätze. 35. Entscheidungsfragen. 36. Ergänzungsfragen. 37. Disjunktive Fragen. 
Zusammengesetzter Satz .

38. Parataxe. 39. Unbezeichnete Hypotaxe. 40. 'A кoเvôิ. 41. Verknüpfung.

Hypotaxe ................

42. Volkstümliche und literarische Schreibweise. 43. Vom Wesen der Hypotaxe. 44. Syndetische Hypotaxe. 45. Merkmale der Abhängigkeit.

Relativsätze .............

46. Allgemeines über den Charakter des Relativsatzes. 47. Relativsätze ohne Relativum. 48. Relativpartikeln. 49. Relativpronomina. 50. Attraktion. 51. Weitere Relativpronomina.

Nebensätze mit Konjunktionen gebildet . . . 44

52. Mehrfacher Ursprung der Konjunktionen.

Konjunktionslose Nebensätze . . . . . . .

53. Mehrfacher Ursprung der konjunktionslosen Nebensätze. 54. Partikeln bei solchen Sätzen.

Verschiebung in Nebensätzen . . . . . .

55. Personenverschiebung. 56. Modusverschiebung. 57. Tempusverschiebung.

Die Stellung des Verbums im Hauptsatz... .

58. Ein psychologisches Stellungsgesetz. 59. Ein rhythmisches Stellungsgesetz. 60. Mittelstellung sekundärer Natur. 61. Mittelstellung des Verbums.

Endstellung des Verbums .........

62. Endstellung als Stilmittel.

Anfangsstellung des Verbums .......

63. Okkasionelle Anfangsstellung. 64. Anfangsstellung als Stilmittel. 65. Das satzeröffnende 'es'. 66. Anfangsstellung im Aufforderungssatz.

Inversion ................ . .

67. Ungerade Folge. 68. Inversion nach 'und'. 69. Schaltesätze. 70. Ausnahmen von der Inversion.

Stellung des Verbums im Nebensatz.....

71. Der Unterschied vom Hauptsatz. 72. Der Ursprung des Nebensatzes.

Ellipse ...............

73. Verschiedene Arten der Ellipse. 


\section{Formenlehre.}

Seite.

Genus und Numerus . . . . . . . . . 63

74. Genus. 75. Numerus.

Nominativ (und Vokativ) . . . . . . . . . 66

76. Nominativ. 77. Vom Vokativ.

Akkusativ . . . . . . . . . . . . . . . .

78. Akkusativ des Objekts. 79. Akkusativ des Inhalts. 80. Der Akkusativ bei den Verben der Bewegung. 81. Adverbieller Akkusativ und Akkusativ bei Präpositionen. 82. Doppelter Akkusativ. 83. Adnominaler Akkusativ.

Genitiv . . . . . . . . . . . . . .

84. Genitiv des Objekts. 85. Genitiv des Inhalts. 86. Prädikativer Genitiv. 87. Adverbieller Genitiv. 88. Genitiv bei Adjektiven. 89. Doppelter Genitiv. 90. Adnominaler Genitiv. 91. Genitivus partitivus. 92. Genitivus subjektivus und objektivus. 93. Genitivus possessivus. 94. Genitivus definitivus. 95. Genitivus qualitatis.

Dativ

96. Dativ des Objekts. 97. Der Dativ bei Verben als einziger Kasus. 98. Doppelter Dativ. 99. Dativus commodi und ethicus. 100. Adnominaler Dativ. 101. Der Dativ an Stelle des Lokativ. 102. Der Dativ an Stelle des Ablativ. 103. Der reine Instrumental. 104. Der Dativ an Stelle des Instrumental.

Starkes und schwaches Adjektivum . . . . . 88

105. Das schwache Adjektivum. 106. Das starke Adjektivum.

Die Nominalformen des Verbums oder das Verbum infinitum .............

107. Bedeutung und Funktion des Infinitivs. 108. Akkusativus cum Infinitivo. 109. Der adnominale Infinitiv. 110. Erweiterungen im Gebrauch des Infinitivs. 111. Neue Infinitive. 112. Das Participium Praesentis. 113. Das Participium Praeteriti.

Nominaler und verbaler Satzbau ......

114. Das Verbum finitum. 115. Beschreibender und erzählender Stil.

Genera Verbi

116. Die Funktionen der drei Genera. 117. Das Medioreflexivum. 118. Das Passivum. 119. Vermeidung des Passivs. 
Seite.

Vorbemerkungen zu den Tempora . . . . 109

120. Aktionsarten. 121. Die Tempora des Germanischen.

Praesens und Praesens historicum . . . . 111

122. Das reine Präsens. 123. Präsensumschreibung. 124. Praesens historicum.

Das Futurum ............. 115

125. Das Präsens als Futurum. 126. Umschriebenes Futurum.

Die Tempora der Vergangenheit . . . . . 117

127. Präsensbedeutung des Präteritums. 128. Das Tempus der Erzählung. 129. Das Präteritum als Perfektum. 130. Das neue Perfekt. 131. Die Bildung bei den Transitiven. 132. Die Bildung bei den Intransitiven.

Die Modi ................ 121

133. Der Indikativ. 134. Der Imperativ. 135. Der Konjunktiv Praesentis. 136. Der Konjunktiv Praeteriti. 


\section{Einleitung.}

1. Begriff der Syntax. Wir verstehen unter Syntax erstens die Lehre vom Satz, und unter 'Satz' verstehen wir seine ihm von Paul gegebene weiteste Definition: den sprachlichen Ausdruck einer Verbindung mehrerer Vorstellungen, die sich in der Seele des Sprechenden vollzogen hat, wonach auch Wortverbindungen wie Träume Schäume!; Ich ein Lügner? Sätze sind. Die Verbindung der Vorstellungen ist der Satz, die Vorstellungen selber sind durch Wortformen ausgedrückt. Jede Wortform hat ihre Bedeutung oder 'Funktion' im Satze. Wir verstehen unter Syntax daher zweitens die Funktionslehre der Formen im Satze. Es ist zuzugeben, daß man diesen zweiten Teil als völlig im ersten enthalten begreifen kann; denn eben nur insofern sie Funktionen im Satze haben, gehören die Formen überhaupt in die Syntax. Und selbst ursprünglich funktionslose Einzelformen wie etwa der Vokativ sind nicht immer ganz außerhalb des Satzgefüges geblieben. Es wäre - technisch gesprochen - möglich, die ganze Formenlehre in der Satzlehre unterzubringen. Hauptsächlich aber aus praktischen Gründen, besonders aus dem der Übersichtlichkeit, wollen wir uns entschließen, in den Bahnen der meisten neueren Syntaxdarstellungen indogermanischer Sprachen weiter zu wandeln und die Lehre von den Formen in einem zweiten Teile zu sammeln, auch unter der Gefahr, manche Dinge zweimal berühren zu müssen.

Naumann, Deutsche Syntax. 
2. Grenzgebiete. Noch finden längst nicht alle Erscheinungen auf unserm Gebiete ihre Erklärung, aber bei der Bewahrung und Fortdauer vieler einzelner unter ihnen spielt doch, scheint es, eine große Rolle der S til. Wie verhält es sich mit den Grenzen zwischen Syntax und Stil? Syntaktische Erscheinungen sind die Objekte auch der Stilistik, welche natürlich ihre Objekte auch noch auf anderen Gebieten der Grammatik hat. Syntaktische Erscheinungen können zu besonderen Stilmitteln werden oder anders ausgedrückt: es gibt Stilmittel bei Individuen oder ganzen Nationen, die ihre Erklärung in der Syntax finden. Ursprünglich nur unter ganz besonderen syntaktischen Umständen eingetreten, können sie ihre syntaktische Funktion verlieren und $\mathrm{zu}$ einer allgemeinen Stilregel werden. So liegt bei der 'Inversion nach und' zu gewissen Zeiten in gewissen germanischen Sprachen kein syntaktisches Gesetz mehr vor, sondern nur ein Stilgesetz. Der Stil erhebt zur Allgemeinheit und vernichtet damit zugleich den ursprünglichen syntaktischen Sinn. Syntaktisch hatte die verschiedene Stellung des attributiven Genitivs vor oder nach dem regierenden Substantiv verschiedene Bedeutung; zu gewissen Zeiten jedoch schwand diese und die Voranstellung ward ein allgemeines (poetisches) Stilgesetz. Der Stil wählt aus unter den Möglichkeiten der Syntax. Er kann ihre Feinheiten tilgen und eine Verminderung der Sprachmöglichkeiten bedeuten; er kann aber auch wie in Versteinerung bewahren und dem Forscher frühere syntaktische Möglichkeiten aufweisen, die längst keine Funktion mehr haben. Eine ursprünglich syntaktische Erscheinung, herausgenommen und verallgemeinert verleiht ein besonderes stilistisches Gepräge. Die volkstümliche Poesie hat die Schlußstellung des Verbums im Satze nie ganz aufgegeben, sie gehört ihrem Stil an, der sie bewahrte; 
unsere Syntax kennt sie nicht mehr. Den prädikativen Gebrauch des Akkusativs der älteren Sprache bewahrt der hohe poetische Stil noch heut. Eingeschobene oder angehängte Aussagesätzchen, an Stelle von Relativsätzen, bewahren einen syntaktischen Urzustand und verleihen gewisser Poesie zugleich einen sehr intimen Reiz; syndetischen Gebrauch des Nebensatzes bewahrt allein derselbe Stil, um Hypotaxe scheinbar zu vermeiden. Wir kommen auf alle diese Dinge unten an Ort und Stelle noch zurück. Aller Orten und aller Enden sind der Syntax Erscheinungen entwachsen, die nur noch die Bedeutung stilistischer Feinheiten besitzen. Die Syntax ist wie ein starker Baum, an dessen Ästen. und Zweigen die Stilmittel wie Laub und Blüten hangen.

Bereichern kann der Stil die Syntax nicht, denn er kann nicht gegen ihre Gesetze verstoßen. Er kann nur diese oder jen $\Theta$ Möglichkeit für ein gewisses Gebiet oder für gewisse Zeit zu einem Gesetze machen, wie z. B. das Pronomen beim Imperativ. Speziell auf die Wortfolge hat auch der Rhythmus mindestens so großen Einfluß wie der Stil, falls man ihn nicht einfach unter Stil mit begreifen will. Ein und dasselbe rhythmische Gesetz ließ die uralte Distanzstellung der Gruppenglieder sich so lange erhalten und veranlaßte die Mittelstellung des Verbums. Auch die Logik, mit der die Sprache an sich nichts zu tun hat, wirkt in gewissem Grade wohl stets, zeitweilig aber in verstärktem Maße auf die Syntax ein, man denke an die Lehre von der Kongruenz oder an die doppelte Negation.

3. Die wichtigste syntaktische Literatur.

Zur Definition der Syntax: J. Ries, Was ist Syntax? 1894; vgl. dazu Delbrück im III. Bande seiner Vergleichenden Syntax S. 1 ff. - Über Dinge prinzipieller Natur sowie auch über syntaktische Einzelheiten sind 
überaus wichtig H. Pauls Prinzipien der Sprachgeschichte, bes. die Kap. VI, VII sowie XV-XVIII. Ferner der II. Band von W. Wundts Völkerpsychologie, Die Sprache II. Teil, 1912.

Vergleichende Syntax; eine zusammenfassende Darstellung des ganzen Gebietes: B. Delbrück, Vergleichende Syntax der indogermanischen Sprachen, 3 Bde., $1893-1900=\mathrm{Bd}$. III $-\mathrm{V}$ von Brugmanns und Delbrücks Grundriß der vergleichenden Grammatik der indogerm. Sprachen. - Eine vorbildliche knappe Darstellung der indogerm. Satzlehre von K. Brugmann in seiner Kurzen vergleichenden Grammatik der indogerm. Sprachen, 1904, S. $623-705$.

Deutsche Syntax; zusammenfassende Darstellungen des ganzen Gebietes: Jacob Grimm im (III. u.) IV. Band seiner Deutschen Grammatik, 2. Ausg. neuer vermehrter Abdruck, 1870-98. - O. Erdmann, Grundzüge der Deutschen Syntax, 2 Bde., 1886 und 1898 (der 2. Band von O. Mensing). - H. Wunderlich, Der deutsche Satzbau, 2 Bde., 2. Ausgabe 1901. - Formenlehre von Verbum, Nomen, Pronomen im III. Bd. von W. Wilmanns Deutscher Grammatik, 1906-09.

Drei wichtige Monographien über die Syntax einzelner Schriftsteller: O.Erdmann, Untersuchungen über die Sprache Otfrids, 2 Bde., 1874. - O. Behaghel, Die Syntax des Heliand, 1897. - V. E. Mo urek, Beiträge und Weitere Beiträge zur Syntax des althochdeutschen Tatian, 1894-97.

Zusammenfassende Darstellungen der Syntax einzelner Dialekte in: W. Streitbergs Gotischem Elementarbuch, 1910, S. $161-256$; A. Heuslers Altisländischem Elementarbuch, 1913, S. 124-211; H. Pauls Mittelhochdeutscher Grammatik, 1904, S. 87-193. - Hier möge 


\section{$-5-$}

auch H. Wunderlich, Unsere Umgangsprache in der Eigenart ihrer Satzfügung, 1894, genannt sein.

Syntaktische Einzeluntersuchungen: K. Held, Das Verbum ohne pronominales Subjekt in der älteren deutschen Sprache, Palaestra 31, 1903. - A. Deneke, Der Gebrauch des Infinitivs bei den ahd. Übersetzern des 8., 9. Jahrh., 1880. - E. Dickhoff, Das zweigliedrige Wortasyndeton in der älteren deutschen Sprache, Palaestra 45, 1906. - K. Rick, Das prädikative Participium Praesentis im Althochdeutschen, 1905. - W. Wagner, Die Stellung des attributiven Genitivs im Deutschen, 1905.

R. Sch a chinger, Die Kongruenz in der mittelhochdeutschen Sprache, 1889. - B. Delbrück, Zu den negativen Sätzen, 1910. - K. Tomanetz, Die Relativsätze bei den althochdeutschen Übersetzern des 8. und 9. Jahrh., 1879. G.N e ckel, Über die altgermanischen Relativsätze, Palaestra 5, 1900. - B. Delbrück, Zu den germanischen Relativsätzen, 1909. - O. Behaghel, Der Gebrauch der Zeitformen im konjunktivischen Nebensatz des Deutschen, 1899. - B. Delbrück, Zur Stellung des Verbums, 1911. H. Winkler, Germanische Casussyntax I. Der Dativ, Instrumental, örtliche und halbörtliche Verhältnisse, 1896. B. Delbrück, Synkretismus, ein Beitrag zur germanischen Kasuslehre, 1907. - H. Herchenbach, Das Praesens historicum im Mittelhochdeutschen, Palaestra 104, 1911. H. Paul, Die Umschreibung des Perfektums im Deutschen mit haben und sein, 1902.

Von Zeitschriftenaufsätzen nennen wir nur einige besonders wichtige der jüngeren Jahrgänge; die übrigen wird man in obiger Literatur verzeichnet finden. O. Behaghel, Fernstellung zusammengehöriger Wörter im Deutschen, Indogerm. Forsch. 31, S. 371 ff.; Ich habe geschlafen, Zs. f. d. Phil. 32, S. 64 ff.; B. Delbrück, Der germanische Opta- 
tiv im Satzgefüge, PBB. 29, S. $201 \mathrm{ff}$; Beiträge zur germanischen Syntax, PBB. 36, S. 355 ff.; 37, S. 273 ff.; Das schwache Adjektiv und der Artikel in Germ., Indogerm. Forsch. 26, S. 187 ff.; W. Braune, Ahd. -î als Relativpartikel, PBB. 36, S. 557; R. Lenk, Die Syntax der Skeireins, PBB. 36, S. 237 ff.; C. Kraus, Über die mhd. Konjunktion 'unde', Zs. f. d. A. 44, S. 149 ff. 


\section{Satzlehre.}

\section{Subjekt und Prädikat.}

4. Subjekt. Die Glieder des Satzes - seine Redeteile: Subjekt, Prädikat, Objekt, Attribut, Adverb - können einzelne Wörter oder auch Wortgruppen sein. Die beiden Elemente des zweigliedrigen oder normalen Satzes, notwendige Elemente jedes mehrgliedrigen Satzes, sind Subjekt und Prädikat. Subjekt kann ein Substantivum, substantiviertes Adjektivum oder Pronomen sein; seine Form ist der Nominativ (s. § 76), statt dessen in der 3. Person auch der Genitivus partitivus möglich ist: got. ni was im rumis (griech. тómos), ahd. ioh brast thes wines.

5. Subjektlose Sätze. Scheinbar subjektlose Sätze gab es in der Frühzeit der Sprache, als die Person noch nicht durch ihr Pronomen ausgedrückt zu werden brauchte, weil die Endung noch genügte; nur in Fällen besonderen Nachdrucks wurde das pronominale Subjekt gesetzt. Diesen Zustand bewahrt das Gotische; es bewahrt ihn aber auch die volkstümliche Umgangssprache bis zur frühnhd. Zeit, in formelhaften Wendungen sogar bis heute, denn sie bedarf in ihrer Lebendigkeit der pronominalen Verdeutlichung nicht; ahd. willis trinkan; spenis mih mit dīnèm wortun, wili mih...; chümo kiscreib, filo chümōr kipeit; wānu, wān, neweiz, halto; mhd. wāne (woene), neiz, meine; nhd. bitte, danke, geschweige; frühnhd. pit euch, lieber her; acht wohl, sie werden ...; hoff, du wirst... Auch in bestimmten syntaktischen Verbindungen wie in asyn- 


\section{$-8-$}

detischer und syndetischer Parataxe konnte der volkstümliche Stil diesen Zustand festhalten; vgl. ein juncvrouwe, heizt Lünete; der spranc üf, sprach zehant; sō ligt mein muoter am Rein, ist tōt; syndetisch: ez geschach doch ime und sage iu wie. - Zunehmende Abschleifung der Endungen begünstigte aber von frühahd. Zeit an die Setzung des Pronomens als Mittel einer äußeren Kennzeichnung, besonders in aller Sprache mehr literarischen Charakters; mit der in Bezug auf das Genus des Subjekts mehrdeutigen 3. Person mag dies begonnen haben. Die Wirkung dieses literarischen Stiles hat sich zu Zeiten, besonders im Ahd., Frühmhd., sogar bis auf den Imperativ erstreckt; ahd. $n i$ zwivolo thu; drag thu; niene furhte du dir; mhd. her keiser, sit ir willekomen. Bei ausdrücklicher Betonung war und ist auch hier das Pronomen freilich ursprünglich; $d a$ siehe $d u z u$.

6. Impers onalia. Als ursprünglich eingliedrige Sätze, d. h. als Sätze bestehend aus nur einem Wort oder nur einer Wortgruppe, gelten die 'Impersonalia', ursprünglich wahrscheinlich subjektlose Verbalformen, namentlich zum Ausdruck physischer und psychischer Erscheinungen bestimmt. Vgl. got. rignida "es regnete", anord. rigner "es regnet". Im Anord. kam dieser Satz ohne psychologisches Subjekt zu großer Verbreitung, er gehört zum Stil dieser Sprache; aber im Deutschen hat er alsbald in $i z$, ez, es ein formelles Subjekt erhalten, wurde also damit auf die normale Form des Satzes gebracht; vgl. ahd. $i z$ a bandēt; mhd. ez äbandet; ez regent. Dieses Hilfsmittel steht im Zusammenhang mit dem Auftreten des Pronomens beim Verbum überhaupt (s. o.). Beim alleinstehenden Impersonale steht das Pronomen im Mhd. und Nhd. immer (es regnet), im Ahd. und Frühnhd. kann es unter dem Einfluß der volkstümlichen Umgangssprache auch fehlen; vgl. ahd. 
gilimphit "decet"; sō heiz wirt ze sumere; frühnhd. ist nit not; ist ouch nit beschehen. Steht ein Kasus obliquus dabei, so kann das Pronomen im Ahd. und Frühmhd. noch fehlen, mir limphit; tunchet mir reht; vom Mhd. ab aber nur noch bei Inversion, mich müet; desgl. wenn ein abhängiger Satz folgt: ahd. skinet, taz...; mhd. ez schinet wol, daz..., aber bei Inversion nu ist zit, daz...

7. Prädikat. Das Prädikat ist nicht notwendig [aber tatsächlich meist] eine finite Verbalform: vgl. got. gop salt

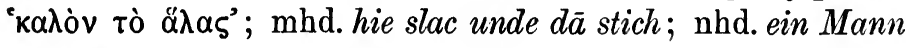
ein Wort, vgl. § 1 . Statt der finiten Verbalform kann auch eine Verbindung von Kopula und Prädikativum (Subst., Adj., Adv.) eintreten. Kopula war ursprünglich nur das Verbum substantivum (sin, wesan, werpan); vgl. got. ik im hairdeis gods; sah wairpip mikils. Später sind auch andere Verben zur Kopula geworden, so scheinen, dünken, heissen, nennen, gehen, stehen, sterben, bleiben u. a., von denen einige diese Fähigkeit wieder verloren haben. Vgl. ahd. ist mihhil giheizan; mhd. ir vater hiez Dankrāt; aller wïbe wünne diu gēt noch megetīn; ein mensche mac wol selic sīn, daz dā stirbet megetin; anord. er meyjar andaz "die als Mädchen sterben"; nhd. er bleibt König. Bei gehen, stehen, sterben verlangt das Nhd. die Vergleichspartikel als oder wie; vgl. aber noch Wendungen wie Schildwache, Gevatter stehen. Der Stil der höheren Poesie kann noch heute auf das als verzichten, vgl. bald fliegst du Braut im Reihn, Voss; passivisch: ein zartes Kind ward sie verpflanzt nach Frankreich, Schiller; mhd. aber durchaus usuell: d̄̄ wart ich empfangen hère frouwe. Beim adjektivischen Prädikativum gebraucht das Nhd. nur die unflektierte Form, er liegt tot, geht nackt; die ältere Sprache kennt auch die flektierte: ahd. er gāt mittēr; mhd. er liget töter (§ 106). 


\section{$-10-$
Wortgruppen.}

8. Gruppenglieder und ihre Distanzstellung. Wortgruppen sind Satzglieder, die durch neu hinzugetretene Begriffe näher bestimmt oder erweitert sind. Da zur Kennzeichnung der Beziehung und Zusammengehörigkeit der Gruppenglieder in ältester Zeit die Flexionsendungen genügten, war ihre Trennung innerhalb des Satzes auch im Germanischen möglich. Der archaische Stil der alten germanischen Poesie hat diese syntaktische Möglichkeit in der sogenannten abgetrennten Apposition geradezu zum Prinzip erhoben; aber auch die ältere gehobene Prosa bewahrt noch manches von ihr, vgl. aus Notker: tār die chreftigen steina noh ligent, manige after felde; an dero diu ida gleiz lütteres coldes; auch in pi des cheiseres ziten Zenonis ist die Apposition (cheiseres) von dem von ihr bestimmten Substantivum (dem Namen) getrennt, vgl. den gewöhnlicheren Fall der Nachstellung der Apposition aus dem ahd. Isidor fona Danihelis ziide avur dhes forasagin (a tempore itaque Danihelis prophetae). Wir reden dann von Distanzstellung der Gruppenglieder.

Unleugbar ist es das Gefühl für einen ganz bestimmten Rhythmus, das die lange Bewahrung und teilweise Bevorzugung der Distanzstellung entgegen der logischen $\mathrm{Zu}$ sammenstellung des Zusammengehörigen veranlaßt. Der Rhythmus, der sich beim Lesen ergibt, ist derselbe in dem Satze an dero diu ida gleiz lútteres coldes wie in der Wortgruppe $p i$ des cheiseres ziten Zénonis. Beidemal ist das eingeschlossene Wort (gleiz, zitten) den umgebenden Wörtern gegenüber schwächer betont. Den stärksten Ton hat das unmittelbar vorhergehende Wort. Die Tonfolge ist also: stark, schwach, mittel. Und es kann nun wohl kein Zweifel sein, daß eben dieser Schwachton der Grund dafür 
ist, weshalb das Wort eingeschlossen wurde, d. h. sich an das Wort mit stärkstem Ton enklitisch anlehnte, und daß somit dasselbe alte rhythmische Gesetz vorliegt, welches, wie wir noch sehen werden, das Verbum finitum in die Mittelstellung des Satzes trieb, s. unten \$ 59-61. - Die Abneigung der älteren Sprache bis in die frühnhd. Zeit (und teilweise noch weiter) gegen die Zusammenstellung der zusammengehörigen Gruppenglieder geht sehr weit und betrifft keineswegs bloß die Apposition. Wir geben hier Beispiele der häufigsten Typen:

Trennung des Nomens von seiner Bestimmung durch das Verbum: got. twans aihta sununs; ahd. s. die obigen Beispiele, dazu sïd Dētrïhe darbä gistuontun fateres mines; mhd. dō daz der keiser vernam Dyoclecianus; üze dir der rinne flōz allir gnäde; und noch Goethe: der geschwinde die Spuren tilget des schmerzlichen Übels.

Trennung des Nomens von seiner Erweiterung durch das Verbum: ahd. sowiesō min tac mich begrīfe unte minn ente; mhd. daz ir nie nichein de sunnen gesach noch den mānen sō lieht; und Schiller: so lang es Gott gefällt und Talbots Schwert.

Trennung des Substantivs von seiner Bestimmung durch das regierende Nomen: as. thuru thes kēsures thanc fan Rümuburg; ahd. Beispiele s. oben; mhd. ze der herzogin hüs vom wizen sē; nāch unser frouwen tag der verholnen; in unsir vrouwin ère Marien; sente Johannis tag ewangelisten; nhd. des Pfarrers Tochter von Taubenhain.

Trennung des Substantivs von seiner Erweiterung durch das regierende Nomen: ahd. dero sunnūn verte unde des mänen; mhd. sant Johannes muoter und sant Jacobes.

Trennung des Partizips oder Adjektivs von seiner Bestimmung durch das regierende Nomen: ahd. tise geweneten huorra ze theatro; mhd. ich was ein vollez vaz 
süntlicher schanden; du brinndiu minne über elliu lant; die schoene frowe als der morgenstern.

Trennung des Adjektivs oder Partizips von seiner Erweiterung durch das regierende Nomen: ahd. micheles magenes unde ungebrostenes; weitere Beispiele s. unten $\S 23$.

\section{Gruppen mit Verbum.}

9. Verbum mit Infinitiv. Näher bestimmt wird ein Verbum durch die Formen des Verbum infinitum. So kann z. B. der Infinitiv hinzutreten, um die Absicht oder die Folge der verbalen Handlung zu bezeichnen; er geht baden, er lehrt rechnen. Der Gebrauch dieses reinen Infinitivs war in der älteren Sprache viel uneingeschränkter als heut; er steht noch im Mhd. nach beginnen, woenen, fürhten, swern, erlouben, rāten, manen, suochen u. a. m., wo heut das Gerundium, d. h. der Dativ des Infinitivs mit der Präposition $z u$, seine Funktion übernommen hat; nhd. ich beginne zu reiten. Dieses Gerundium an Stelle des reinen Infinitivs ist indessen schon seit ahd. Zeit vorhanden, ghibis zi chisehanne; nicht verdrängt ist der Infinitiv heute nur noch bei wenigen Verben wie wollen, sollen, müssen, werden (vgl. die Bildung des Futurs), können, mögen, dürfen auch lehren, heissen, lassen, sehen, hören, bleiben; bei brauchen scheint in unserer Zeit schon wieder der Umschwung zum Gebrauch des reinen Infinitivs eingetreten zu sein.

10. Accusativus cum Infinitivo. Infinitive transitiver Verben können eine akkusativische Ergänzung bei sich haben; nur scheinbar entsteht dann ein Acc. c. Inf. im Sinne des Lateinischen, as. thuo bādun thia liudi that word wendian. Handelt es sich um Infinitive intransitiver Verben, so ist der Akkusativ nicht deren Objekt, sondern das des Hauptrerbs, mhd. die porten vant er offen stên. Diese zweite Art hatte wohl unbeschränkte Möglichkeit, 
aber auch ein Acc. c. Inf. der ersten Art war in der älteren Sprache, als noch nicht das Gerundium den Infinitiv so stark verdrängt hatte, häufiger als heute. Heute ist er nur noch bei den Verben 'heissen, lassen, hören, sehen, lehren', die den reinen Infinitiv als nähere Bestimmung bei sich haben, möglich; ich heisse den König wählen; ich seh eine Brücke schlagen (beidemal passivisch). Die Sprachentwicklung ging offenbar dahin, diese Konstruktion mit Hilfe eines abhängigen Satzes (dass-Satzes) zu vermeiden, obwohl Schriftsteller gewisser Zeiten, deren Sprachgefühl unter der Einwirkung des Lateinischen stand, dieser Tendenz und damit dem syntaktischen Gebrauch der Sprechsprache ihrer Zeit zuwiderhandelten, so z. B. die ahd. Tatianübersetzer; Notker; die Humanisten; Lessing, dieser jedoch nie ohne $z u$, also eigentlich Acc. c. Gerund. Ihr Stil blieb aber hierin ohne Einfluß auf das allgemeine Empfinden und die syntaktische Weiterentwicklung.

11. Verbum mit Partizipium. Zur näheren Bestimmung verbinden sich mit der Verbalform vornehmlich in prädikativem Gebrauch auch die Partizipia; ahd. fuar druhtin bredigönti; siu quam ruafenti; mit thên er lag biwuntan; wir se sehèn gehêrête. Die enge Verbindung mit den Verben sein, werden, haben führte, wie bei werden mit dem Inf., zur Bildung zusammengesetzter Tempora. - Da es möglich war, das Part. Praet. auch rein als prädikatives Objekt mit dem Verbum zu verbinden, mhd. ich tuon näch iu gesant, si wil mir ungelōnet län, so nimmt man an, daß sich hieraus der absolute Gebrauch einiger mit un- negierter Partizipien gebildet hat, wie mhd. ungerochen, unverscholt; nhd. unbeschadet, ungeachtet. Ein anderer absoluter Gebrauch hatte sich im Ahd. unter Benutzung der Adverbialform des Part. Praes. bei ungleichem Subjekt gebildet, so tuondo neist nehein weg (= quo fit, ut nullus locus relin- 
quebatur). Speziell im Ahd. ist nämlich neben der flektierten und unflektierten Form im Präsens anch eine Adrerbialform auf -0 mōglich, er fuar ilönto. Eine Nachbildung des lat. Gerundirs, zeigendo nach ostentando, braucht man wohl nicht anzunehmen.

12. Datirus absolutus. Der reine Dat absol. im Ahd. (ohne Prāposition) gilt als eine Nachahmung des lateinischen $\mathrm{AbL}$ absol.; bin gote helphante thero arabeito zi ente; bislszanèn thinēen turin. Diese Konstruktion gehört zum gelehrten Stil der ahd. Autoren; aber sie blieb ohne Einflub auf die Zukunft, denn bereichern kann der Stil die Srntax nicht. - Ein Dat. absol. hat sich rielleicht im Gotischen selbstāndig entwickelt, indem zunāchst nur zum Datirotjekt des Verbums ein attributives Partizip hinzutrat, dann aber diese Konstruktion auch bei anderen Nominalbegriffen, die nicht im Verhältnis des Objekts zum Hauptrerb standen, angenommen wurde; zunächst also qimandin pan dustiddjerlun imma pai blindans [rgl. eine entsprechende Konstruktion mit dem Akk.: voisandan gasah ina attal, dann aber auch raginondin Pontiau Prilatan ... varp vourd.

13. Erweiterung des Verbums. Erweitert kann die Verbalform werden durch ihre blobe Wiederholung oder durch die Hinzufügung der gleichen Form eines synonymen oder auch inhaltlich verschiedenen Verbs mit oder ohne Syndesis; vgl bet Kinder bet; die sangen sangen sangen wounder-wonderschim; sie bewegt sich, schwebt. Unter dem Begriff Variation oder 2- und 3-Gliedrigkeit ist diese verbale Erweiterung besonders aus dem Stil der alten Proesie, aber auch aller guten und gehobenen alten deutschen Prosa bekannt, vgl. aus Notker: disiu vournōt unde léret in (haec instruit); ordenost unde scafföst unde rihtest (gubernas). Volkstümlicher und mehr der Umgangs- 
sprache gemāß war hier bis in das 17. Jahrh. hinein die Asyndese, as. Johannes stôd, dōpte allan dag (baptizarit): ahd. quämun fleagente, fräzun daz (venerunt rolucres et comederunt); frühmhd. sie giengen zesamene sprächex Der rolkstümliche Stil hat diese rerbale Wortașndese über die mhd. Blütezeit, die ihm abgeneigt war, bewahrt: in Ausgang des Mittelalters stand sie, abgesehen ron einzelnen Autoren wie Lather, wieder in besonderer Blüte (dise pfeffein gieng, sagt in andachth, erst seit dem 1\%. Jahrh. rerliert sie sich, ohne doch aus der rolkstümlichen Poesie gänzlich rerschwunden zu sein.

14. Verbum mit Sabstantir. Die Verbalform kann ferner durch Substantirbegriffe näher bestimmt werden und zwar in allen Kasusformen aufer dem Tokatir: aus dem Gebrauch dieser adrerbalen Kasus ergeben sich ihre grammatischen Grandbedeutnngen. So bezeichnet der Genitir denjenigen Nominalbegriff, den die Terbalhandlung nur berührt, nicht rollstïndig ergreift; der Datir denjenigen, den sie nur entfernter betrifft; der Akkusatir aber den, den sie ganz und zunächst betrifft Der Nominatir aber bezeichnet den Begriff, ron dem die Tatigkeit ausgeht; erst seit der Entwictlung des Passirams auch den, der betroffen wird, also ganz allgemein den Gegenstand der Ausage. Näheres unter den einzelnen Kasus - Auch Pronominalbegriffe Lönnen unter den gleichen Cmstīnden zur näheren Bestimmung dienen, descleichen Adjektira, mhd. owch gienc der walt irildes rol: nhd. ich traf ith gesind an, ferner Adrerbia, wich mahl kefinden. ich suneifle nicht und Praipositionen, ich gehe monuse

\section{Gruppen mit Sabstantivace.}

15. Substantir mit Substantir. Näher bestimnt fann ein Substantir werden darch ein anderes Suhstantir. 
welches, wenn es sich mit ihm im gleichen Kasus befindet, in engerer Verbindung Attribut, in freierer Apposition genannt wird. Die Apposition, die ja allermeist an Stellen steht, wo wir heute einen Nebensatz bilden könnten, stellt ein sehr altes Mittel parataktischer Ausdrucksweise dar. Der archaische Stil der epischen Poesie hat sie deshalb mit Vorliebe bis in die mhd. Zeit bewahrt, besonders in der Distanzstellung, s. o. §8; vgl. ahd. sō imo se der chuning gap, Hüneo truhtìn; mhd. Volkèr und Hagne und ouch Ortwin laschten in dem strite vil maneges helmes schin mit fliezendem bluote, die sturmküene man. Bei Kontaktstellung erscheint von früh an die Voranstellung neben der Nachstellung des bestimmenden Substantivs, obzwar diese öfter als jene; got. Xristus frauja; piudans Herodes; ahd. Hërōd ther kuning neben ther kuning Hëröd; as. Ërodes the cuning neben cuning Herodes. Vermutlich ist die Nachstellung - eine nachträgliche Hinzufügung - die usuellere gewesen und hat die Voranstellung ursprünglich nur bei besonderer Betonung stattgefunden. Freilich verschob sich im Deutschen die Tonlage, besonders beim attributiven Herr und Frau, fast bis zur Tonlosigkeit; so konnten im Mhd. die verkürzten Formen her und frou entstehen; vgl. her Sifrit, aber Sifrit der herre. - Von früh an ist auch die engste, bis zur Verschmelzung in einen Begriff gehende Verbindung zweier Substantiva zu beobachten; vgl. as. god fader $=$ nhd. Gott Vater im Gegensatz zu Gott Sohn; mhd. frou magt = Frau, die noch Jungfrau ist; nhd. Königinmutter, Prinzregent.

16. Attributiver Genitiv. Aber das bestimmende Substantivum kann auch im Genitiv stehen; wir reden dann von einem attributiven Genitiv oder einer Genitivapposition, deren Distanzstellung als eines alten Stilmittels schon oben gedacht worden ist. Für Kontaktstellung vgl. 
got. waldufni kindinis; ahd. kotes willun, hella fuir, pehhes pina; mhd. ein brünne rötes goldes; nhd. der Jüngling edlen Gefühls. Bei Kontaktstellung war der Platz dieses attributiven Genitivs vor oder nach dem regierenden Substantivum ursprünglich wiederum von der Betonung abhängig; usuell war die Nachstellung, insofern wohl für gewöhnlich das Substantiv den Hauptton trug, vgl. altlat. pater familias im Gegensatz etwa zu mater familias, okkasionell bei besonderer Betonung die Voranstellung, vgl. vulgärlat. Mercuris die (Mercredi) im Gegensatz zu Martis die (Mardi) u. a. Besonders Genitive von Namen sind deshalb in allen Zeiten gern vorangestellt worden, ahd. Davides sunu; mhd. des Etzelen wip; nhd. zu Karls Zeiten; so auch der Genitiv von 'Gott' mhd. diu gotes hant; nhd. von Gottes Gnaden. Der Stil wählt aus unter den Möglichkeiten der Syntax. Der ungewöhnlichere Gebrauch erschien als der schönere; die Voranstellung des attributiven Genitivs bei Kontaktstellung wurde ein Stilgesetz aller gehobenen Sprachen. Im Anord., das sich eines prosaischen Stiles befleißigt, ist die Nachstellung die Regel; im Deutschen aber ist in ahd. und mhd. Zeit die Voranstellung die poetische Stellung, im Mhd. sogar bis ror den unbestimmten Artikel, der werlde ein wunne, im Ahd. bis vor die Präposition, fireo in folche; folches at ente, aber nhd. aus Leibes Kräften. Ganz offenbar aus einem bestimmten Stilbedürfnis hat z. B. der ahd. Übersetzer des Isidor fast immer den Genitiv vorangestellt, ausdrücklich gegen die Vorlage; vgl. mit freuwidha olee "oleo laetitiae".

17. Ein adnominaler Dativ existiert wohl im Deutschen nur scheinbar bei prädikativem Substantivum; tatsächlich ist er dann nähere Bestimmung des Prädikats; got. sijai allaim andbahts; ahd. ther in drōst was; mhd. er ucer den besten wol genōz. Auch in ahd. di wart demo

Naumann, Deutsche Syntax. 
Balderes volon sin vuoz birenkit gehört der Dativ zum Verbum, nicht zu vuoz. In Verbindungen wie mhd.ein vorlouf allen; dū widerstrite ('Gegner') viendes rāte regiert den Dativ gleichfalls der verbale Begriff, der den beiden Nomina agentis zugrunde liegt. Entsprechendes läßt sich bei einem 'adnominalen' Akkusativ beobachten; mhd. $d \bar{u}$ schirmerinne gotes hantgetät; von lesern getreide üf dem velde.

Ein adnominaler Instrumental begegnet in der älteren Sprache noch zuweilen, got. goleins meinai handau; ahd. nam Maria nardon filu diurēn werdon; liuti fëhemo muate, wird dann aber durch die Präposition (mit dem Dativ) ersetzt.

18. Attributives Adjektivum. Ein attributives Adjektiv kann ein Substantiv näher bestimmen und muß dann mit ihm in gleichem Kasus stehen. Seine Stellung war ursprünglich wiederum durch den Ton geregelt; usuell stand es voran, denn es trug wohl gewöhnlich den Ton. Diese Stellung ist auch im Germanischen für gewöhnlich durchaus die Regel und im Anord. blieb diese alte usuelle Stellung wiederum die herrschende. Got. sa liuba bropar; ahd. michil wuntar; mhd. ein schoene magedin; anord. skamma stund "eine kurze Weile". Diese Beispiele entstammen, wenn auch längst kein besonderer Nachdruck mehr in der Voranstellung empfunden worden sein mag, doch der alten syntaktischen Ursache der Voranstellung, eben dem besonderen Nachdruck. Ursprünglich hatte aber wohl jedes adjektivische Attribut seinen besonderen Nachdruck, andernfalls wurde es gar nicht verwendet; 'stehende Epitheta' sind sprachlich sekundärer Natur. Deren Funktion ist gewissermaßen nur pleonastisch oder ausschmückend, ohne besonderen Ton; ihre Stellung ist daher hinter dem Substantiv. Diese Funktion hatte im Germanischen das Possessivpronomen erhalten und im Nord. und Got. so bewahrt; urnord. magu minino 'meinen Sohn'; anord. son sinn, haugr minn; got. gup meins, haubip 
pein; im Deutschen ward es vermutlich von der Analogie zur usuellen Stellung der Adjektiva aus dieser Nachstellung wieder befreit; ahd. sin fater, üsere liuti, minn fater. Nachgestellt liebt es, wie auch das Adjektivum, im Deutschen nur der volkstümlich-poetische Stil. Denn erstens liebt er die 'stehenden Epitheta', also attributive Adjektiva rein ausschmückender, unbetonter Natur: so wurde deren Nachstellung als poetisch empfunden und verallgemeinert in der Poesie. Zweitens darf man wie beim attributiven Genitiv sagen, daß die okkasionelle Stellung wiederum als die poetische empfunden worden sei; wie dort die Voranstellung, so ward hier die Nachstellung ein Stilgesetz der poetischen Sprache. Und der poetisch-volkstümliche Stil bewahrt die alte syntaktische Möglichkeit der Nachstellung bis heute; ahd. barn unwahsan, fateres mines, hërron göten, güdea gimeinūn; mhd. degen guot, willen min; nhd. ein Mündlein rot, Röslein rot, Ritter kühn, die Tulipanen gelb und weiss, Ringlein fein, Allerliebster mein.

19. Substantiv mit Adverb. Schließlich noch die nähere Bestimmung eines Substantivs durch Adverbien. Attributive Verbindung mit einem Raumadverb ist nichts seltenes; der Mann hier, irmingot obana, then sē hiar nidana. Auch die Verbindung mit einem Richtungsadverb ist heut nicht selten; eine Fahrkarte dorthin; der Weg hierher. In älterer Zeit läßt sie sich selten nachweisen, vgl. Goethe Berge wolkig himmelan; im Hildebrandslied sēoliddante westar ubar wentilsēo.

20. Erweiterung des Substantivs. Erweitert kann das Substantiv werden durch seine bloße Wiederholung oder durch die Hinzufügung der gleichen Form eines synonymen oder auch inhaltlich verschiedenen Substantivs mit oder ohne Syndesis. Wie beim erweiterten Verbum bediente sich besonders der Stil der gehobenen Sprache 
dieser 2- (und 3-)Gliedrigkeit, vgl. aus Notker zimber unde geziug (= machinas), rōsā unde ringelen unde violae; aus dem Heliand: cunnies eftho cnōsles; wurdgiscapu, metod endi maht godes. Und wie beim Verbum so war auch hier volkstümlicher und der Umgangssprache gemäß bis in das 17. Jahrh. hinein, mit der typischen Abneigung bei der mhd. Dichtersprache, die Asyndese; vgl. ahd. floug er sunnūn pad, sterrōno strāaa, wega wolkōno; mennisken in erdo, sternen in himele (bei Notker); mhd. von rittern frouwen, üf bluomen gras (Wolfram); üf wengel, mündel rōt; frühnhd. all strassen, gassen; von spiessen, hellebarten. So auch bei Namen: vgl. eine ahd. Notiz zu Ps. 21, 19 der Notkerschen Psalmenübersetzung in der St. Galler Handschrift unde sint hiuto Richarth, Poppo, quorum usw., eine Eigentümlichkeit, die auch in den Stil der alten Urkunden übergegangen ist, vgl. Wacco, Gundila cum filiis suis; Wigrih, Asa cum duobus filiis Uto, Heimolf; pro anima Atanae serviant tibi Altolf, Hettila.

\section{Gruppen mit Adjektivum.}

21. Adjektivum mit Substantivum. Ein Adjektivum kann durch Substantiva näher bestimmt werden, die im Genitiv und Dativ (Ablativ, Instrumental, Lokativ), später auch im Akkusativ stehen. - Der Genitiv stand von früh an bei einer Reihe von Adjektiven wie "wert, würdig, voll, begierig, froh, gewaltig, teilhaftig, satt, müde, gewahr, kundig, eingedenk' und ihren Gegenteilen, vgl. got. wairps mizdons, ahmins weihis fulls; ahd. wisduames follo; as. sprākono spāhi; mhd. kindes swanger, strites sat; nhd. seines Lohnes wert, voll süsses Weines (Luther); die Hengste begierig des Stalles, des Treibens müde (Goethe). Auch bei Farb- und Maßadjektiven und bei 'alt'; vgl. rōsen rōt, bluotes rōt, grā des häres, drīer tageweiden lang, 
drièr jāre alt. $\mathrm{Zu}$ allen Zeiten hat man, scheint es, im Deutschen die Voranstellung des Genitivs bevorzugt, sie mindestens als die edlere empfunden. Seit nhd. Zeit hat bei vielen dieser Adjektiva den Genitiv der Akkusativ verdrängt, besonders bei 'alt' und bei den Maßbezeichnungen; doch wird fast durchgängig der Genitiv noch als stilistisch edler empfunden.

Der Dativ steht ron früh an bei einer Reihe von Adjektiven wie 'nah, fern, lieb, feind, kund, gleich, nützlich, gemäß usw. [Über seinen Ursprung aus dem zugrunde liegenden Verbalbegriff gilt dasselbe wie vom Genitiv und Akkusativ bei Adjektiven, s. $\S 88, \S 100]$. Vgl. got. modags bropr seinamma; as. odrun mannun gilih; ahd. chüd was her chōnnēm mannum; Otachre ummet tirri; mhd. den vienden was er herte. Der Dativ vertritt hier teilweise und in anderen Fällen wie got. unledans ahmin, as. wāpnun wunde, anord. fríđir sýnum 'schön von Gesicht' den alten Instrumentalis. Den Ablativ vertritt der Dativ nach Komparativen in der alten Sprache, got. maiza Johanne bamma daupjandin; as. èr dōmes dage; ahd. wizero snēwe; den Lokativ vielleicht in ags. legere foest 'auf dem Lager fest', mōde crceftig 'klug in seinem Sinne'. [§ 101-104.]

22. Adjektivum mit Adverb. Ein Adjektivum kann durch ein Adverb näher bestimmt werden; vgl. got. filu manags 'sehr viel'; ahd. ummet spähēr, ummet tirri; mhd. unmāzen schoen; nhd. ewig jung, einst so schön.

23. Erweiterung des Adjektivs. Erweitert kann ein Adjektivum werden durch ein anderes unter denselben Umständen wie ein Verbum und ein Substantivum (s. diese). Über das Stilmittel der 2- (und 3-) Gliedrigkeit gilt dasselbe wie beim erweiterten Verbum und Substantivum; vgl. aus Notker micheles unde ungebrostenes (= inexhausti); aus dem Heliand mildean endi guodan, māri endi mahtig. Bei attri- 
butivem Gebrauch ist es im As. und Ahd. üblich, das eine Adjektivum vor, das andere asyndetisch hinter das Substantivum zu stellen, as. gōdoro wordo spāhlīcoro; ahd. ein suozé(r) fisc luzzelèr. Diese umrahmende Stellung ist im Mhd. die gewöhnliche, mehr mit Asyndese: der stolze ritter guot, die schonen tohter sin, lieben vriunde min, zwō galie niuwe als ohne sie: arme liute und dürftige, ein trïebez wolken unde dic, ahd. micheles magenes unde ungebrostenes; so merkwürdigerweise im Anord. gewöhnlich: gott ráp ok drengelegt 'ein guter ritterlicher Rat'. Asyndetische Voranstellung beider Adjektiva mag aber trotzdem sehr alt und volksmäßig sein; vgl. anord. mildir fréknir menn (Họ́vamọ́l 47 (48), 1); frühmhd. einen schœnen guldin vingerlin, einen rōten siden roc, mit siner linden wizen hant; sie ist durch die ganze mhd. Zeit sehr beliebt und ist heute durchaus die übliche. Hierbei wird das alte Asyndeton kaum aufgegeben, man sagt nur ganz ausnahmsweise ein grosser und guter Mann, mhd. alte und wise liute. Asyndetische Nachstellung begegnet $\mathrm{zu}$ allen Zeiten ganz selten, mhd. ein ritter gemeite, herlich gereite; einen stern lauter, klar. Nachgestelltes Syndeton ist in der frümhd. Zeit beliebter als in der Blütezeit, ein helet kuone unde snel.

Mit der Asyndese substantivierter und prädikativ gebrauchter Adjektiverweiterungen verhält es sich wie mit dem verbalen und substantivischen Asyndeton, s. diese; vgl. diu süeze, reine; sin schilt was alt sware breit; wird ich schwach, unfruot.

\section{Gruppen mit Adverbium.}

24. Bestimmung und Erweiterung des Adverbs. Ein Adverb kann durch ein Adverb näher bestimmt werden, got. filu mais = nhd. viel mehr, as. sō wido = nhd. so weit. Es kann unter den bekannten Umständen auch erweitert 
werden, vgl. nhd. mehr und mehr; ahd. vielleicht ostar enti westar (für lat. in oriente et occidente). Vielleicht müßte man indessen, wie richtig bemerkt worden ist es handelt sich um den bekannten, von Haupt übersetzten Spielnannsreim - ostar, westar übersetzen, denn bis in das 17. Jahrh. hinein entsprach hier wiederum das Asyndeton dem volkstümlicheren Gebrauch; vgl. ahd. want er giscreib uns suazo, ofono filu fram; hera duoder; enteo ni wenteo;

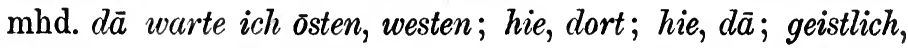
werltlich mac si mich wol laden; frühnhd. fornen, hinden; ganz spötlich, närrisch; früntlich, menschlich.

Ein Adverb kann durch ein Substantivum, wohl ausschließlich im Genitiv, näher bestimmt werden; ahd. wanana lantes?, vgl. nhd. woher des Wegs?; got. ni waiht ubilis; ahd. ni mag er finden wehseles wiht. Aus diesem Gebrauche erklärt sich auch der Genitiv in negativen Sätzen, in denen er anscheinend kaum noch von der Negation abhängig ist, vgl. mhd. mir kom so lieber geste nie. Zugrunde liegt hier letzten Endes ein adnominaler Genitiv und zwar der des geteilten Ganzen.

\section{Kongruenz und Inkongruenz.}

25. Kongruenz. Zur Kennzeichnung der Beziehungen der Gruppenglieder untereinander und ihrer Zusammengehörigkeit hatte sich in den indogermanischen Sprachen ihre Übereinstimmung in den Flexionsendungen herausgebildet. Diese formelle Übereinstimmung der zusammengehörigen Glieder in Genus, Numerus, Kasus und Person heißt Kongruenz. Aber nicht immer und überall hat dieses unter dem Zwange formaler Logik sich verallgemeinernde syntaktische Hilfsmittel Geltung erlangt, und die natürliche Rede zeigt, z. B. wenn im Bewußtsein des Sprechenden 
die Bedeutung eines Wortes seine Form unterdrückt, noch und immer wieder mannigfache Spuren der Inkongruenz. 26. Inkongruenz der Person. Bei mehreren pronominalen Subjekten steht das Verbum meist im Plural und zwar in der 1. Person, falls im Subjekt eine 1. Person vorhanden ist, in der 2. Person, falls das Subjekt nur eine 2. und 3. Person enthält; vgl. mhd. ich und min geselle (wofür man auch er setzen könnte) müezen uns scheiden; daz du und diniu kint (wofür man auch sie, siu setzen könnte) deste swecher miiezet sin. Singular des Verbums, regelrecht aber die 1. Person steht z. B. in dem Satze die weil ich und er junk pin (Keller, Fastnachtsp. 728, 26).

In einem Relativsatze, angeknüpft an eine 1. oder 2. Person, richtet sich das Verbum entweder nach dieser und steht auch in der 1 . oder 2. Person oder es richtet sich nach dem Relativum und steht in der 3.; vgl. as. Gabriel bium ic hetan, the gio for goda standu; mhd. $d u$ valscher man, der die ungerehten machest sleht; oder aber as. fadar $\overline{u s a}$, the is an them hohon himila rikea; mhd. du sniterin, diu daz korn ab dem velde snīdet. In nhd. Zeit wird nach dem Relativum das Pronomen wiederholt und verlangt dann seine Person, du der du hier bist.

27. Inkongruenz des Numerus. Wenn mehrere Subjektswörter zu einem Prädikat gehören, so steht im Deutschen das Verbum im Singular oder Plural, je nachdem wann es in das Bewußtsein des Sprechenden tritt. So scheint bei ungrader Folge der Singular zu überwiegen; vgl. got. wairpip pus faheds iah swegnipa; ahd. fuar druhtinn inti sine ubar einen lantsē; mhd. daz hōrte der künic gerne und alle sine man; daz hät ir schoene und ir giiete gemachet und ir rōter munt, der sō lieplīchen lachet; nhd. es sollte Meer und Land nicht einem dienen. Ausnahmen gibt es freilich vom Gotischen an. - Bei grader Folge läßt sich 
keine Regel aufstellen, vgl. Schiller im Lied von der Glocke: dass sich Herz und Auge weide neben Markt und Strasse werden stiller; got. Andraias iah Filippus qebun neben malo iah nidwa frawardeip; mhd. ir höfscheit unde ir güete beswärten ir gemüete neben Dietrich und Etzel weinen dö began. - Bei halb grader, halb ungrader Folge, d. h. in der Einschachtelung zwischen 2 Subjektwörter oder, wie wir oben $\S 8$ sagten, bei der Trennung des Subjekts von seiner Erweiterung durch das Verbum herrscht der Singular, weil hier allzu deutlich von jedem der Subjekte etwas einzeln, vom zweiten etwas nachträglich ausgesagt wird; vgl. zu den Beispielen von $\S 8$ noch ahd. thär Martha was ioh Maria; mhd. ir herze erbibete und alle ir lider und bei Schiller Meister rührt sich und Geselle.

Ist das Subjekt ein kollektiver Begriff, enthält es also der Bedeutung nach eine Mehrzahl, der Form nach aber den Singular, so steht das Verbum in den hauptsächlich am Latein geschulten Perioden unserer Sprache im Singular; aber in Zeiten einer natürlichen, volkstümlichen und lebendigeren Redeweise trat und tritt hier die Inkongruenz alsbald zutage. Beispiele für diese finden sich sogar bei Ulfilas und im Althochdeutschen; vgl. got. setun bi ina managei; ahd. quam menigi thero Judeöno èr, dröstun thär thio swester, bätun... Im Mhd. steht nach Begriffen wie her, diet, volc, schar, pfaffeheit, kristenheit der Plural des Verbums außerordentlich oft; noch im älteren Nhd. ist der Gebrauch sehr verbreitet, Luther alle Menge deines Hauses sollen sterben und noch bei Goethe: wie eine rasende Menge Kapellen, Kirchen, Klöster anfallen. In nhd. Schriftsprache begegnet hier die Inkongruenz höchstens, wenn von dem Kollektivum ein partitiver Genitiv Pluralis abhängt, eine Menge Kartoffeln sind erfroren. So rufen auch filu, filo, vil, ursprünglich ein singulares Substantiv im 
Neutrum, ferner manec, nhd. genug, wenig und ihre Entsprechungen, auch das verallgemeinernde mhd. swaz die Inkongruenz hervor; vgl. got. filu manageins laistidedun afar imma; mhd. darumbe muosen degene vil verliesen den lip; nhd. der Worte sind genug gewechselt; mhd. swaz hie werder liute sint. Umgedreht regieren Zahlbegriffe den Singular des Verbums; ahd. ther iāro was fiarzug inti sehs; die da gessen hatten, der war viertausend (Luther); zweimal zwei ist vier. Es wird die Zahl wie eine Einheit behandelt; vgl. dazu auch das zusammenfassende ein vor Zahlangaben in volkstümlicher Rede; doch kann ich heimlich ein zwanzig Reiter zu euch stossen lassen; wol an ein tausend Jahr. Begriffe wie 'Männer, Kleider, Rosse, alle Dinge, Hände' u. a. m. regieren gleichfalls oft den Singular und einmal ist die syntaktische Möglichkeit der Inkongruenz mit singularem Verb nach formalem Plural des Subjekts zwar nicht für eine ganze Epoche, doch aber für einen einzelnen Autor, Wolfram von Eschenbach, gradezu zum Stilgesetz geworden; Sätze wie driu grōziu fiwer gemachet was; nāch dem selben reit pusüner; an disen aht frouwen was röcke grüener denn ein gras usw. finden sich bei Wolfram massenhaft.

Steht das Prädikatsnomen im Plural, das Subjekt aber im Singular, so richtet sich das Verbum im Numerus nicht nach diesem, sondern in durchaus üblicher Weise nach dem Prädikatsnomen; vgl. anord. petta ero mikel tifpendi $=$ nhd. das sind grosse Neuigkeiten; ahd. daz gras sint $\bar{a} k u s t i$; mhd. ez heizent allez degene; daz sint allez megede.

28. Inkongruenz im Genus. Eine Inkongruenz im Genus kann beim attributiven Adjektiv eintreten, wenn das regierende Substantiv dem grammatischen Geschlecht nach zwar ein Neutrum, dem natürlichen nach aber eine 
männliche oder weibliche Person bezeichnet; vgl. got. gup meins; as. gisähun that barn godes ēnna (Akk. mask.) standan; mhd. ich armer Dietmāres kint; ein offeniu süeziu wīp. Sie tritt auch zwischen dem Substantivum und dem seine Funktion wiederholenden Pronomen ein; vgl. as. thō quam thar ōc èn wîf gangan ..., Anna was siu hètan; mhd. ein edel magedin, ... si wart ein schcene wip; daz gotes kind, der uns erlöste; nhd. das Gräflein, es blicket hinüber, es dünkt ihm, als läg er im Fieber. Bei Worten wie 'Mädchen, Weib' usw. wird heute nur äußerste Pedanterie die Kongruenz durch längere Perioden hindurchführen.

Ein als Subjekt gebrauchtes Demonstrativ- oder Interrogativpronomen kann im Neutrum stehen und sich dergestalt in Inkongruenz mit dem prädikativen Substantiv befinden, vgl. got. niu pata ist sa timrja?, ahd. dat was sō friuntlaos man; mhd. daz eine was hèr Dietrich, daz ander Hagene. Ausnahmen gehören in die Schulsprache; vgl. ahd. ist thesêr iuwēr sun (aus der Tatianübersetzung); anord. ok sú varp saétt peira "und dies wurde ihr Vertrag".

29. Inkongruenz im Kasus. Die größere Selbständigkeit, durch die sich die Apposition vom Attribut unterscheidet, erweist sich auch in ihrer kasuellen Inkongruenz mit dem regierenden Substantivum, die von früh an zu belegen ist. Vgl. aus Dürer: ich bin ... mit Meister Jan Prevost, ein guter Maler..., gen Prüg gefahren; aus Goethe: nur kontrastierte die Person des Kardinals, ein kleiner zusammengefallener Mann...

Inkongruenz kommt zuweilen vor, indem bei 'heißen, nennen' mit dem doppelten Akkusativ der Name in den Nominativ, statt in den Akkusativ tritt; mhd. daz man in hiez der bāruc (Wolfram); nhd. ich hiess ihn mein Montan (Gellert).

Bemerke umgedreht Herstellung von Kongruenz = Assimilation des zu einem Infinitiv gehörigen Prädikats- 
nomens an das persönliche oder persönlich gedachte Objekt des Hauptverbums; besonders im Anord., vgl. betra er bér at vera gódum "besser ist es dir gut zu sein", aber auch im Deutschen, vgl. Goethe: lass das Büchlein deinen Freund sein.

30. Kongruenz im Modus. Der Modus des Nebensatzes assimiliert sich zuweilen an den des Hauptsatzes; vgl. mhd. got müeze im lōnen, daz er mir wage sī "dafür daß er mir hold ist".

\section{Hauptsätze.}

31. Einfacher und zusammengesetzter Satz. Überblicken wir die Sätze im Strom einer Rede, so werden sie sich am leichtesten in einfache und zusammengesetzte Sätze zergliedern lassen. Aus dem Begriff 'zusammengesetzter Satz' ergibt sich eine zweite Einteilungsart, nämlich in Haupt- und Nebensätze. Ein Gebilde wie der König lebt und (oder denn) er regiert sein Land ist nur scheinbar ein zusammengesetzter Satz; es zerfällt nach Entfernung der Kopula in zwei einfache selbständige Sätze. Wir reden dann von der Verknüpfung zweier koordinierter Sätze. Ein Gebilde aber wie der König lebt, weil ( $d a$, damit, dass, indem, während) er das Land regiert ist notwendig ein zusammengesetzter Satz; die Herausnahme der Konjunktion löst es nicht in zwei einfache selbständige Sätze auf; es besteht aus Haupt- und Nebensatz. Dieser Unterschied zwischen Verknüpfung und Zusammensetzung ist indessen nur historisch, ein gewordener.

32. Aufforderungs- und Aussagesätze. Wir teilen die Hauptsätze ihrer psychischen Funktion nach ein in Aufforderungs- und Aussagesätze. Unter Aufforderungssätzen verstehen wir auch die Wunsch-, Befehls-, usw.-Sätze mit. Diese Scheidung der Sätze hat sich gewiß schon im 
ersten Stadium der Ursprache vollzogen und ihr einziger Unterschied hat vermutlich zuerst nur in verschiedener Betonung gelegen. Der König lebe! Der König lebt. Mit beiden Arten von Sätzen können zwei Formierungen vorgenommen werden, die sich auf ihren Inhalt beziehen: sie können in Frage gestellt, sie können ganz verneint werden. Der König lebe? [er möge nicht vielmehr sterben?]. Der König lebt? - Der König lebe nicht! Der König lebt nicht. 33. Negierte Sätze. Die Verneinung findet also ibren besonderen sprachlichen Ausdruck, wohl überall und seit je. Die negativen Sätze erwecken syntaktisch kein besonderes Interesse, abgesehen von der Stellung der Negation. Diese tritt in Wahrheit nicht zum ganzen Satze, sondern immer nur zu einem Satzglied oder nur zu einem Gruppenglied. Der Mann ist nicht gelaufen. Kein Mann ist gelaufen. Ich habe keinen Mann laufen sehen. Der Mann ist nicht sehr gelaufen.

Die Negation (germ. got. ahd. ni, mhd. ne, en, n) steht im Indogermanischen unmittelbar vor dem Begriffe, den sie negieren soll und auch für das Germanische ist das die Regel; also wenn sie das Prädikat verneint: ahd. ih ni weiz und noch mhd. ich enmac. Das nhd. nicht steht hinter dem Verbum, weil wir unter seiner Einwirkung seit mhd. Zeit das vorausgehende ne verloren haben, zu dem niht erst pleonastisch hinzugetreten war. - Substantivische Negationsbegriffe, die ein Subjekt oder Objekt im Satze vertreten können, sind eben dadurch gebildet, daß die Negationspartikel unmittelbar vor dem positiven Begriffe stand, den sie negierte (niemand = ahd. nioman, got. ni manna; nichts $=$ ahd. niowiht, got. ni waiht(s)); desgleichen negierte Zeit- und Raumadverbien (niemals, nie, nirgend usw.).

Bei so völliger Verschmelzung geschah es, daß die 
Negation nicht mehr genügend empfunden und beim Verbum noch einmal in ihrer gewöhnlichen Stellung wiederholt wurde, ahd. nioman weiz neben nioman ni weiz. Bereits im Gotischen läßt sich diese Erscheinung bei ni waiht beobachten, ni mahtedi taujan ni waiht; niu andhafjis waiht neben niu andhafjis ni waiht. Im Deutschen ist die doppelte Negation durchaus geläufig, ahd. nioman nist guot; sie ni quedent imo niowiht; mhd. $j \bar{a}$ enweiz hie nieman; ern bōt mir nie die êre. Durch den häufigen Gebrauch von Sätzen des Typus ich enweiz niht ward allmählich niht zur Hauptverneinungspartikel und wurde das ne entbehrlich, so daß man schon um 1200 sagen kann ich weiz niht. Dies niht tritt dann überhaupt an die Stelle des ne, immer unter Bewahrung der doppelten Negation, also mhd. uns hāt daz nieman niht geseit aber auch noch mit ne (also dreifach negiert) ichn gelache niemer niht. Besondere Verstärkung der Negation war ursprünglich nicht der Zweck dieser Verdoppelung, hat sich aber leicht als ihre Folge eingestellt. Nach dem Vorbild des Lateinischen auf das Deutsche angewandte Logik hat die doppelte Negation aus unserer Schriftsprache wieder beseitigt; daß sie eine Bejahung erziele, redet die Logik unserm Sprachgefühl vergebens ein. Die Mundarten und der Stil der volkstümlichen Poesie bewahren sie bis heute.

34. Fragesätze. Aber der jeweilige Fragesatz kann sich, wie man sieht (oben $\S 32$ ), von seiner aufforderungsoder aussagesatzmäßigen Urformation noch immer allein durch einen veränderten Empfindungston, den wir für das Schriftbild durch das Fragezeichen andeuten, unterscheiden. Wir erhalten somit die wichtige Gruppe der Fragesätze, die man insofern auch als eine dritte Gruppe den Aufforderungs- und Aussagesätzen gegenüberstellen kann, als sie ihrerseits wieder negiert werden können. 
Wenigstens kann die alleinige Unterscheidung durch den Empfindungston noch immer für die beiden Arten von Fragesätzen gelten, die wir soeben oben erhalten haben, die einfachen Satzfragen (lebt der König?) und die deliberativen Fragen (es lébe der König?), die man auch unter dem Namen Entscheidungsfragen zusammenfassen kann; Fragen, auf die man ein $j a$ oder nein erwartet.

35. Entscheidungsfragen. Einfache Entscheidungsfragen sind: positiv got. gasailvis po qinon?, negativ ahd. neweist tu daz Kroesus erretet ward? Abgesehen von dem veränderten Empfindungston und der invertierten Wortstellung, über die unten gehandelt werden wird, finden wir kein Charakteristikum des Fragesatzes. Die Neigung dazu hat aber, wie im Lateinischen, so auch innerhalb des Gotischen und Althochdeutschen zu besonderen Fragepartikeln geführt. Vgl. im Gotischen die Partikeln: 1) $u$, angehängt an Verba oder Pronomina maguts-u driggkan stikl?, sa-u ist sa sumus izwar?; 2) ni-u, wenn man eine bejahende Antwort und 3) ibai, wenn man eine verneinende Antwort erwartet, vgl. ibai mag blinds blindana tiuhan?, niu bai in dal gadriusand? - Für das Ahd. vgl. das bei Notker gebräuchliche, stets nur einen negierten Fragesatz beschließende na: neweist tu na?, ne mag tie richen nieht hungeren noh tursten na? Und ferner das im Ahd. nicht seltene inunu, enonū, enoni, innū, eno, welches bald 'num', bald 'nonne' ausdrückt und den Fragesatz einleitet: enoni twont thaz heidane man? (nonne); inno trifet tih tero deheinez ana? (num). - Aus nhd. Zeit gehören etwa hierher das obd. mundartliche gelt, ferner denn, nun, wohl u. a. m. 36. Ergänzungsfragen. Es gibt aber noch eine dritte Art von Fragesätzen, die Ergänzungs- oder Pronominalfragen. Diese unterscheidet von den Aussagesätzen, 
abgesehen vom veränderten Empfindungston, ihr ihnen ejgentümliches, im Indogermanischen mit kw-, im Germanischen mit $h w$ - anlautendes Interrogativpronomen; nhd. wer, was, wie, wo, wann, warum, weshalb. Partikeln können hinzutreten. Die Partikel denn, die nachgestellt im Neuhochdeutschen gern erscheint, bereitet sich schon im Got. vor; has நаnnu sa sijai. Im älteren Deutschen erscheint besonders gern $n \bar{u}$ vor dem Interrogativum; mhd. $n \bar{u} w \bar{a}$ moht er anderswā ein friuntlicher binden zuo den ziten vinden; nü welhes leben ist reiner; nü wer was der üfme schilde vor dem Wasgensteine saz; nü waz hulfe mich, ob ich unrehte strite; [indirekt mit eingeschobenem nü: wer dir $n \bar{u}$ gevalle baz]. Auch $j a$ erscheint; vgl. im Volkslied $j a$ wer ist der da singet? (Ulinger).

37. Disjunktive Fragen. Bei disjunktiven Fragen hat im Deutschen der erste Teil die Gestalt der einfachen Entscheidungsfrage, der zweite wird durch 'oder', ahd. eddo odo, mhd. odo od oder eingeleitet. Im Got. steht im ersten Satze $u$, den zweiten leitet wie im Deutschen pau oder aibpau ein; vgl. skuldu ist in sabbatim piup taujan aippau unfiup taujan?

\section{Zusammengesetzter Satz.}

38. Parataxe. Wirkliche Zusammensetzung zweier Sätze erfordert die Subordination des einen unter den andern, des Nebensatzes unter den Hauptsatz. Stehen zwei andere ohne Pause aufeinander folgende Sätze des Redestromes in engem syntaktischen Zusammenhang, so ist ihre Zusammensetzung nur scheinbar und sie befinden sich mit einander in Koordination oder Parataxe. Die älteste und volkstümlichste Form dieser Parataxe ist auch hier wiederum die asyndetische; vgl. got. jah in urrunsa usgaggip, gahraineip allans matins; as. skrēd the 
wintar ford, geng thes gêres gital; ahd. spenis mih mit dinèm wortun, wili mih dinu speru werpan; einēr frägèt, anderề. antwurtit. Der Stil der volkstümlichen Poesie und der der Umgangssprache haben diese Asyndese zu allen Zeiten bewahrt. Er liess seinen falken fliegen, er liess seine winde stieben, er eilet alsobalde zu einem finstern Walde (Ulinger).

39. Unbezeichnete Hypotaxe. Diese Parataxe steht in der älteren Sprache und noch heute in der Volkspoesie und in gewissen Wendungen der Umgangssprache sogar dann, wenn innerliche Abhängigkeit dèr Sätze vorhanden ist und sicher gefühlt wird - ein Rest jener einfachen Syntax aus der Zeit, da es noch keine bezeichnete Hypotaxe gab. Vgl. as. habda im sö bihalden... word endi wistom ...: ni mahta man is an is spräcun werdan, an is wordun giwar; ahd. sine jungirun ouh wārun hungrage, bigunnun raufan diu ahar; Hiltibrant gimahalta: her was hērōro man; mhd. dō sāhen Bloedelines man, ir herre lag erslagen; ich hän die kunst und ouch den sin, ich genise wol. Im Kinderlied: Dein Häuschen brennt, dein Mütterlein flennt, dein Vater sitzt auf der Schwelle. Besonders oft im Mhd. begegnet die eingeschobene Parataxe, vgl. in vil kurzen zìten, ich wilz iuch horen lān, sach man zin rīten.

40. 'A $\operatorname{cò}$ koıvov̂. Auch relative Bedeutung des einen Satzes kann bei reiner Parataxe vorliegen. Vgl. ahd. ih scal iu sagēn imbot, giböt ther himilisgo got = 'einen Befehl, welchen Gott geboten hat'; mhd. mit zühten si ze hüse bat ein frouwe, saz darinne; ...ein wiltpret, wil ich euren gnaden schenken (Keller, Fastnachtsp. 60,16). Daß auch hier reine Parataxe vorliegt, lehrt die Verbstellung; da jedoch der zweite Teil meistens wohl eine weniger wichtige Tatsache enthielt, ist das Satzverhältnis zweifellos hypotaktisch gefühlt worden. Es wäre jedoch völlig verkehrt, hier etwa die Ellipse eines Relativums anzunehmen.

Naumann, Deutsche Syntax. 
- Ohne eigenes Subjekt gebildet, gehört solch ein parataktischer relativloser Relativsatz mit zu den intimsten Reizen volkstümlicher Poesie; vgl. im Volkslied wol über eine Wiese, war grüne; in zwei Leilichen, waren weisse; da trug ich blau, bedeutet stät; im Orendel: sie fuorent über daz wazzer, heizt die Tiber; Goethe: im Osten von Flandern liegt ein einzelner Busch, heisst Hüsterlo. Vgl. aus der Umgangssprache: ein Herr, sieht aus wie ein Fürst; usw.

41. Verknüpfung. Die Asyndese kann seit alters aufgehoben werden, ohne daß doch die parataktische Koordination aufgehoben wird, durch sogenannte Verknüpfung, indem eine Reihe von Partikeln, die ein kopulatives, disjunktives, adversatives, konsekutives, kausales Verhältnis ausdrücken, dem zweiten Satz vorangestellt wird, so nhd. 'und, auch, oder, aber, doch, jedoch, 'da, nun, so (mhd. giuz üf den stein, sō hāstu guot heil), denn, sondern' und ihre got., ahd., mhd. Entsprechungen, von denen eine Reihe jedoch die Inversion des Verbums im Gefolge hat. Oder es wird Verknüpfung erreicht durch Partikeln für beide Sätze wie zwar - aber, weder - noch, entweder - oder. Auch durch andre Mittel noch vermag sich die Zusammengehörigkeit zweier koordinierter Sätze auszudrücken, indem ein Pronomen in einem Satze das Substantiv im andern wiederaufnimmt oder vorausnimmt, z. B. der Mann geht voraus, wir müssen ihm folgen und umgedreht; got. sa ist sunus meins sa liuba, pamma hausjaib.

\section{Hypotaxe.}

42. Volkstümliche und literarische Schreibweise. Hypotaxe, Subordination ist die eigentliche $\mathrm{Zu}$ sammensetzung; sie ist wahrscheinlich das Produkt später, schon literarischer Epochen. Umgangssprache und Stil der volkstümlichen Poesie bewahren noch heute die alte 
parataktische Ausdrucksweise. Vor allem der gelehrte Stil liebt die Hypotaxe, anders ausgedrückt, er liebt die Nebensätze. Man vergleiche z. B. Stücke aus der 'Kritik der reinen Vernunft' mit Stücken aus der 'Isabella von Egypten'. Kant: Auf welche Art und durch welche Mittel sich auch immer eine Erkenntnis auf Gegenstände beziehen mag, so ist doch diejenige, wodurch sie sich auf dieselben unmittelbar. bezieht, und worauf alles Denken als Mittel abzweckt, die Anschauung. Arnim: Sieh dort, schluchzte die Alte, auf dem Berge steht ein Dreifuss, dreibeinig, aber nicht dreieinig. Gott weiss nichts von ihm, und doch heisst er das hohe Gericht, wer vor dem Dreifuss vorbeikommt, der kann noch lange beten, das Fleisch, was da die Sonne kocht, das wird in keinen Topf gesteckt, es hängt daran, bis wir es abnehmen. Sei ruhig, du armes Kind, und schrei nur nicht, dein Vater hängt da oben, aber sei nur ruhig, wir holen ihn diese Nacht und werden ihn in den Bach werfen mit allen Ehren.

Wie von aller Hypotaxe, so gilt das auch von der indirekten Rede. Längeres Verbleiben in indirekter Rede zeugt für literarische Schreibweise. Volksmäßig ist der alsbald einsetzende Übergang in die direkte Rede. Gedacht Ulenspiegel, waz im da zu thun wer. Dahin kemen vil frembd heren, die lassen mich unbegabt nit... Freilich kann auch grade dieser Übergang zum Mittel kunstmäßigen Stiles werden, wie das im Altnordischen der Fall ist. Björn kvad pat frestast mundu; ok hirdi ek aldri, hvart hánum likar vel eda illa. "Björn sagte, darauf könnte er lange warten; und kümmre ich mich im Leben nicht drum, ob ihm das paßt oder nicht”.

43. Vom Wesen der Hypotaxe. Wir werden, wie wir aus der Verbstellung im Nebensatz noch erkennen werden, das ganze Wesen der Hypotaxe als eine ver- 
steinerte Parataxe beurteilen können. Im zusammengesetzten Satz hat erst nachträglich einer der beiden Sätze syntaktisch untergeordnete Funktion bekommen, d. h. er ist ein Nebensatz geworden; und zwar ursprünglich nur der, der eine nähere Bestimmung hinzufügte, den man als eine Apposition zum Subjekt, Objekt, Prädikat oder zum ganzen Satz auffassen konnte, nicht der, der die ganze Aussage oder die ganze Handlung trug. Der Mann, der das tut, soll sterben; 'der das tut' ist nichts anderes als eine Apposition zum Subjekt 'Mann'. In einem Satze wie ahd. ih weiz, er imos lonōt ist 'er imos lōnot' Objekt oder Apposition zu dem auch mit $i z$ oder $d a z$ ausdrückbaren Objekt; vgl. mhd. ich woune, si beide tören sint. Wahrscheinlich ist jenes ahd. Gefüge schon hypotaktisch gefühlt worden; man kann aber auch erklären, zwei alte parataktische Hauptsätze lägen vor, von denen der eine, wie in Versteinerung, die Endstellung des Verbums bewahrt habe. Wir werden noch sehen, daß beide Erklärungen schließlich auf dasselbe hinauslaufen. Von der unbezeichneten Hypotaxe trennt unser ahd. und mhd. Beispiel die Verbstellung.

44. Syndetische Hypotaxe. Asyndetisch treten die Nebensätze an. Wenn aber, wie wir sagten und noch sehen werden, die Hypotaxe letzten Endes nichts anderes ist als Parataxe und Nebensätze gleichsam versteinerte Hauptsätze sind, so muß auch hier, wie sie es in Parataxe bei 'Verknüpfung' war, neben der Asyndese die Syndese möglich sein. Es muß möglich gewesen sein, einen 'Nebensatz' an den Hauptsatz durch 'und' anzuknüpfen. Wiederum hat, beim Relativsatz, der Stil der volkstümlichen Poesie diese uralte syntaktische Möglichkeit bewahrt, und wir werden darin zugleich einen Beweis für unsere Auffassung vom Wesen des Nebensatzes als eines ursprünglichen 
Hauptsatzes erkennen. Vgl. aus dem Volkslied: das Brïnnlein und draus ich trinken soll; das Mägdlein ist nit über hundert Meil und das mir werden muss; aus dem jüngeren Hildebrantslied: ich zerhow im sin brinne mit einem schirmeschlag und das er siner muter ein ganz jar zu klagen hat; Ulinger: den ersten schrei und den sie tet. Wir betrachten dieses 'und' als uralt, erhalten aus der Zeit, da der Relativsatz noch nicht rein als solcher gefühlt worden ist. Im Volkslied wirkt es zugleich als ein Mittel, die Hypotaxe scheinbar wieder aufzuheben, ähnlich wie im Wessobrunner Gebet an der Stelle dō dār niwiht ni was enteo ni wenteo enti do was der eino almahtico cot und noch sonst einige Male im Ahd. enti die Hypotaxe aufheben soll, hier nur freilich vor dem Hauptsatz, weil Haupt- und Nebensatz umgestellt sind. Aber zugrunde liegt beidemal dasselbe Prinzip, die Glieder eines hypotaktischen Gefüges syndetisch $\mathrm{zu}$ verbinden. Vgl. auch folgenden Gebrauch aus dem Volkslied (Ulinger): und da sie in den wald ein kam, und da sie leider niemand fand.

Noch heute nicht ungewöhnlich und besonders im Mhd. durchaus üblich, aus dem Ahd. aber nicht belegbar, ist die syndetische Verknüpfung eines konditionalen und konzessiven Nebensatzes mit dem Hauptsatz, besonders wenn er konjunktionslos gebildet ist. Wiederum liegen ja ursprüngliche Hauptsätze (Frage- und Aufforderungssätze) vor; vgl. mhd. den hetich sicherliche verholne gerne gesehen, unde mohtiz mit gevōge geschehen; ez wirt mir ein vil süeziu $n \bar{o} t$, und soldich durch si ligen tōt. Desgleichen in einem im Mhd. nur so erhaltenen konjunktionslosen adversativen und temporalen Nebensatze: dur waz habt ir mich miv benomen, und ir min alsō kleine gert "da ihr doch so wenig meiner begehrt"; due wurden gote gehōrsam alle di dā wāren, und si diu grōzen zaichen sāhen. Es wäre hier 
völlig verkehrt, 'unde' etwa als eine eigentliche Konjunktion aufzufassen, sie müßte dann wohl durchaus die Endstellung des Verbums im Gefolge haben, die aber in den beiden ersten Beispielen nicht eingetreten ist und die sie in den letzten beiden Beispielen nicht veranlaßt hat, genau so wie es oben ( $(42)$ in der Constructio ảmò koเvoû völlig verkehrt gewesen wäre, die Elllipse eines Relativums anzunehmen. Es ist daher auch an sich nie anders als mit 'und' zu übersetzen. Unwahrscheinlich vom Standpunkt unserer Darlegung aus wird es uns ferner dünken, wenn man, wie es geschehen ist, dieses 'unde' aus der Ellipse vorhergegangener, einander koordinierter Nebensätze erklären wollte: nur der letzte dieser Nebensätze mit der ihn anknüpfenden Partikel sei bewahrt. Welche merkwürdige Ellipse, die nicht auch dieses 'unde' mit unterdrückt hätte! Anknüpfung aber ist es allerdings. Wir reihen diese mhd. Sätze mit 'unde' in einen größeren $\mathrm{Zu}$ sammenhang ein, der auf der Erkenntnis vom Wesen aller Hypotaxe als ursprünglicher Parataxe beruht. Auf der alten, sich daraus ergebenden syntaktischen Möglichkeit, einen Nebensatz mit 'und' anzuknüpfen beruht das Stilmittel, welches dieses 'und' bewahrt, die Glieder eines hypotaktischen Gefüges syndetisch zu verbinden und damit scheinbar die Hypotaxe aufzuheben.

In allen diesen Fällen kann auch der Nebensatz vorausgestellt werden und trotzdem sein 'und' behalten; mhd. und kume ich wider ze miner maht, sō ist reht; und soll ich drumb verderben, ich diene ir alle die wile ich lebe; im Volkslied (Ulinger): und komst du nicht so behende, mein leben hat schier ein Ende; relativisch und der das tut, soll sterben.

45. Merkmale der Abhängigkeit. Als Zeichen der Abhängigkeit eines Satzes haben sich, abgesehen von 
der besonderen Stellung des Verbums, allmählich besondere satzverbindende Wörter, Konjunktionen, Relativpronomina herangebildet, ferner die sogenannte Personenverschiebung und die sogenannte Modusverschiebung. Über alle diese Charakteristika s. u. $\$ 46-57$.

\section{Relativsätze.}

46. Allgemeines über den Charakter des Relativsatzes. Ursprünglich war der Charakter des Relativsatzes nur der des reinen Bestimmungssatzes, der nichts als eine Apposition ausdrückt; der die Handlung weiterführende Relativsatz hat als jünger zu gelten. Der Relatirsatz ist ein, meist asyndetisch, an- oder eingegliederter Satz, in welchem die Relativpartikel oder das Relativpronomen - soweit sie vorhanden sind - nur die Stelle eines nicht immer besonders ausgedrückten Substantivbegriffes aus dem Hauptsatz vertreten. Die An- oder Einfügung war ursprünglich parataktisch gemeint; die bei der reinen Apposition wie versteinert bewahrte Endstellung des Verbums ließ ihn dann auch äußerlich als Nebensatz erscheinen, was er seinem Inhalt nach von Haus aus war.

47. Relativsätze ohne Relativum. Über die Möglichkeit, Glieder rein parataktischer Sätze (liegt ein einzelner Busch, heisst Hüsterlo) als Relativsätze aufzufassen s. o. $§ 40$. Hier lag jedoch nicht die Nebensatzstellung des Verbums vor.

Aber auch wenn das der Fall ist, braucht die spezielle Bedeutung eines Relativsatzes nicht immer durch ein Relativum ausgedrückt zu werden. Der Relativsatz kann auch ohne dieses wie eine Apposition antreten und zwar auch in dieser Form mit oder ohne Asyndese gemäß seinem oben entwickelten parataktischen Ursprung. Vgl. ahd. asyndetisch mit themo brunnen, thē nü quīst "von 
dem du nun sprichst"; then weg, sie faran scoltun "den sie fahren sollten"; heil thi krist, thi therero liuto kuning bist. An das Pronomen personale ist die relative Bedeutung des Satzes nicht etwa geknüpft, es kann stehen oder fehlen; vgl. ahd. sprah Thomas, er ein thero einlifo was; funtun einan man, mit namon Simeon hiez; mhd. mit dir, dü eine kröne bist aller èren.

Ferner nun aber syndetisch: mhd. die wìle und ich daz leben hān "und welche ich lebe"; an der selben stunt und ez im chom durch den munt; nü sit miv willekomen ze dem und ich nū haben mac. Besonders im Mhd. ist dieser syndetische Gebrauch des Relativsatzes ohne Relativum nicht selten. Wieder dürfte es schwerlich richtig sein, diesen Relativsatz, sowie die andern mit 'und' angeknüpften Nebensätze in syndetischer Hypotaxe s. o. $\$ 44$, durch Ellipse vorhergegangener koordinierter Nebensätze zu erklären. Die wile und ich daz leben hān wird nicht zu trennen sein von das Brünnlein und draus ich trinken soll, und beide werden der gleichen Beurteilung unterliegen. Es sind die syndetischen Formen des unbezeichneten und des bezeichneten Relativsatzes und sie stehen an sich völlig gleichberechtigt den asyndetischen (ich diene $i$. alle) die wile, ich lebe und das Brünnlein, draus ich trinken soll gegenüber. Sie beruhen beide auf der Parataxe, die letzten Endes aller Hypotaxe zugrunde liegt, und auf der sich daraus ergebenden syntaktischen Möglichkeit, einen Nebensatz durch 'und' anzuknüpfen.

Andrerseits braucht ein Relativsatz nicht immer durchaus nur diese Bedeutung zu haben; konjunktionale liegt z. B. vor im mhd. daz ist ein gröziu tugent, der fride machet "daß man"; einem sō gewanten man, der nie mäge hie gewan "daß er". 48. Relativpartikeln. Zur Charakteristik eines Relativsatzes genügen ferner bloße Relativpartikeln, in denen 
sich zeigt, daß prinzipiell eine gewisse Wesensgleichheit der Relativsätze mit den konjunktionalen Nebensätzen besteht. So stehen vornehmlich im Anschluß an einen Zeitbegriff: got. ei, ein Lokativ eines alten indogermanischen Pronominalstamms mit der Bedeutung 'da, wo'; ferner got. $p e i=$ ahd. as. the, der Form nach entsprechend zu beurteilen. Vgl. got. und pata weilos pei mip im ist brupfaps; ahd. in themo dage the her ni wänit inti in theru ziti the her ni weiz. Got. pei, ahd. the erscheinen dann aber auch mit erweiterter Funktion als Kasus generalis des Relativums überhaupt; vgl. got. (hier freilich nicht ohne vorhergehendes neutrales Indefinitum) patahah pei wileip bidjip; as. èn gifrōdot man, the sō vilo consta wisero wordo; ahd. in berge the er mo zeinti; furi thie, the giloubenti sint. So scheint auch ahd. thär ursprünglich selbständige Relativpartikel gewesen zu sein; ferner ward als solche sō gebraucht bis ins 18. Jahrh. hinein und wurde von einzelnen Neueren im archaisierenden Stil wieder hervorgeholt, vgl. ahd. allaz sō thir liub ist; mhd. der vil grōzen liebe, sō min herze an sī hăt; nhd. die Saat so deine Jagd zertritt (Bürger). - Genetisch ist zu bemerken, daß, wie ein großer Teil der Konjunktionen, so auch diese Partikeln ursprünglich zum Hauptsatz gehören; es sind erstarrte adverbiell gebrauchte Kasusformen, die erst durch eine Verschiebung der Pause zwischen den beiden Sätzen zum Nebensatz gezogen worden sind. Auszugehen ist also auch hier vom relativlosen Relativsatz.

49. Relativpronomina. Wir haben von relativlosen Relativsätzen und solchen mit Relativpartikeln gesprochen. Eine dritte Stufe in der Entwicklung des Relativsatzes bezeichnet das Relativpronomen. Im allgemeinen bedarf in unserer Sprache ein Relativsatz eines solchen. Zunächst funktioniert als Relativum das Demonstrativum. Es ist 
wahrscheinlich, daß auch dieses seiner Natur nach ursprünglich nur dem Hauptsatze angehörte, daß es dann mit der Relativpartikel, auf die es hinwies, verschmolz und mit Verschiebung der Pause in den Nebensatz geriet. Das Relativpronomen wäre dann also aus 'Korrelation' entstanden, indem die Partikel des Nebensatzes sich auf das Demonstrativum des Hauptsatzes zurückbezog. Die Entwicklung ging dann dahin, daß die Partikel überflüssig wurde und dann das Pronomen allein zur Kennzeichnung des Relativsatzes genügte. Ahd. ther thār usw. ist dann als das Primäre anzusehen, got. $s a$ als Neuerung zu beurteilen.

So finden wir denn im Got. sa-ei, $i z-e i$ (= anord. $e r$, es), pat-ei, sō-ei, sei <*si-ei, vgl. saei sandida mik, mip mis ist; Judas ... izei skaftida sik; mit der Neuerung, d. h. ohne die Partikel has ist saei gailjai mik, nibai sa gaurida us mis. Auch das Personalpronomen kann in Got. durch angefügtes $e i$ relative Bedeutung erhalten $p u$ bas is puei stojis.

Den got. Bildungen sa-ei usw. entspricht ahd. ther thār, ther the, ags. se $p e$, ahd. ther sō [ein ahd. der-i gibt es nicht!]; den got. Bildungen $i k-e i, p u-e i$, entspricht ahd. ih thār, in the usw. Vgl. ahd. fater unsēr, thī thār bist in himile (mhd. $d u$ da bist i. h.); wē iu Pharisei, ir the forslintet thes, ther ther mih santa; ein von then, thie dār hangētun; mhd. si vliesent beide ir arbeit, der dā hoert und der dā seit; allez daz der ist; ahd. zi selben sancte Petre, ther sō giang in then sē. Dann mit verschwundener Partikel: tho ward thār irfullit thaz forasago singit; si birit sun zeizan, ther ofto ist iu giheizan. Korrelation, in dem der Hauptsatz ein neues Demonstrativum aufnimmt, ist natürlich immer wieder von neuem möglich und in einigen dieser Beispiele bereits enthalten. 
Für das Mhd. charakteristisch ist die Doppelfunktion des Pronomen als Demonstrativum im Hauptsatz und als Relativum im Nebensatz: dō dähte ich an daz jener sprach; sì funden in dā er lac.

50. Attraktion. Wenn das Relativum ursprünglich dem Hauptsatz angehörte, so wird man sich nicht darüber verwundern, daß es noch langhin in der von der Rektion des Hauptsatzes verlangten Kasusform erscheint. Vgl. got. ei galaubjaip pammei insandida jains "dem (welchen) jener gesandt hat"; ahd. thia gilouba . . la läz ih themo iz lisit thār "dem (der) es liest"; mhd. prises des erwarp sin hant "des Preises (welchen) seine Hand"; swen genüeget des er hat "dessen (was) er hat". Im Anord. ist dies fast die Regel geworden. Man nennt diese Erscheinung Attraktion= Richtung des Pronomens nach dem Hauptsatz; aber historisch richtiger wäre es von unserm Standpunkt aus, die (heute normale) Rektion des Pronomens nach dem Nebensatz so zu nennen, weil sie die jüngere ist. Sie ist im Deutschen die Regel geworden; verallgemeinert hat sie sich vielleicht aus solchen Fällen, wo beide Sätze den, wenigstens der Lautform nach, gleichen Kasus verlangten, vgl. ahd. er rihtit thaz in worolt ist; mhd. under die da wāren.

51. Weitere Relativpronomina. Außer mit dem Demonstrativum bilden wir Relativsätze aber auch mit dem Interrogativum 'wer, was, welcher'. Diese Bildung hat einen doppelten Ursprung. Erstens entstand sie aus dem indirekten Fragesatz, indem der Nebensatz nicht als Frage-, sondern als Inhaltssatz aufgefaßt wurde; von hier aus hat sich dann der relativische Gebrauch des Interrogativums ausgedehnt. Hierher werden die ahd. Beispiele gehören: thaz er thaz gihörti, waz druhtin thes giquāti; wer iz wāri fon in, wer sulīh tāti. 
Zweitens haben sich diese Relativpronomina aus dem Indefinitum - der zweiten ihm von vornherein zukommenden Bedeutung unseres Pronomens, vgl. ahd. sprah er odo deta waz -, genauer aus seiner verallgemeinernden

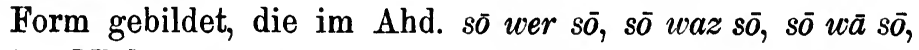
im Mhd. swer, swaz, swā usw. lautete, an deren Stelle sich dann seit dem 14. Jahrh. die einfachen Interrogativa drängten. Wer steht nur substantivisch, adjektivisch funktioniert dafür welcher (welch Baum nicht gute Früchte trägt, der - (Luther)), das ungefähr aus derselben Zeit stammt und dem das verallgemeinernde swelher vorausgegangen war. Irgendwelche Bedenken gegen den Gebrauch von 'welcher' als Relativum liegen also vom Standpunkt der historischen Syntax aus nicht vor. Daß es sich von der adjektivisch-indefiniten, dann rein relativen Funktion auch auf die substantivisch-indefinite, dann rein relative Funktion verbreitete, mußte wohl auch ohne Einwirkung des lateinischen 'qui' zustande kommen; vgl. Luther: welchen der Herr lieb hat, den züchtiget er (noch indefinit); Schiller: das grosse gigantische Schicksal, welches den Menschen erhebt, wenn es den Menschen zermalmt.

\section{Nebensätze mit Konjunktionen gebildet.}

52. Mehrfacher Ursprung der Konjunktionen. Es war zuerst nie seine Form, die den Nebensatz zum Nebensatz machte, auch nicht das Relativpronomen, die Relativpartikel oder die Konjunktion, welche sämtlich sekundärer Natur sind, sondern allein sein Inhalt, der weniger wesentlich war als der des Hauptsatzes. Nur psychologisch war der Nebensatz untergeordnet. Wie Relativpartikel und -pronomen so gehörten auch die Konjunktionen ursprünglich gar nicht zum Nebensatz, sondern zum Hauptsatz. Ich sehe, dass es regnet ist entstanden 
aus ich sehe das: es regnet. Die Konjunktionen sind erstarrte, adverbiell gebrauchte Kasus, die, nachdem sie durch eine Pausenverschiebung in den Nebensatz hineingeraten sind, sich verallgemeinert haben auch auf Fälle, wo ihre Kasusform der Konstruktion nach nicht hin paßte.

Hierher gehört vor allem die Konjunktion dass der Dass-Sätze, got. ei, pei, patei; ahd. mhd. daz; häufig eingeleitet durch eine Präposition, die gleichfalls die Verallgemeinerung der Form des Akkusativus Singularis Neutrius des Pronomens mit erklärt (umbe, āne, fur, üf: daz; bedaz 'während'). Mit der verschiedenen Funktion der Dass-Sätze hat die einfache Konjunktion nichts $\mathrm{zu}$ tun, denn die hängt vom Verbum des Hauptsatzes ab. Ferner all die temporalen, konzessiven, komparativen, konditionalen usw. Konjunktionen, von denen wir die wichtigsten nennen: got. mippanei 'während', sunsei 'sobald als', faurbizei 'beror', panei (jünger ohne Partikel ban) 'wann', bipe 'als, nachdem', unte (<*und-be) 'solange als, bis'; ahd. (mhd.) do 'als, da'; bidiu, mit diu (thaz) 'indem, während, als'; biz, unz (daz) 'bis, solange als' [ursprünglich und noch lange alle diese immer mit dem hinweisenden $d a z$ verbunden]; sit (daz) 'seitdem'; ahd. $\bar{e} r$, mhd. $\bar{e}$ 'bevor' (e dann, $\bar{e} d a z) ; n \bar{u}$ (nu) (daz) 'als, nachdem, da'; sō 'sodaß, doch, obgleich'; got. swe, swaswe, ahd. mhd. alsō, sō, sam 'wie'; alsō 'als ob': danne nach Komparativen 'als'; sō wanne, mhd. swenne 'wenn'.

Wieder andere Konjunktionen, kausale, gehörten ursprünglich weder dem Hauptsatz noch dem Nebensatz an, sondern bildeten für sich selber einen kurzen (eingliedrigen) Fragesatz; so ist ahd. hwanta, mhd. wande, wan 'da, weil' nichts anderes als das interrogative hwanta 'warum'. Mhd. daz schreip der herre (unbe daz), wand ein strit under sinen jungern was ist entstanden aus daz schreip der herre. Wand? Ein strit under sinen jungern was. Noch langhin 
ist deshalb hier im Nebensatz die Hauptsatzstellung (Mittelstellung) des Verbums gleichwie in reiner Parataxe möglich gewesen (wan er vorhte des orses val). Seit nhd. Zeit kann man mit der ja in sprachlichen Dingen nicht seltenen Wiederholung ein und desselben Prozesses unser 'warum' in der lebendigen Umgangssprache sich zu einem gleichen Gebrauche rüsten sehen; vgl. er tats nicht, warum? er wollte nicht $=$ weil er nicht wollte; zu einer Nebensatzstellung des Verbums jedoch wird es wohl so leicht nicht kommen. - Unser 'weil' ist entstanden aus mhd. die wile, ahd. dia wila unz und gehört also zur ersten Kategorie der Konjunktionen, die aus dem Hauptsatz stammt.

\section{Konjunktionslose Nebensätze.}

53. Mehrfacher Ursprung der konjunktionslosen Nebensätze. Von völlig anderer Entstehungsart sind die konjunktionslosen Konzessiv- und Konditionalsätze. Wieder liegt freilich letzten Endes keine Hypotaxe vor, sondern Parataxe; lagen aber bisher den Nebensätzen Aussagesätze zugrunde, so liegen ihnen nun Aufforderungsund Fragesätze zugrunde. Wir finden deshalb hier eine völlig andere Verbstellung. Es sind Hauptsätze in Aufforderungs- oder Frageform, die hier wie Nebensätze fungieren; sie haben keine Konjunktion verloren, denn sie haben nie eine gehabt. Kommt er, so sehe ich ihn ist entstanden aus kommt er? So sehe ich ihn und mag ers tun, ich folge ihm nicht aus mag ers tun! Ich folge ihm nicht. Vgl. got. ip waurbeina in Tyre iah Seidone landa mahteis..., airis pau... idreigodedeina; ip 'aber' ist nur eine anknüpfende Partikel. Ahd. ni duas thī sō, lōn ni habēs thū es nihein; mhd. gist du mir dīn swester, sō wil ich ez tuon; konzessiv: mhd. nu lät in sin min lantman, ich wolde im doch helfen. 
54. Partikeln bei solchen Sätzen. Keine Konjunktionen sind von Haus aus got. jabai, nibai, niba, d. h. sie sind es nicht, die dem mit ihnen eingeleiteten Satz die untergeordnete Funktion verliehen. Sie sind nichts als die Bejahungs- und Verneinungspartikel $j a$, $n i$, verstärkt durch die Versicherungspartikel $b a$, bai. An sich sind Sätze wie der folgende konjunktionslos, got. jabai afletip mannam missadedeins ize, afletif jah izwis atta izwar; vgl. nhd. hast du es já getan, so gestehe es ein. Got. nibai kaurno in airpa gaswiltip, silbo ainata aflifnip unterscheidet sich von obigem ahd. Beispiel ni duas thü sō, lōn ni habēs zunächst nur durch die mit bai verstärkte Negation. Daß aber diese gotischen Partikeln allmählich als Konjunktionen gefühlt wurden, zeigt wohl die sicher hier erst sekundäre Nebensatzstellung des Verbs. Ein Gegenstück im Mhd. ist die zuweilen belegte Nebensatzstellung im konjunktionslosen Konzessivsatz: ir nāhen oder verre in disiu lant geriten sit, mich bedunket; dō rieten sine vriunde, ez liep oder leit siner muoter wore, daz er...

Dieselbe Partikel $b a i, b a$ liegt dem got. $i b a i$, $i b a$, das wir als Partikel direkter Fragesätze schon kennen gelernt haben, ahd. $i b u, u b i, o b a$, mhd. nhd. $o b$ zugrunde, nur mit dem deiktischen idg. ${ }^{*} e$ versehen wie in lat. equidem zu quidem. Auch die mit dieser Partikel gebildeten indirekten Fragesätze haben also als konjunktionslose Nebensätze zu gelten, desgl. die deutschen mit $o b=$ wenn gebildeten Bedingungssätze. Die Partikel ward dann als Konjunktion gefühlt, und damit ist auch die Endstellung des Verbums für diese Sätze typisch geworden. Der Unterschied dieser neuen Konjunktionen von den alten besteht darin, daß diese ursprünglich dem Hauptsatz angehörten, jene aber stets ihrem Nebensatz.

Schließlich darf man als konjunktionslose Nebensätze 
auch die indirekten Fragesätze ansehen, die mit dem Interrogativum gebildet sind, vgl. got. ei jah jus witeip ha bi mik ist, ha ik tauja. Vom direkten Fragesatz unterscheiden sie sich durch die für den Nebensatz typische Verbstellung.

\section{Verschiebung in Nebensätzen.}

55. Personenverschiebung. Charakteristisch für alle indirekt wiedergegebene Rede oder indirekt wiedergegebenen Gedanken, Befürchtungen, Hoffnungen, Wahrnehmungen usw. ist die Personenverschiebung. Er sagt, (dass) er weiss (direkt: ich weiss); er fürchtet, wir würden essen (direkt: sie werden essen); befiehl ihm, dass er geht (direkt: du sollst gehen); er fand, ich mache Fortschritte (direkt: du machst Fortschritte); got. andhöfun, ei ni wissedeina (direkt: wissedeima). Mit dem W.esen des Nebensatzes hat aber diese Erscheinung von Haus aus nichts zu tun. In dem ursprünglich parataktischen Satz liegt gar keine Rede usw. vor, sondern der Bericht des Erzählers von der reinen Tatsache. Sie antworteten (und) sie wussten es nicht; er fand (es) (und) ich mache Fortschritte; er fürchtet (es) (und) wir werden essen; befiehl ihm das (und) er geht. - Aus derselben berichtenden Form erklärt sich die Verschiebung der Orts- und Zeitbestimmung in abhängiger Rede: er sagte gestern, er komme heut her (direkt: ich komme morgen hin), ursprünglich gedacht: er sagte (es) gestern (und) heute kommt er her.

56. Modusverschiebung. Abhängigkeit eines Satzes wird in der älteren Sprache mehr als heute, nicht bloß in abhängiger Rede usw., durch den Konjunktiv seines Verbums bezeichnet; mhd. er wānde, ez sin schimpf ware; doch er guot ellen trüege, Ërec in von dem rosse schiet. Der Konjunktiv steht in Wunschsätzen, Absichtssätzen, Dass-Sätzen, die eine subjektive Vorstellung ausdrücken, 
verallgemeinernden Relativsätzen, in Sätzen mit 'als $o b$ ', 'danne' nach Komparativen; in Nebensätzen, auf die sich die Negation des negierten Hauptsatzes bezieht (ez mac nimmer geschehen, daz ich iuwer wīp werde), in abhängiger Rede, indirekter Frage. Aber bei der Erklärung von er sagte, (dass) er käme aus er sagte (das:) er käme sollten wir 1) er komme und 2) er kommt erwarten. Es handelt sich also um eine Modus- und fernerhin um eine Tempusverschiebung, abgesehen von der soeben besprochenen Personenverschiebung. Wieder geht die Erklärung von der ursprünglichen Parataxe aus. Der Konjunktiv hat sich verallgemeinert aus den Fällen der abhängigen Rede, wo er auch in der direkten sowohl aussagenden wie fragenden Rede möglich war, d. h. aus den Fällen, wo ein Zweifel oder eine Ungewißheit in der Aussage oder in der Frage vorhanden war.

57. Tempusverschiebung. Für die Zeitenfolge gilt in der älteren Zeit bis zum Ausgang des Mhd. die Norm, daß das Präsens des Hauptsatzes den Konjunktiv Praesentis im Nebensatz verlangt und das Präteritum im Hauptsatz den Konjunktiv Praeteriti im Nebensatz, falls nicht ein besonderer Unterschied der beiden Zeiten, etwa daß die Tatsache des Nebensatzes noch für die Gegenwart und Zukunft gilt (got. Moses gamelida, ei nimai bropar is; mhd. ich wolde daz ir ze gemache ritent mit mir an dirre stunt) oder daß sie der des Hauptsatzes vorausliegt (got. ni hugjaip ei qemjau; ahd. ni hugi weih thir sagêti), ausgedrückt werden soll. Das Nhd. kennt keine derartige Regelung der Zeitenfolge mehr; hier scheint im Singular der Konjunktiv Praesentis durchgeführt zu sein (er sagte, er komme, er sei, er schlafe), wofür im Plural nur deswegen hauptsächlich der Konjunktiv Praeteriti steht (er sagte, dass sie kämen; er sagt, sie kämen), um eine Unterscheidung vom

Na uman, Deutsche Syntax. 
Indikativ Praesentis (kommen) zu ermöglichen - zuungunsten freilich der früher reduplizierenden Verben, wo die Form mit dem Indikativ Praeteriti zusammenfällt (riefen).

Der älteren Sprache ist also durchaus gemäß: er sagt, dass er komme; er sagte, dass er käme; got. frah, ha wesi pata; aflet uns patei skulans sijaima; ahd. viat er, wio er Abelan sluagi; ih sentu, thaz ir irkiasêt. Hier liegt also, wie schon oben gesagt, in er sagte, dass er käme bei der Erklärung aus der Parataxe eine Tempusverschiebung vor (direkt: ich komme), indem der Konjunktiv Praeteriti den Konjunktiv Praesentis vertritt. Wieder erklärt sich diese Verschiebung, wenn man davon ausgeht, daß ursprünglich keine Rede, sondern ein Bericht des Sprechenden vorliegt, der auch die Handlung des abhängigen Satzes von seinem Standpunkt aus erzählt. Sie sagten, sie kämen = sie sagten, (und) sie kamen, dann mit verallgemeinertem Konjunktiv.

Wir haben somit nun sämtliche Charakteristika der Nebensatzbildung erklärt - bis auf eines, das der Endstellung des Verbums; alle waren sekundärer Natur, erst im Laufe der Entwicklung zu Merkmalen des abhängigen Satzes geworden. Überall schimmerte zuletzt klar die ursprüngliche Parataxe hervor. Wir werden sehen, daß die Endstellung des Verbums den Schlußstein in dieser Erklärung bildet.

\section{Die Stellung des Verbums im Hauptsatz.}

58. Ein psychologisches Stellungsgesetz. Die durch die vollen Endungen ermöglichte Freiheit der Wortstellung im Satze im Urzustand der Sprache war doch nicht so groß, daß sie nicht letzten Endes durch ein psychologisches Grundgesetz geregelt wurde. Der Begriff, der im Bewußtsein des Sprechenden zuerst vorhanden war und der den Ausspruch des Gedankens oder der Vor- 
stellungsverbindung 'überbaupt veranlaßt hat, wird auch zuerst ausgesprochen. Er ist der wichtigste und sein sprachlicher Ausdruck trägt den stärksten Ton im Satze. So ist die erste Tonstelle im Satze zugleich die am stärksten betonte. Das stärker betonte Wort rückt weiter nach rorn; so regelt sich die Tonfolge nach der Wichtigkeit der zugrunde liegenden Begriffe, d. h. nach der Folge ihres Auftretens im Bewußtsein des Sprechenden. Deshalb beginnen die Ergänzungsfragen mit dem Interrogativpronomen, die Satzfragen mit dem Verbum (Kennst $d u$ das Land...??), die Aufforderungssätze gleichfalls mit dem Verbum, der Aussagesatz gewöhnlich mit dem Subjekt, als dem Ausdruck des Begriffes, von dem etwas ausgesagt werden soll.

59. Ein rhythmisches Stellungsgesetz. Dazu kommt ein anderes: die zweite Stelle im Satz gilt nicht dem am zweitstärksten betonten Wort, sondern die erste und stärkste Tonstelle zieht wie ein Magnet die schwachbetonten und unbetonten Wörter an sich, so daß diese an die zweite Stelle im Satze gelangen. Danach folgt erst das zweitstärkste Wort, dann das drittstärkste usw. Es ist offenbar ein rhythmisch-musikalisches Gesetz, welches hier in das psychologische Gesetz eingriff, sodaß sich für den gewöhnlichen Aussagesatz (der König regiert das Land) die rhythmische Folge: starkbetont, schwachbetont, mittelbetont eingewöhnt hat. Im allgemeinen ist nämlich von Anfang an das Nomen stärker betont als das Verbum, weshalb auch in der germanischen Poesie wahrscheinlich ursprünglich allein und späterhin weitaus in der Mehrzahl Nomina und Nominalformen des Verbums den Stabreim tragen, d. h. Haupthebungen sind. So hat auch im Altindischen das Verbum keinen Akzent im Hauptsatz und verhält sich enklitisch zum vorhergehenden hochbetonten Wort. Die usuelle Wortfolge im dreigliedrigen Aussage- 
satz ist also im Deutschen Subjekt, Prädikat, Objekt geworden; jede andere Wortfolge ist okkasionell. Usuell ist die Mittelstellung des Verbums; genau so verhält es sich bei den alten griechischen Prosaklassikern. Okkasionell ist die Anfang- und die Schlußstellung. Man nennt die usuelle Stellung auch die grade Folge.

60. Mittelstellung sekundärer Natur. Wenn auch im Deutschen und in der Sprache der griechischen Klassiker die Mittelstellung des Verbums die Norm geworden ist und im Altindischen sogar Tonlosigkeit des Verbums im Hauptsatz eingetreten ist, so kann dies dennoch hier überall sekundäre Entwicklung sein. Sehr wahrscheinlich stellt diese Norm nicht den Urzustand dar, sondern das Ergebnis einer durch die gemeinsam zugrunde liegenden beiden Stellungsgesetze in die gleichen Wege geleiteten Entwicklung. Unbetont war das volle Verbum finitum, soweit es sich nicht um die bloße, meist einsilbige Kopula handelt, von vornherein selbstverständlich nicht, sondern nur schwach-oder schwächerbetont. Es sind außer dem okkasionellen Fall, wo der Prädikatsbegriff den Objektsbegriff, aber nicht den Subjektsbegriff an Tonstärke übertraf, Fälle denkbar, wo der Objektsbegriff fehlte und noch schwächer betonte Pronomina, Partikeln und andere Satzteile hinter dem Subjekt sich eingliederten. Beidemal kam dann das Verbum in die Endstellung. Nach Analogie konnte dann auch wohl diese Stellung usuell geworden sein, wie das ja im Lateinischen der Fall ist; rex enim regit, dann auch rex terram regit. Und tatsächlich scheint das auch im Germanischen der Fall gewesen zu sein, bevor die Mittelstellung normal wurde; es scheint eine Epoche mit usueller Endstellung, aus der dann auch die Nebensätze stammen, der Epoche mit usueller Mittelstellung vorangegangen zu sein. 


\section{$-53-$}

61. Mittelstellung des Verbums. Die Stelle hinter dem ersten und stärksten Ton im Satze ist also im Deutschen der usuelle Platz des Verbums geworden. Diese Kontaktstellung, wie man sie auch zu nennen pflegt, hat sich entwickelt aus der schwächeren Tonstärke, die der Verbalform zukam im Vergleich mit den Nominalformen des Satzes. Schon das Gotische zeigt die Neigung, das Verbum an die zweite Stelle des Satzes rücken zu lassen; vgl. den Hauptsatz sa galeifip inn mit dem Nebensatz saei inn galeipip. Und schon in urnordischer Runeninschrift begegnet die Mittelstellung: ek Hagustaldar hlaiwido magu minino 'ich $\mathrm{H}$. begrub meinen Sohn'. Das Gefühlsmäßige dieses Satzes liegt in der stärkeren Betonung des Objekts, welches daher an das Ende rückte. Man kann auch sagen, daß der monumentale Stil (s. u.) in dieser Runeninschrift aufgegeben wurde zugunsten der inzwischen modern gewordenen Sprechsprache, die zugleich den Empfindungsgehalt mehr hervortreten ließ. - Die Verwandlung der mittleren Betonung des Verbs in schwache hat indessen wohl nicht mit diesen okkasionellen Fällen, sondern vermutlich mit den Formen des Verbum substantivum (ist, was) begonnen und von hier aus sich dann verallgemeinert; her was eo folches at ente.

\section{Endstellung des Verbums.}

62. Endstellung als Stilmittel. Der monumentale Stil der ältesten Runendenkmäler bedient sich, wie es scheint, noch gern der Endstellung des Verbums. Vgl. einige der urnordischen Runeninschriften vom 4.-6. Jahrh.: ek Hlewagastir Holtingar horna tawido ich Leugast der Holting das Horn machte'; Dagar par runo faihido 'Tag diese Runen schrieb'; Harabanar wit jah ek Erilar runor waritu 'Wir zwei Hraban und ich Jarl die Runen ritzten'; vgl. auch 
mik Marila wurta 'mich M. machte' und die deutsche Inschrift auf der Spange von Freilaubersheim bik Dapena golda 'dich, D., grüßte er'.

Die Prosa des Ulfilas zeigt schon einen moderneren Stil, aber in der Skeireins begegnet die Endstellung noch öfters, sah unkunnands ... in tweifl gadraus; desgleichen begegnet sie in der ags. Prosa häufig: ond he his feorh generede. Wahrscheinlich ward sie aus einem gewissen Stilbedürfnis heraus angewendet, aus dem auch die verhältnismäßig häufigen Beispiele der Endstellung im ahd. Isidor zu erklären sind, vgl. fona hreve aer Lucifere ih dhih chibar (genui te). Doch ist sie sonst in der Prosa schon bei Notker völlig unmöglich.

Der archaische Stil der Stabreimdichtung liebt die Endstellung sehr; ahd. sunufatarungo iro saro rihtun; itk $m \bar{\imath}$ de $\bar{e} d r e$ wèt; forn her ōstar giweit und noch vier andere Fälle allein im Hildebrandslied. Die volkstümliche Poesie hat auf die Endstellung nie verzichtet; mhd. Sifrit der snelle zuo dem künege trat; Ludwic ze Hartmuote sinem sune sprach. Die Bewahrung dieser alten syntaktischen Möglichkeit trägt wesentlich bei zu einem besonderen volkstümlichen und altertümlichen Gepräge. Dem Stil der mhd. höfischen Poesie war sie deshalb zu unmodern, er vermied sie; in Hartmanns Erec begegnet sie unter Benutzung im Reim noch 357 mal, wie man gezählt hat, in seinem Iwein nur noch $47 \mathrm{mal}$. Einige weitere Beispiele aus der volksmäßigen Poesie bis heute: Spervogel: in himilrīche ein hūs stāt, ein guld̄̄n wec darin gāt; Luther: gross Macht und viel List sein grausam Rüstung ist; im Volkslied: ein meidlin an dem laden lag; traut Henslein über die heide reit; Heine: der König stieren Blicks dasass. - Die ganze Endstellung gehört in Deutschen nur noch in das Gebiet der Stilistik; aber sie wäre nicht möglich, 


\section{$-55-$}

wenn nicht eine Epoche syntaktischer Berechtigung vorangegangen wäre.

\section{Anfangsstellung des Verbums.}

63. Okkasionelle Anfangsstellung. Die Anfangsstellung war vermutlich von jeher nur okkasionell und trat ein, wenn das Verbum besonders betont war. So finden sich früh öfters die Verben 'sollen' und 'wollen' satzeröffnend; vgl. anord. vil ek eige go $p$ gayia 'will ich nicht die Götter anbellen'; ags. and sceall beon se lēesta

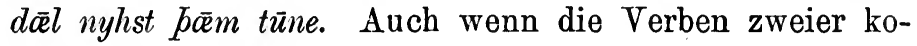
ordinierter Sätze korrespondieren, kann diese Korrespondenz durch Anfangsstellung beider Verben deutlicher bezeichnet werden. Hierher gehört vermutlich die deutsche Runeninschrift auf der größeren Spange von Nordendorf, die nach neuerer Lesung und Übersetzung lautet: loga $\bar{b}$ ore Wódan; wigip ponar unka Leubwinje 'disponit ab initio W., benedicit Th. nostrum amborum Leubwiniam'. Besonders gern aber erhielt das Verbum im erzählenden Aussagesatz die Anfangsstellung, weil hier natürlich das Geschehen besonders leicht den Ton trug.

64. Anfangsstellung als Stilmittel. Von hier aus versteht es sich, daß besonders in der anord. Erzählungsprosa die Anfangsstellung sich $\mathrm{zu}$ einem wesentlichen Charakteristikum des Stiles entwickelt hat; tók Rognvaldr skip bau; hét annarr Hárekr usw. Auch im Deutschen begegnet sie dergestalt nicht selten: wand her do ar arme wuntane bougā; holōda inan truhtīn; lietz her heidine man obar sēo lìdan. $\mathrm{Zu}$ einer stilistischen Verallgemeinerung oder starken Ausbreitung wie im Nordischen ist es im Deutschen nicht gekommen, aber die volkstümliche Erzählungsweise hat die Anfangsstellung noch lange festgehalten: spricht $z u$ ihm das Weib; wollten ihn da die ge- 
lehrten Herrn mir nichts, dir nichts ins Karzer sperrn; sah ein Knab ein Röslein stehn usw. Besonders wirkt es im Märchen mit ganz eigentümlichem Reiz auf unser Stilgefühl, wenn wir lesen: Sprach der König; Dachte der Bruder Lustig usw.

65. Das satzeröffnende 'es'. Hat der Stil die Voranstellung zu besonderen Zwecken bewahrt, so war sie doch seit mhd. Zeit syntaktisch nicht mehr lebendig. Man beginnt sie zu tilgen in der Erzählung durch das sogenannte satzeröffnende 'es', das Neutrum des Pronomens der dritten Person; ez wuohs in Burgonden ein edel magedin; es braust ein Ruf wie Donnerhall; es ging ein Mann im Syrerland. Eigentlich können wir also noch heute jede Erzählung mit dem Verbum beginnen: es war einmal ein König; die Voranstellung ist nur unkenntlich gemacht durch das völlig sekundäre 'es', das in seiner rein pleonastischen Natur ja sogar im Falle des Plurals steht: es ritten drei Reiter zum Tore hinaus. Dies $e z$ kann wohl eingeführt sein, um die Lebhaftigkeit, die in der Voranstellung des Verbums vermeintlich liegt, aufzuheben; zunächst dann wohl in feierlicher Erzählung wie in der Predigt $i z$ was ein heidinischer wissage der hiez Barlaam und an gehobenen Stellen der Poesie ez was ein küneginne gesezzen über sē. Sein Ursprung könnte aber auch in einer syntaktischen Unterscheidung von Satzfragen und konjunktionslosen Nebensätzen liegen: Ritten drei Reiter zum Tore hinaus hätte schließlich auch interrogativ oder konditional verstanden werden können. Doch ist diese zweite Erklärung dem ganzen Charakter sprachlicher Entwicklung zufolge die weniger wahrscheinliche.

66. Anfangsstellung im Aufforderungssatz. Aus psychologischer und rhythmischer Notwendigkeit ist hier die Anfangsstellung des Verbums usuell; hol ihn der 


\section{$-57-$}

Teufel; rette sich wer kann. Nur bei besonderer Feierlichkeit erscheint auch hier wiederum die Deckung durch das satzeröffnende ' $\mathrm{es}$ '; es freue sich, wer da atmet im rosigen Licht; es fürchte die Götter das Menschengeschlecht. Leichte Deckung durch Interjektionen oder durch eine nominale oder adverbielle Bestimmung (nū fuatiri scāf mīnu; die rede lāt belïben; lang lebe der König) ist hier von früh an belegt und hat jene Deckung durch 'es' ermöglicht.

\section{Inversion.}

67. Ungerade Folge. Es ist $\mathrm{zu}$ bemerken, daß das erste betonte Satzglied durchaus nicht immer das Subjekt zu sein braucht; immer aber zieht es jenem rhythmischen Gesetz zufolge das Verbum in Kontaktstellung, sodaß das Subjekt in diesem Falle nun dem Verbum nachfolgt. Man redet dann von invertierter oder ungrader Folge. Die erste Tonstelle kann durch ein Prädikatsnomen vertreten sein: Karl hiess der Kaiser; anord. Ingólfr hét madr 'J. hieß ein Mann'; ahd. tōt ist Hiltibrant; oder durch das Objekt, ahd. taz urlub kab imo Zeno; anord. Teit fódde Hallr 'den T. erzog H.'. Es kann aber auch jede temporale, lokale, adverbiale Bestimmung sein, beliebiger Länge, die den Satz eröffnet und Inversion veranlaßt: ahd. tho quam Herodes; zi gote rihta si iro muat; mit gèru scal man geba infähan; am Anfang war das Wort; da steh ich nun; altgutnisch: firi bann tima oc lengi eptir siban tropu menn 'vor dieser Zeit und lange noch darauf glaubten die Menschen'; in Lebensfluten, in Tatensturm wall ich auf und $a b$; ahd. wela gisihu ih in dinèm hrustim; aus der Skeireins: inuh fis qam gamains allaize nasjands; garaihtaba warp bi swiknein sokeins gawagida.

Inversion veranlaßt auch die in der älteren Sprache besonders beliebte Partikel $j \bar{a}, j \bar{j}$, mit der man Aussage- 
sätze einleitet, die dann etwas Ausrufungssatzmäßiges bekommen. Vgl. ahd. wola druhtin min, jā bin ih scalc thīn, fingar thinan dua ana mund minan; mhd. jō enwas ich niht ein bèr wilde. Oder mit einem eingeschobenen pleonastischen doch; mhd. jā sint iu doch genuogen diu moere wol bekant. Dieser letzten Art entstammen mit Unterdrückung der eröffnenden Partikel die im Nhd. üblichen, mit Anfangsstellung des Verbums, Inversion und doch gebildeten Sätze wie: gelang es mir doch; tue ich doch alles, was ich kann. 68. Inversion nach 'und'. Hierher gehört nun auch die heute so verpönte und doch so harmlose Inversion nach 'und'; vgl. wir haben Ihre Lieferung erhalten und danken wir Ihnen. Sie muß sich aus einem alten starktonigen 'und' entwickelt haben. Starktonigkeit des 'und' läßt sich denken, wenn von dem damit eingeleiteten Satz nichts anderes als das reine Moment der Hinzufügung neu und wichtig ist. Denn so wie bei zwei syndetischen Begriffen den Hauptton das Syndeton tragen kann (Paul ist dagewesen, Emma nicht! Nein, Paul und Emma sind dagevesen!), so kann es ihn auch bei zwei syndetischen, koordinierten Sätzen tragen. In einem solchen Falle mußte dann syntaktisch die Inversion eintreten. Auch sie ist gemeingermanisch; im Anord. ist sie Stilregel geworden: peir kómo til bings ok fóro peir 'sie kamen zum Ding und fuhren sie'. Auch im Deutschen ist sie nicht ungewöhnlich seit je; vgl. unde cham mir ougōn lieht (Notker); und was im sin gevidere alrōt guldìn (der von Kürenberc); diu naht hete ende und kom der tac (Wolfram im Parzival); er sitzet üf dem himel und gēnt im diu bein herabe üf die erden (Bruder Berthold); die Gräber taten sich auf und stunden auf viele Leiber der Heiligen (Luther); bald darauf klopfte es wieder an und war ein anderer Fuchs vor der Tür (Grimm im Märchen). Im 17., 18. Jahrh. war sie 
Stilregel wie im Altnordischen. - Wir knüpfen also mit dieser Erklärung an die Kontaktstellung des Verbums an. Die Erklärung aus der Anfangsstellung mit proklitischer Deckung wie bei $e z$ würde voraussetzen, daß die Starktonigkeit des Verbums usueller war als die mittlere.

69. Schaltesätze. AusInversion nachadverbieller usw. Bestimmung oder nach dem vorangegangenen Objekt, wenn nämlich der vorausgeschickte Teil der Rede oder des Gedankens als Objekt des Verbs genommen wird, erklärt sich auch die ungrade Folge der Schaltesätze; sagte er, glaube ich; zuo sinem brütloufte bat er daz si qucemen; wēttu irmingot, quad Hiltibrant, obana ab hevane. Bemerkenswert für das Nhd. ist die Erweiterung des Verbum dicendi im Schaltesatz durch ein anderes Verbum beliebiger Bedeutung; vgl. aus Goethe: es ist wohl noch Zeit, versetzte Wilhelm und reichte der alten einen Louisd'or hin, verschafft sie uns, was wir wünschen ... Dies neue Verbum steht an Stelle von Sätzen mit 'indem' oder eines Partizipiums.

70. Ausnahmen von der Inversion. Wenn auch gemeingermanisch, so ist die Inversion wie ja die ganze Mittelstellung des Verbums doch nichts absolut Primäres. Deshalb kann sich auch der altertümliche Stil der Poesie über sie hinwegsetzen; vgl. ahd. forn her östar giweit; sìd Dëtrïhhe darbā gistuontun; mhd. daz sper er undern arm sluoc; sō sềre zesamen sī stāchen, was die archaische Färbung ganz besonders erhöht. Wie man sieht, fällt dann der Strom des Stils, wie ein freigegebenes Wasser, in sein altes Bett der Endstellung des Verbs zurück.

\section{Stellung des Verbums im Nebensatz.}

71. Der Unterschied vom Hauptsatz. Usuell ist die Endstellung des Verbums im Nebensatz; das Verbum folgt dem Subjekt auch da, wo Partikeln, adverbielle Be- 
stimmungen an der Spitze des Satzes stehen. Das ist der prinzipielle Unterschied vom Hauptsatz. Vgl. den Nebensatz: nun der König kam; aber den Hauptsatz: nun kam der König; got. saei inn galeibip gegenüber dem Hauptsatz sa galeipip inn; ahd. dō där niwiht ni was, aber der Hauptsatz dö was der eino; anord. hann spyrr, hverr bessi madr er aber direkt: hverr er bessi madr?; vgl. ferner got. ei frauja qimands gahausidedi; ags. poette pāra wundra mēst was; ahd. dat ero ni was; sō iz regenōt (aber der Hauptsatz: sō nazzēnt die bouma). Nie ist das Verbum im Nebensatz aus der Endstellung in die Mittelstellung, aus der mittleren Tonstärke in die schwache übergegangen, weil der Ton im Verbum des Nebensatzes immer ein andrer blieb als der des Verbums im Hauptsatz, was wir heute freilich nur noch an seiner Wirkung erkennen. So hat auch im Altindischen das Verbum im Nebensatz seinen Ton nicht verloren. - Anfangsstellung mit Inversion ist auch hier wie im Hauptsatz okkasionell vorhanden, hier natürlich unter Deckung durch die den Nebensatz einleitende Partikel oder Konjunktion, bei besonderer Tonstärke des Verbums; got. afar patei matida so managei, bigitan $v a r p \ldots$ (das Essen hat stattgefunden und trotzdem ist noch etwas übrig; matida ist hochbetont); anord. kennir hann, at brotinn var larlegrinn; direkt: brotinn var $l$. 'zerbrochen war der Schenkelknochen'; deutsch: ich sage, dass gebrochen ist der Friede, erklürt der Krieg usw.

Die Stellung der übrigen Satzglieder ist nicht verschieden von der des Hauptsatzes. So stehen auch in der älteren Zeit die Formen des Verbum infinitum hinter den finiten; ahd. thaz wir sin thionōnti; bei Notker: do manige liute... hara ubere bigondon varen. Beim Fortschritt des Prinzips der Endstellung geriet aber das Finitum ganz ans Ende, was sich schon bei Notker findet, êr Anti- 


\section{$-61$}

cleristus rīchesōn begondi, und heute die Norm ist. Doch finden sich noch vielfach Ausnahmen, grade bei großen Sprachmeistern (Goethe, Grimm), wobei man dann wohl den "Eindruck einer naiven Behaglichkeit und Bequemlichkeit" zu empfangen meint; vgl. Goethe: welches denn manchem der Nachgebornen mag zu Gute gekommen sein.

72. Der Ursprung des Nebensatzes. Wir finden also als die usuelle Form des Nebensatzes die Form des urgermanischen Aussagesatzes: grade Folge und Endstellung desVerbums, die sonst überall im Germanischen syntaktisch gänzlich aufgegeben war und die nur der poetischarchaische Stil noch festgehalten hat. Unsre Nebensätze in $§ 71$ nun der König kam, do dār niuiht ni was unterscheiden sich in nichts von unsern Hauptsätzen in $\S 70$ forn her ōstar giweit, sìd Dētrïhhe darbā gistuontun. Ein Nebensatz, herausgelöst und herausgenommen, ergibt die reine Urform des germanischen Aussagesatzes mit der mittleren Betonung des Verbums aus der Zeit, da er auch den Kontakt und Inversion verlangenden Partikeln und Adverbien noch nicht unterlegen war; do manige liute hara ubere begondon varen $=$ ek Hlewagastir Holtingar horna tawido = deinde rex terram regit. Unsere Nebensätze sind nichts anderes als gleichsam syntaktisch versteinerte Aussagesätze, in die Struktur des Satzes aufgenommene versteinerte Appositionen, und anders ist ja ihr ursprünglicher Inhalt nicht $\mathrm{zu}$ bewerten. Alle Hypotaxe löst sich in ursprüngliche Parataxe auf. Ahd. ich weiz her imos lōnōt ist einige Jahrhunderte zuvor noch als reine asyndetische Parataxe verstanden worden. Erst als die Mittelstellung für den Hauptsatz usuell wurde, machte sich der syntaktische Unterschied zwischen Haupt- und Nebensatz fühlbar. Der Nebensatz entstammt der Epoche der usuellen Endstellung des Verbums im Aussagesatz. 


\section{$-62-$}

\section{Ellipse.}

73. Unter Ellipse verstehen wir das usuelle Fehlen von Satzgliedern, die zum Verständnis entbehrlich sind, nicht deshalb, weil sie aus dem Vorhergehenden zu ergänzen sind, sondern weil sie sich aus der äußeren oder inneren Situation des Sprechenden ohne weiteres ergeben. Wir führen folgende Fälle an:

Ellipse des Substantivs neben dem Adjektivum: unser Brauner (scil. Hengst; ahd. der brūn); der Zehnte (Teil); zur Rechten, got. taihswo 'die rechte (Hand)'; [umgedreht Fehlen des Adjektivs neben dem Substantiv in unsern Grüßen: Morgen !, Mahlzeit!]; neben attributivem Genitiv: bei Müllers, ahd. in Sandolfes (hüse); s'ist heut Simons und Judae (Tag)! Über Ellipse des regierenden Substantivs beim prädikativen Genitiv bei den Verben 'sein' und 'werden' s. u. § 86 .

Ellipse des Subjekts: sammir (got helfe). Ellipse des Objekts: zesamne liezens strichen (scil. diu ors); ebenso einspannen, sprengen (springen lassen), ferner schiessen, schlagen und viele andere ursprünglich transitive Verben, die durch elliptischen Gebrauch zu intransitiven geworden sind; s. § 78. Desgleichen nehmen wir wohl Ellipse des Objekts zu Recht an bei einer Reihe von Verben, die den Dativ regieren und diesen als einzigen Kasus bei sich haben, so bei got. tekif imma scil. den Leib, das Kleid, den Arm wie bei nhd. öffne ihm scil. die Türe; s. u. § 96 .

Ellipse des Verbum finitum: sammir got (helfe); $n \bar{u}$ zuo des der neve si; $\bar{u} z$ minen ougen balde; wer da?; zum Henker!; er auf und davon!; Gnade!

Ellipse von Sätzen: Vrouve, daz ir scelic sīt!; Wie sēre si daz rach!; Ob diu nahtegal iht singen könne? jā si singet! In diesen Beispielen ist der Hauptsatz mit den Verben des Wünschens, Sagens und Fragens unterdrückt. 


\section{Formenlehre.}

\section{Genus und Numerus.}

74. Genus. Eine direkte Übertragung vom natürlichen Geschlecht scheint zunächst für die große Mehrzahl der Nomina nicht vorzuliegen. Das grammatische Geschlecht scheint sich vielmehr zunächst nach rein äußeren Assoziationen, besonders nach dem Klang der Endungen, bestimmt zu haben. Nomina mit der Endung os funktionierten männlich [ganz gleich, ob man vielleicht bereits aus einem andern psychischen Grunde anders zu fühlen begonnen hatte], weil zufällig das Wort für „Mann" und für einige männliche Tiere von Arten, bei denen der natürliche Geschlechtsunterschied dem Menschen wesentlich war, diese Endung hatte (*wiros, *ekwos), und Nomina mit der Endung $-\bar{a},-\bar{\imath}$ funktionierten weiblich, weil das Wort für „Frau" usw. diese Endung besaß. Diese Endungen ihrerseits hatten aber ursprünglich nichts mit dem natürlichen Geschlecht zu tun, sondern hatten irgend eine andere Funktion, vielleicht eine schlechthin, ohne Genusunterschied, individualisierende. Ihnen gegenüber übertrug sich auf die Endung -om eine verallgemeinernde, kollektive Bedeutung, und weil dergestalt wohl die Worte für etwas Unentwickeltes, Frzeugtes (Frucht u. dergl.) diese Endung besaßen, funktionierten alle Wörter auf -om in dieser Richtung, mit einem Worte: „neutral“. So sind Wurm, Arm männlich; Fliege, Zunge weiblich; Rind, Bein sächlich geworden ohne irgend ein geistiges Prinzip. 
Aber ganz ohne ein solches kommt man in der Erklärung des grammatischen Geschlechts nicht aus. In diese äußerliche Regulierung hat eine andere, im allgemeinen vermutlich jüngere, korrigierend eingegriffen, die Übertragung vom natürlichen Geschlecht, sehr oft eine Metapher, eine Art dichterischer Vorgang. Unter ihrem Zwange regelten sich vermutlich die Verhältnisse von Sonne und Mond (zuvor im Geschlecht beide nicht ohne Schwankung; mhd. diu māne unde auch der sunne), Tag und Nacht, Himmel und Erde u. a. m. Andrerseits wirkt das Gesetz der äußeren Assoziation immer noch nach, demzufolge die Neutra ahd. wanga, gruzzi und die Maskulina ahd. slango, snecko Feminina geworden sind, nachdem ihre Endung zu - $e$ abgeschwächt war.

Der Widerstreit beider Richtungen, äußerer und innerer Beziehungen, wirkt fortdauernd noch in der Syntax nach. Erst hier nun verstehen wir die uns schon bekannte Erscheinung der Inkongruenz im Genus, vgl. § 28. In Wendungen wie got. gup meins; mhd. ich armer Dietmäres kint; die schöne Annerle; die hässlichste meiner Kammermädchen (Wieland); bei der Anknüpfung von Sätzen mit femininem Pronomen an Weib, Frauenzimmer, Backfisch usw. besteht die Inkongruenz in der Verdrängung des grammatischen Geschlechtes durch das natürliche.

Vom neutralen Wort auf -om übertrug sich wiederum die verallgemeinernde, kollektive Bedeutung, die ihr zu Grunde lag, auf das ganze Neutrum überhaupt; vgl. got. all bagme godaize (bagms aber mask.); ahd. manno liobosta; mhd. guot unde līp, daz wāget er; auch praedikativ: got. niu pata ist sa timrja?; ahd. thaz bin ih; mhd. ich bin ez Jwein; vgl. oben $\S 28$.

75. Numerus. Im Plural stehen vorwiegend Substantiva, die eine deutliche Mehrheit bezeichnen, so von 
Personen, vermutlich an Stelle des alten Dualis: ahd. hiwun, eldiron (Gatten, Eltern); von Festen, die eine der Zahl nach durchaus bekannte Reihe von Tagen umspannen, mhd. östern, pfingesten, zen wïhen nahten, nhd. die Fasten, ahd. brütloufti; bei Krankheitsnamen mit der Vielheit ihrer Merkmale, wie Blattern, Röteln, Frieseln, Pocken, Masern; schließlich bei anderen Begriffen, deren Vielheit immer im Bewußtsein liegt oder lag, got. wegos „Wogen“, bokos „Buch"; nhd. Alpen, Niederlande, Trümmer, Eingeweide, Kaldaunen, Wehen, Gliedmassen, Reisige.

Die volkstümliche Syntax liebt es, den Plural zu vermeiden durch eine Reihe aufgezählter Singularia, die den Inhalt eines zusammenfassenden Plurals erschöpfen, z. B. durch 'Vater und Mutter' für 'Eltern', vgl. Es wusst weder Vater noch Mutter im Volkslied; so er möchte Urlaub haben von Vater und Mutter, Da verliess er Vater und Mutter im Volksbuch (Magelone). Vgl. ferner: fraw, man, pfaff, lay, münch, nunn = alle; wip noch man = keine usw. Aus dem Wesen dieser Aufzählung erklärt sich der häufige Singular des Verbums, falls sie grade das Subjekt betrifft; jeder Begriff ist dann einzeln gedacht; vgl. die Inkongruenz beim Numerus oben $\S 27$. - Ferner ersetzt den Plural ein singulares Kollektivum: got. fadrein „Eltern", ahd. liut, nhd. Menge, Volk, Paar, Schock, Dutzend, das Geschwister, hierzu die Geschwister erst sekundär, wie ahd. liute zu liut, got. fadreina, fadreinam zu fadrein; wobei dann das Verbum häufig im Plural steht, siehe die Inkongruenz beim Numerus oben $\S 27$; vgl. auch got. pai fadrein. - Drittens ersetzt den Plural der sogen. generelle Singular, bei dem das Individuum die ganze Gattung vertritt; vgl. ahd. so muater kindiline duat; seit mhd. Zeit mit Artikel: ein man sol haben ère; es irrt der Mensch; morgen kommt der Schwed; vgl. auch Formeln

Naumann, Deutsche Syntax. 
wie ïber Stock und Stein usw. - Endlich ist der Plural unnötig, wenn die Mehrzahl schon durch ein Zahlwort ausgedrückt ist; mhd. siben vuoz landes; nhd. zwei Mann; drei Paar Stiefel.

Sonst steht der Singular im Allgemeinen bei Namen, außer in appellativem Gebrauch, vgl. mhd. ahi waz man ir noch hiute siht, der Marke und der Isolde oder wenn ihre Träger wirklich mehrfach vorhanden sind, as. Judāsōs twēna. Ferner bei nur einmal vorhandenen Gegenständen, wo nur besondere Stilarten eine Ausnahme machen, wie bei Sonne, Mond, Welt der wissenschaftliche Stil, weil für ihn die Einmaligkeit des Vorhandenseins nicht besteht (aber das Weltall); bei Stoffbezeichnungen wie Gold, Fett, Staub, Eis, wo nur etwa der Kaufmannsstil eine Ausnahme macht, indem er verschiedene Arten von Fetten usw. unterscheiden will (eine frühe Ausnahme ist diu wazzer, eine poetische die Lüfte); schließlich bei Abstrakten wie Mut, Durst, Frost, Schlaf, Neid usw., jedoch begegnet in der älteren Sprache grade hier nicht selten der Plural, ahd. fora skamōn 'vor Scham'.

\section{Nominativ (und Vokativ).}

76. Nominativ. Außer als Kasus des Subjekts fungiert der Nominativ auch als Kasus des Prädikatsnomens. Beispiele für die erste Funktion erübrigen sich; zur zweiten vgl. oben $\S 7$. Der Gebrauch besaß früher größere Ausdehnung als heute, der Nominativ als Prädikatsnomen ist heute nur noch bei einer geringen Anzahl von Verben wie sein, werden, bleiben, scheinen, dünken, heissen möglich. Vgl. mhd. dā wart ich empfangen hëre frouwe; diu gēt noch magetin; er soll walden hërre allenthalben. Im Volkslied: dasz ich mägdlin von euch kam und noch heut in der Poesie möglich, Goethe: Asche lag der 
edelste Troer am Boden, Knabe sass ich. Vgl. noch die erstarrt überkommenen Wendungen: Brache liegen, Posten stehn u. a. m. Seit mhd. Zeit ist auch die Verbindung des Prädikatsnomens mit dem Artikel möglich; mhd. $\bar{E}$ rec der èrste an sie $\mathrm{kam}$; er lief ein tōre in dem walde; Schiller: ein zartes Kind ward sie verpflanzt, aber ahd. kind ward er faterlōs.

Von früh an macht sich jedoch eine sich steigernde Tendenz zur Vermeidung dieses Gebrauches geltend; zunächst durch Umschreibung mit Präpositionen: got. $d u$, ahd.zuo mit Dativ; got. so saurga izwara du fahedai wairpip; ahd. eddo ih imo ti banin werdan. Seit mhd. Zeit auch mit für: die sint erkant für guotiu wip; seit nhd. Zeit durch an: da der Tag am heissesten war. Eine andere Umschreibung ist die mit als, nhd. auch mit wie, welche aus dem Vergleichssatze stammen, d. h. aber: die Funktion des Prädikatsnominativs ist von einer völlig anderen Konstruktion übernommen worden; mhd. er gnas als ein saelec man. - Auch die Verben, die die alte Konstruktion noch heute bewahren, unterlagen zeitweilig den Neuerungen; ahd. $n \bar{u}$ thie zi gote sint genant; frühnhd. wir sind als ein Fluch der Welt.

Eine gewisse Verwandtschaft mit dem Wesen des Vokativs zeigt ein alleinstehender Nominativ, der sich außerhalb der Konstruktion des Satzes befindet, zunächst in Ausrufen: got. frauja mip pus!; ahd. heil, wih dohter!; mhd. wan diu tarnkappe - sie waren tōt dā bestān; nhd. noch ein Schritt, so ist er verloren! Aus diesem alleinstehenden Nominativ im Ausruf stammt die im volkstümlichen Stile so sehr beliebte Prolepse: der Nominativ vor dem Satze und seine Wiederaufnahme im Satze durch ein Relativpronomen, z. B. Kaiser Karl, der war ein starker Held; ahd. Agamemnon, der irrah an dero zestördo Troiae..; 
mhd. diu swert, die sniten sēre; nhd. der Türmer, der schaut zu mitten der Nacht; der Wind der weht, der Hahn der kräht. Die angegebene Entstehung dieses Gebrauches erhellt aus den Fällen mit veränderter Konstruktion; mhd. die Hiunen, der garten sich zwei tüsent. Bei anderen Kasus ist diese Prolepse seltener und wohl sekundär.

77. Vom Vokativ. Gegenüber einer Tendenz des Nominativs, die ihn außerhalb der Satzkonstruktion zu setzen sucht s. o., besteht beim Vokativ, d. h. dem Kasus, der ursprünglich völlig selbständig, gewissermaßen einen Satz für sich bildete und bildet, eine vom Ahd. und As. zum Mhd. sich steigernde, später jedoch wieder verschwindende Tendenz, ihn der Konstruktion des Satzes enger zu verbinden, und zwar durch eine beigefügte Apposition im Nominativ mit bestimmtem oder unbestimmtem Artikel; ahd. druhtin min ther guato; mhd. ich wil dich warnen, Hagne, daz Aldriānes kint; im Volkslied: Got grüz euch frow die herzogin; mit unbest. Artikel mhd.: sît willekomen, her Sïfrit, ein edel riter guot. Dieser Gebrauch wird sich verallgemeinert haben aus Fällen, in denen der Angeredete identisch war mit dem Subjekt des Satzes, so daß die Apposition doch eigentlich zu diesem gehörte, wie ein solcher Fall mit Subjekt und Apposition, aber unterdrücktem Vokativ vorliegt in mhd. rïtest $d u n u$ hinnen, der allerliebste man; ohne Subjekt und ohne Vokativ, aber mit Apposition: saget mir, der bapst von Röme.

\section{Akkusativ.}

78. Akkusativ des Objekts. Der adverbale Akkusativ bezeichnet den Gegenstand, der von der Tätigkeit des Verbums am intensivsten betroffen wird und zwar näher betroffen wird als der Gegenstand, der im Dativ und vollständiger als der, der im Genitiv steht, vgl. $§ 14$. 
Da das Gefühl für das Maß dieser Nähe und dieser Vollständigkeit zeitweilig Schwankungen unterliegt, so schwankt der Gebrauch bei einzelnen Verben auch zeitweilig zwischen Akkusativ und Dativ (s. u. $\S 96$ ) und Akkusativ und Genitiv (s. u. § 84).

Der Akkusativ bezeichnet dann das unmittelbare Objekt oder auch das Resultat der Verbaltätigkeit; er trägt den Stein; er baut ein Haus. Solche Verben, die usuell eine dieser beiden Arten von Akkusativen bei sich haben, heißen transitive Verben; solche, die für gewöhnlich 'absolut' gebraucht werden, heißen intransitive. Transitive Verben sind 'setzen, tun, wirken, leisten, schaffen, senden, machen, bilden, füllen, heilen, sparen, hören' u. a. m.; früher wurde auch eine Reihe von Verben transitiv gebraucht, die heute höchstens nur noch einen Akkusativ des Inhalts (s. u.) bei sich führen können, wie "klagen, weinen, zürnen, seufzen, dienen, beten u. a. m.'; vgl. die mhd. Beispiele: ir ietweder klagen began des anderen ungemach; sine wunden weinde si aber dō (ahd. weinota then bruader); daz zurnde sêre der helt; ich siufte minen ungewin; der diene guotes wibes gruoz; ahd. thaz kind sie thār thō betōtun. - Intransitiva sind: "hoffen, blühen, kommen, gehen, singen, sterben, horchen, darben u. a. m.'. Durch gewohnheitsmäßige Ellipse des Objekts konnten, wie wir schon oben $\S 73$ sahen, transitive Verben zu intransitiven werden; so sprengen $=($ ein Pferd $)$ springen lassen ; rennen $=$ rinnen lassen ; mhd. erbeizen 'absteigen' $=$ (das Pferd) beißen, fressen lassen; so heute "klagen, weinen, zürnen usw.'; oder sie haben jederzeit beide Funktionen wie 'räumen, bauen, jagen, treiben, schießen, schlagen u. a. m.'. Andrerseits können mit einiger Freiheit intransitive Verben durch Analogie zu transitiven selbst transitiv werden, vgl. er darbte das Essen (Chr. Weise) mit 
'darben' nach 'sparen'; es horcht der Alte die Lieder ((roethe) mit 'horchen' nach 'hören'.

79. Akkusativ des Inhalts. Auch bei den Intransitiven ist dagegen von früh an ein sogenannter Akkusativ des Inhalts möglich. Pleonastisch wird hier im Akkusativ der Bedeutungsinhalt des Verbums wiederholt, zunächst wohl nur von Substantiven, die gleichen Wortstammes mit dem Verbum sind, dann aber auch von Synonymen und schließlich von nur deren Inhalt angebenden Sinnesverwandten. Im ersten Falle ergibt sich das in aller gehobeneren volkstümlichen Sprache so ungemein beliebte Stilmittel der Figura etymologica. Vgl. got. haifst haifstjan, huzd huzdjan; ahd. sang singan, werk wirkan, släf släfan; mhd. sprunc springen, rāt rāten, slac slagen, trunc trinken; nhd. gar schöne Spiele spiel ich mit dir; das den grossen Gedanken deiner Schöpfung noch einmal denkt. Die zweite Stufe mit einem Akkusativ des Synonymum stellen dann dar Verbindungen wie: eid swern (statt Schwur schwören), rauba birahanen, stimme schrien, wig fehten, stürme strïten, Tränen weinen, den ewigen Tod sterben. Die dritte Stufe mit dem Inhalt angebenden Sinnverwandten: Lied singen, halleluja singen, Ball spielen, Brett spielen, reien springen, einen strit gesigen, Blut weinen, Blut schwitzen, Wut schnauben. Alle Grenzen hat schließlich dieser Gebrauch überschritten in Stile der Poesie des 18. Jahrhunderts, besonders bei Klopstock, Hölty u. a.; vgl. der Himmel jauchate dir Lieder; da weinte sie Freude; Liebe rauschen die Blätter; die Nachtigall flötete Wehmut; Zorn blickt mein blaues Auge; die Seelen schauerten Wonne. 80. Der Akkusativ bei den Verben der Bewegung. Von hier aus ist auch wohl der Akkusativ bei den intransitiven Verben der Bewegung zu verstehen. Der Weg, die durchmessene Strecke, ihre räumliche und 
zeitliche Ausdehnung ist als ein Akkusativ des Inhalts aufzufassen. Wie 'Lied singen' sich aus 'Sang singen' entwickelt hat, so entstammen den Wendungen 'gang gēn, vart varn' u. a. m. auch die Verbindungen wege varn, eine reise varn, eine mīle rïten usw.; vgl. got. qemun dagis wig; ahd. floug er sunnūn pad, sterrōno strāza; ih wallōta sumaro enti wintro sehstic; mhd. der vuor wazzer unde wege; nū riten si beide nū holz nū heide. Andrerseits ist 'Weg, Reise' usw. auch wiederum das Resultat der Bewegung, vgl. unser vulgäres 'einen Weg, eine Reise machen'. Und schließlich kann auch 'Weg' oder 'Meile' als das sehr intensiv betroffene Objekt aufgefaßt werden, das durch die Bewegung zu überwinden ist, vgl. unser 'Kilometer fressen'. Prinzipiell also, so sehen wir jetzt, kann überhaupt jedes Verbum ein Akkusativobjekt erhalten und die transitiven Verben unterscheiden sich von den intransitiven prinzipiell schließlich nur dadurch, daß bei ihnen die Wahl des Objektes grammatisch unbegrenzt ist, während bei jenen diese Wahl inhaltlich äußerst eng gezogenen Schranken unterliegt.

81. Adverbieller Akkusativ. Aus diesem Gebrauch des Akkusativs bei Verben der Bewegung erklärt sich eine große Reihe adverbieller Raum- und Zeitbestimmungen, die im Akkusativ stehen: heim, alwec, weg in geh weg, kreuz und quer, Tag und Nacht, jeden Morgen, diesen Abend, drei Tage lang, allzeit, alleweil usw.

Akkusativ bei Präpositionen. Unentwickelter oder verkümmerter Begriff des Verbums konnte zuweilen über das Wie und das Wieweit der Bewegung am Objekte im Unklaren lassen. Bei ich ging den Berg konnte der Hörer nicht wissen, ob an, auf, über, unter, vor, hinter, durch, neben, in oder um den Berg gemeint war. Es traten darum eben diese Präpositionen näher bestimmend zum 
Verbum. Nicht von ihnen, die ursprünglich selbst Adverbien sind, hängt der Akkusativ ab, sondern vom Verbum. Aber im Laufe der Sprachentwicklung lösten sie sich vom Verbum, verbanden sich enger mit dem Objekt, mit dem zusammen sie eine selbständige syntaktische Wortgruppe bilden können.

82. Doppelter Akkusativ. Ein doppelter Akkusativ steht beim (transitiven) Verbum zunächt einmal da, wo außer dem Objekt noch ein adverbieller Akkusativ vorhanden ist; vgl. as. Johannes stodd, dopte allan dag druhtfolc mikil; mhd. hin wiste mich der waltman einen stic. So wie hier wird nun überhaupt beim doppelten Akkusativ der eine als der gewöhnliche Objektsakkusativ, der andere (prädikative) als Akkusativ des Inhalts aufzufassen sein; so bei lehren, zunächst ich lehre dich eine Lehre, dann auch den Inhalt derselben: ahd. er lērta sie òtmuati. Ferner steht der doppelte Akkusativ bei den Verben 'hehlen, bitten, heißen, nennen, machen'; vgl. mhd. die wärheit ich dich niht enhil; nhd. so ikr den Vater etwas bitten werdet; got. ina fraujan haitip; ahd. ih mih gotes sunu nemnu; got. biudan sik silban taujī $\bar{p}$; ahd. dī dīne geista machōst poten.

83. Adnominaler Akkusativ. Der adnominale Akkusativ ist sekundär gegenüber dem adverbalen; er entwickelte sich erst über den adverbalen bei prädikativem Gebrauch. Es ist der zugrunde liegende verbale Begriff, der den Akkusativ regiert, s. $0 . \S 17$.

\section{Genitiv.}

84. Genitiv des Objekts. Der adverbale Genitiv bezeichnet den Gegenstand, der von derTätigkeit des Verbums weniger vollständig betroffen wird als das Akkusativobjekt. Er bezeichnet zwar auch ein Objekt des Verbums genau wie der Akkusativ, aber der Verbalbegriff ist nicht 


\section{$-73-$}

auf dessen vollen Umfang bezogen; das Genitivobjekt ist nur ein partitives Objekt. Wir sagten schon oben, daß das Gefühl für das Maß dieser Vollständigkeit des Betroffenwerdens zeitweilig Schwankungen unterliegt, so daß der Gebrauch bei einzelnen Verben zwischen Akkusativ und Genitiv schwankte; vgl. got. greipip pana und gripun is ("nach ihm", aber ohne Erfolg); namuh pans hlaibans... iah pize fiske; hausjand pata waurd und hausjandans pize waurde; gamunan waurdis und Data waurd; mhd. mines släfes brühte neben die hente $b r$.; der guoten rede verheln neben die guoten rede v.; got fürhten neben er forhte Turpines; nhd. giesst Neoptolem des Weins, aber ich giesse den Wein.

Wir werden aber wohl vermuten dürfen, daß ursprünglich kein Verbum, welches nicht etwa den Begriff rein partitiven Tuns ausdrücklich in sich trug, prinzipiell nur im Genitiv das Objekt bei sich führte, daß andrerseits freilich eine Reihe von Verben von vornherein nie für den Genitiv in Betracht kam, weil der ihnen innewohnende Begriff alles partitive Geschehen ausschloß, daß aber die Anzahl aller in Betracht kommenden Verben rein nach Maßgabe der jeweilig in Rede stehenden tatsächlichen oder gemeinten Verhältnisse zwischen Genitivobjekt und Akkusativobjekt unterschied und nach den Umständen jetzt. dieses, dann jenes gebrauchen konnte. Natürlich konnte aber dann im Laufe der Entwicklung dieser oder jener der beiden Kasus bei diesem oder jenem Verbum usuell werden. Bis in das Frühnhd. hinein war dieses mit dem Genitiv bei einer großen Reihe von Verben der Fall, mit denen wir heute usuell den Akkusativ verbinden. Das liegt nicht so sehr oder gar nicht daran, daß wiederum ein Schwanken und Umschwung im Gefühl für das $\mathrm{MaB}$ des Betroffenwerdens des Objektes eingetreten wäre, sondern vielmehr an der allgemeinen Entwicklung des Genitivs, 
die ihn immer mehr von der adverbalen zur adnominalen Funktion entfernte. Oder es tritt statt des Akkusativs, der den Genitiv wieder verdrängt, die Umschreibung mit der Präposition (z. B. von mit dem Dativ) ein; fast nur der poetische Stil verwendet freilich noch heute, besonders in der klassischen Zeit unserer Dichtung, den adverbalen Genitiv.

So steht denn der Genitiv in der älteren Sprache bei den Verben der sinnlichen und geistigen Wahrnehmung; vgl. für das Got. die Beispiele mit hausjan und gamunan oben; ahd. sehan: thes grabes, thero duro; hören: sinero worto; githenken: thes armen skalkes; mhd. $j \bar{a}$ sach er ligen umbe sich der liute sam der steine.

Bei den Verben des Herrschens, Waltens, Verfügens über eine Sache; ahd. waltan (im Got. mit Dativ): desero brunnōno bēdero waltan; mhd. ir phlägen dri künege; in tugenden der si phlac; Luther: die hüteten ihrer Herde. Hier wird auch haban, haben mit dem Genitiv einzuordnen sein; got. swe lamba ni habandona hairdeis; ahd. tü ne habis kescirres (daneben dat dī habēs hēme hèrron gōten); mhd. si hete noch des goldes; Luther: und hätte der Liebe nicht.

Bei den Verben des Essens, Trinkens, Genießens, Sicherfreuens, des Lebens von etwas. Vgl. got. pis hlaibis matjai; ahd. trinkist dū des lüteren brunnen; mhd. daz er sin werde mendende; eines wilden wolves aze ich $\bar{e}$; ahd. hewes lebeen (von $\mathrm{Heu})$; mhd. si lebten niht des windes; Luther: warum lachet des Sarah?; der Gerechte wird seines Glaubens leben.

Bei den Verben des Gebens, Nehmens. Zu got. niman s. 0. ; ei akranis pis weinagardis gebeina imma; ahd. her skancta cehanton sinan fianton bitteres lides; mhd. ich wil im mines brōtes geben.

Bei den Verben des Begehrens, Bedürfens, Wünschens, überhaupt des geistigen oder auch körperlichen Hinstrebens; 
vgl. got. jabai was aipiskaupeins gairneip; ahd. rāmen: thes houbites; tharbēn: swertes, vgl. auch sid Dētrīhhe darbā gistuontun fateres mines; āhten: dero fianto; mangalön: thin; mhd. daz sin niene bristet; nhd. mein Haus entbehrt des Vaters.

Bei den Verben des Füllens, Sättigens; got. ahmins weihis gafulljada; gredagans gasobida biube; so auch bei ahd. mhd. fullen, setten, satōn, sih saten, sih neren usw.

85. Genitiv des Inhalts. Bei den intransitiven unter den aufgezählten Verben, wie bei 'darben' und 'leben' mutet uns das Genitivobjekt wie eines an, das sich einem Akkusativ des Inhalts vergleichen läßt, oder vielmehr auch nur wieder in partitivem Sinne den Teil eines Inhaltsakkusativs bezeichnet; nach ich lebe das Leben ist ich lebe den Glauben gebildet, und partitiv dann dazu ich lebe des Glaubens. Und tatsächlich ist bei einer Reihe von jenen Verben mit Akkusativ des Inhalts auch ein Genitiv des Inhalts belegt. Figura etymologica gibt es nicht blo $B$ prinzipiell beim Akkusativ, sondern auch bei anderen Kasus. So kommt ein Genitiv sogar bei Verben des Gehens vor, den wir heute adverbiell empfinden, vgl. § 87, anord. gengo beir fagra tūna "sie gingen zu den schönen Gehöften"; got. usleibam jainis stadis; manna sums gaggida landis. Vgl. ferner got. insandida ina haibjos seinaizos; ahd. thes wäges er sie wista; nhd. er geht seines Weges. Ein Genitiv des Inhalts auch ist tōdes sterban, und als der Instrumentalis seine lebendige Kraft verloren hatte zu Anfang der ahd. Zeit, da hat sich die Wendung hungivu irsterban nach dem Vorbild von tödes sterban in Hungers sterben verwandelt. 86. Prädikativer Genitiv. Prädikativ ist der Genitiv bei den Verben 'sein' und 'werden'. Vgl. die Beispiele got. Datei (skip) was Seimonis; ibai jah pu bize siponje is; as. $n i$ bist thu thesero burgliudio; ahd. truhtenis ist diu erda; 
mhd. ir roc was grüener varwe; er wart sō baldes herzen; Luther: die reines Herzens sind; nhd. anderen Sinnes werden. Hier handelt es sich wohl nicht um einen ursprünglich adverbalen Genitiv, sondern es liegt wahrscheinlich vielmehr ein durch Ellipse des regierenden Substantivs entstandener adnominaler Genitiv zugrunde.

87. Adverbieller Genitiv. Genau wie beim Akkusativ hat sich aus dem adverbalen Gebrauch ein adverbieller Genitiv entwickelt. Vgl. die Wendungen got. dagis, nahts, mhd. morgens, äbendes; des endes "dorthin"; sturmes, roubes "im Sturm, mit Raub"; zweier spannen breit; nhd. keineswegs, unterwegs, allerorten, spornstreichs, flugs, teils, anfangs u. a. $\mathrm{m}$.

88. Genitiv bei Adjektiven. Sekundär gegenüber dem adverbalen Genitiv ist der Genitiv bei Adjektiven; genau wie der Akkusativ bei Adjektiven wird er vom zugrunde liegenden Verbalbegriff regiert und ist aus prädikativem Gebrauch entstanden, er ist begierig einer Sache = er begehrt einer Sache. Der Genitiv steht so bei den Adjektiven 'gewahr, kundig, eingedenk, teilbaftig, voll, gewaltig, leer, bedürftig, froh' und ähnlichen (§ 21).

89. Doppelter Genitiv. Eine Parallele zum doppelten Akkusativ ist bei dem doch immerhin beschränkten Gebrauch des Genitivs anscheinend nirgends belegt; prinzipiell wäre aber im Germanischen zu einem got. Satze insandida ins haipjos (er sandte sie des Feldes, nach dem Felde) mit rein partitiver Auffassung des direkten Objektes auch eine Form möglich, die got. insandida ize haipjos hieße (ihrer, einen Teil von ihnen). Aber in diesem Falle würde haibjos sehr bald nur noch rein adverbiell empfunden worden sein. Die Sprache vermied den doppelten Genitiv, und rein adverbiell werden auch die beiden Genitive in nhd. ich gehe dieser Tage meiner Wege aufgefaßt. Wir finden 
vielmehr einen Satz wie got. insandida ins haipjos durchaus als die Norm, d. h. stehen bei einem Verbum zwei Objekte, so steht mindestens das Hauptobjekt, also etwa die von der Handlung betroffene Person, im Akkusativ [wenn nicht lieber beide, vgl. den doppelten Akkusativ] und höchstens das zweite, mehr nebensächliche und sekundäre Objekt, also etwa die von der Handlung berührte Sache oder das Gebiet, auf dem die Tätigkeit vor sich geht, im Genitiv; vgl. got. fulljai izwis allaizos fahedais; gredagans gasobida biupe; ahd. thes frewita er hugu sinan; thin kind thih bitte brōtes; fragētun druhtīn therera dāti; mhd. swen got eines guoten wibes wert; des du mich gefraget häst; Luther: der Herr gewähre dich aller deiner Bitte; nhd. ihres Amtes entbind' ich sie.

90. Adnominaler Genitiv. Ein adnominaler Dativ ist in verschiedenen indogermanischen Sprachen, sowie auch in unserer nhd. Umgangssprache durch eine Verschiebung in den Satzverhältnissen entstanden (s. u. § 100); er war ursprünglich adverbal. Es ist nun wohl mit Recht vermutet worden, daß auch der adnominale Genitiv einer solchen, wiewohl älteren Verschiebung in den Satzverhältnissen seine Entstehung verdankt. Wir kommen damit zu der einheitlichen Anschauung, daß die adnominale Funktion bei allen Kasus sekundärer Natur ist. Es leuchtet ein, daß, sowie in jüngerer Zeit der Satz er baut dem Vater - sein Haus zu er baut - dem Vater sein Haus (= des Vaters Haus) geworden ist, daß so auch in älterer Zeit er isst des Brotes - einen Bissen zu er isst - des Brotes einen Bissen oder, wie wir heute stellen, einen Bissen des Brotes, einen Bissen Brot(s) werden konnte. Und nachdem einmal auf diese Weise ein adnominaler Genitiv entstanden war, konnte er sich zu seinen sonstigen Gebrauchsformen leicht fortentwickeln. Vgl. auch die Bemerkungen zum 
Genitivus subjektivus, objektivus und possessivus. - Wir geben einen Überblick über die häufigsten Typen der adnominalen Genitivverbindungen.

91. Genitivus partitivus. Es liegt zunächst überall die Vorstellung von einer Auswahl aus einem Ganzen zugrunde; vgl. got. managei fiske, juka auhsne; ahd. lides zuvei mez, stucchiu brötes; mhd. wines ein becher; im Nhd. ist seit dem 16. Jahrh. die flexionslose Form eingetreten, Fischart: etlich mass wein; Sachs: fünfhundert marck gold, und nur der höhere Stil bevorzugt noch die flektierte Form im Maskulinum und Neutrum, lasst mir den besten Becher Weins in purem Golde reichen. -

So steht entsprechend auch bei genauer und ungefährer Angabe der Auswahl dieser Genitiv, d. h. bei Zahlen und bei Begriffen der Vielheit oder Wenigkeit oder der Negation oder der direkten und indirekten Frage nach diesen Begriffen; got. manageins filu, ainshun drigkandane; ahd. nioman thero friunto; mhd. siner krefte zwō; Luther: seiner Rippen eine, Goethe: langer Jahre zehn; ahd. wer manno; mhd. waz grōzer sorge; nhd. wasWunders; vgl. auch oben $\S 24$ (Genit. nach Adverbien). Engste Auswahl bezeichnet der Superlativ, der daher gleichfalls diesen Genitiv regiert; got. sa smalista apaustaule; ahd. manno miltisto. Eine superlativische Ausdrucksform, eine Steigerung des Begriffes, kommt auch zustande, indem von einem Wort sein eigener Genitiv Pluralis (oder Singularis) abhängig gemacht wird; 'der König der Könige' ist der mächtigste der Könige; vgl. anord. karl karla 'Held der Helden', ahd. skern skernes; knehtes kneht; mhd. wunsches wunsch; grōzer note nōt; nhd. Buch der Bücher.

Eine leicht verständliche Erweiterung dieses Genitivs liegt vor, wenn sich beide Begriffe ihrem Inhalte nach decken, also eigentlich keine Auswahl oder vielmehr die 
Wahl aller in Rede stehenden Personen oder Dinge stattfindet. Wie nach ains steht also der Genitiv auch nach all, got. all waurde, ahd. al gifugiles und nach Teil des Volkes richtet sich Gesamtheit desVolkes, as. thiod Judeōno usw.

92. Genitivus subjektivus und objektivus. Unmittelbar aus dem adverbalen Verhältnis läßt sich vielleicht auch der Genitivus subjektivus und objektivus erklären. Dieser Genitivus ist abhängig von Substantiven, die meist aus einem Verbum abgeleitet sind, und ist entweder Subjekt oder Objekt der im Substantivum immer sehr lebendig vorklingenden Verbalhandlung. Man kann daran denken, ihn zunächst wieder vom doppelten Objekt aus zu erklären, eines Verbums, das etwa gleichzeitig außer dem Genitiv den Akkusativ des Inhalts bei sich führt. Also aus einer Verschiebung in Sätzen wie trinkist du des lüteren brunnen - (einen tranc) oder der Gerechte wird (ein Leben) seines Glaubens leben hätte man die neuen Genitivverbindungen tranc des lüteren brunnen und Leben seines Glaubens erhalten. Andrerseits ist auch wohl angedeutet worden, und das käme vielleicht hauptsächlich für den in Rede stehenden Genitiv in Betracht, daß ein adnominaler Genitiv zuerst vom Prädikatsnomen aus entstehen konnte, welches mit der Kopula an Stelle eines Verbums, das den Genitiv regierte, eingetreten war; so könnte darbā fateres mīnes entstehen aus dem Satze sīd Dētrïhhe darbā gistuontun fateres mines. Auch der adnominale Akkusativ war ja so immer wieder entstanden, konnte sich aber nie weiter entwickeln, weil der Genitiv inzwischen der allgemeine Adnominalkasus geworden war.

Weitere Beispiele für unsern Genitiv sind : got. objektiv waldufni ahmane 'Gewalt über die Geister', subjektiv waldufni kindinis; ahd. gotes minna subjektiv und objektiv (zu Gott); objektiv darbā fateres mines (nach meinem Vater; 
wäre an sich auch subjektiv denkbar); sluzzila himiles objektiv; mhd. subjektiv der küneginne haz; nhd. objektiv Liebe des Vaterlands, daneben subjektiv Liebe des fieien Manns.

93. Gęnitivus possessivus. Mit dem Genitivus subjektivus nahe verwandt ist der Genitivus possessivus, der (im weitesten Sinne) den Besitzer anzeigt. Falls er nicht auf Übertragung von den anderen Fällen beruht, so läßt er sich zur Not aus den Verben der Bewegung erklären. Das Ende des Weges konnte aus Verschiebung des Verhältnisses in einem Satze ich gehe des Weges das Ende entstanden sein. Man müßte dann freilich von hier aus eine starke Weiterentwicklung annehmen. Zur Unterstützung könnte man auf den vielleicht alten Gebrauch der Volkssprache, ein Possessivpronomen hinzuzufügen, hinweisen: des Amtmanns sein Haus (genau wie beim adnominalen Dativ); frühnhd. des löners sin tag; mhd. zweier bischoffe ir rāt; vogel ir alten dōn.

94. Genitivus definitivus. Nahe verwandt ist der sogenannte Genitiv in der Umschreibung. Gemeint ist im Satze nur der Begriff, der im Genitiv steht und nicht der, von dem er abhängt; die schmucklose Rede würde sich mit ihm, freilich dann im Kasus des ihn regierenden Substantivs, allein begnügen. Aber ein gewisser poetischer Stil liebt die Umschreibung mit einem Substantivum, welches begrifflich den von ihm abhängigen Genitiv in gewisser Weise schildert. Es scheint jedoch, als ob dieses Stilmittel dem Deutschen nicht von Haus aus eigentümlich wäre, sondern als ob in ihm ein Einfluß fremder Dichtersprache, der biblischen und der antiken, vorläge. Man beobachtet diesen Genitiv deshalb in ahd. Zeit außer bei Übersetzern im wesentlichen bei Otfrid, wo er indessen auch oft genug auf Übersetzung beruht, vgl. daz sines lichamen hüs= 
templum corporis, selbständig wohl des steines burdin; und ferner wieder, abgesehen von einzelnen mhd. Autoren wie vornehmlich Wolfram, vgl. der riuwen swoeren soum, in unserer klassischen Dichtersprache (Schiller): den Schmuck der Zweige habt ihr abgehauen; ferner Schnee des Alters, Kühle des Regens u. a. m. Es ist interessant zu sehen, wie jedenfalls Notker, der den guten deutschen Prosastil zu schreiben sich bemüht, diesen Genitiv geflissentlich vermeidet, vgl. seine Übersetzung von 'signarem officio stili' mit screib mit temo grifele, von 'levitas alarum' durch mit fettachen.

95. Genitivus qualitatis. Eine sekundäre Bildung ist wohl der Genitivus qualitatis. Er wird kaum unmittelbar aus einem adverbalen Gebrauch abzuleiten sein. Dieser Genitiv bezeichnet die Art und Beschaffenheit des regierenden Substantivs. Vgl. got. dauhtar wintriwe twalibe (von 12 Jahren); ahd. guotera slahta man (von guter Art); comman adales; ein ediles man; mhd. boten guotes willen Hetele dō gewan; ein prünne rōtes goldes; nhd. ein Jüngling edlen Gefühls; ein Mann des Friedens.

\section{Dativ.}

96. Dativ des Objekts. Der adverbale Dativ bezeichnet denjenigen Nominalbegriff, den die Verbalhandlung nur entfernter betrifft, an dem sie gleichsam vorübergeht, um ein anderes Objekt ganz oder teilweise zu treffen, was aber nicht ohne Einfluß auf den Träger des in Rede stehenden Nominalbegriffes bleibt. Ihm gilt die Verbalhandlung, und darum erscheint im Dativ durchaus und ursprünglich nur die Bezeichnung eines lebenden Wesens, einer Person.

Wir haben schon oben beim Akkusativ angemerkt, daß das Gefühl für das $\mathrm{Maß}$ der Nähe und Entfernung 
unsicher sein kann und daß deshalb einzelne Verben Schwankungen im Gebrauch aufweisen; vgl. got. wairp pus in marein neben wairp puk oder nati; mhd. got helfe mich und sō helfe mir got; nhd. er rief mir neben er rief mich; $i c h$ versichere dich und dir. Auch Schwankungen zwischen Dativ und Genitiv kommen vor, so bei 'helfen' (im Got. mit Genitiv), got. gaumjan, galaubjan, trauan.

Bei den Verben, die außer dem Dativ noch einen anderen Kasus bei sich haben, also den Akkusativ oder den Genitiv, wie geben : er gibt mir das Brot oder des Brotes, die also das Objekt mit seiner ganzen oder teilweisen Betroffenheit deutlich angeben, wird die oben definierte Funktion des Dativs ohne weiteres klar. Aber wie steht es bei Verben, die den Dativ als einzigen Kasus haben, wo wie in got. tekif imma "er berührt ihn", wairp pus und deutsch er hilft mir, er ruft mir doch der Dativ anscheinend das volle und nächst betroffene Objekt bezeichnet? Er tut es wohl wirklich nur scheinbar! Ursprünglich und bei den weitaus meisten der hierhergehörigen Verben wird ein durch Ellipse unterdrückter Akkusativ (oder Genitiv) des Objekts oder des Inhalts zu ergänzen sein, genau wie das bei einer Reihe von ursprünglich transitiven Verben der Fall war, die dadurch intransitiv geworden sind; bei anderen hat sich dann die ausschließliche Verbindung mit dem Dativ in Analogie zu diesen entwickelt. Also got. tekip imma "er berührt ihm scil. den Leib, das Kleid, den Arn und dergl', wairp pus in marein scil. 'deinen Körper', got. kukjan "küssen" mit dem Dat. scil. 'dir den Mund und dergl., er ruft mir scil. 'den Ruf, den Befehl, meinen Namen und dergl.' als ein Akkusativ des Inhalts. Wir besitzen eine Reihe von jüngeren Wendungen, die aufs deutlichste die Annahme der Ellipse des Objekts erfordern; vgl. mhd. einer binden (scil. daz hār) "eihr das 
weibliche Gebände anlegen"; einem ze äder läzen (scil. daz bluot); dem rosse hengen (scil. den Zügel) „es laufen lassen, eilen, jagen"; einem spannen (scil. den Bogen), ,auf jemand zielen"; nhd. öffne ihm (scil. die Tür). Bei anderen wie glauben, danken ist die Ellipse des Objekts noch immer in unser Belieben gestellt. Bei Verben der Rede kann diese selbst, direkt oder indirekt wieder gegeben, als Objekt genügen; vgl. ich sage dir, ich sage dir: min geselle kum mit mir; got. 'amen' qipa izwis. Oder es wird ein Objekt ausdrücklich gesetzt: dat sagètun mi. Zu 'danken' vgl. ahd. gode thancódun oder mit ausdrücklichem Objekt mhd. des gruozes si dō dancten den reken über al. Die Verba des 'Gebens; Nehmens, Bringens, Tragens, Mitteilens, Zeigens' haben seit je meist gleichzeitig den Dativ der Person und den Akkusativ des Objekts bei sich.

97. Der Dativ bei Verben als einziger Kasus. So steht denn der Dativ als einziger Kasus bei den Verben des 'Helfens, Dienens, Nützens, Freundlich gesinnt seins usw.'. Vgl. got. guda skalkinon iah mammonin; ahd. ther gerno gode dhionōt; mhd. dem nützent niht die frühte. Bei got. galeikan 'gefallen' (guda); frakunnan 'verachten' (baim anparaim); hatizon 'zürnen' (mis); bairgan 'bewahren': bairgip izai $=$ 'er birgt sie (scil. ihr das Leben) $=$ er bewabrt sie'.

Bei den Verben des 'Glaubens, Gehorchens'. Vgl. got. galaubjan: waurdam meinaim (ahd. mit Objekt: thaz giloubi tha mir); got. Damma hausjaip 'auf den höret' = 'dem höret scil. seinen Befehl'; windos iah marei ufhausjand imma; as. ne williad iro drohtine hōrien, aber mit sächlichem Objekt im Akkusativ: hēlag word hörean ne willead.

Bei den Verben des 'Kommens, sich Näherns, sich Neigens vor jemand, Folgens, Berührens'. Vgl. ahd. boton quement mine thir; got. gamotjan, nehjan: imma; mhd. 
wannen dir diz ors si komen; nhd. wenn dir nun diese Zeichen kommen; ags. $p a$ he heofonum ästāg 'da stieg er zum Himmel auf'; ahd. niggan: imo; anord. stód upp ok neigdi honum; ahd. nū willih thaz mir volgōn; got. siponjan: Jesua; got. has mis taitok; anord. tók jarl honum pá vel 'berührte ihm freundlich viell. die Hand, d. h. nahm ihn freundlich auf'.

Bei den Verben 'sein' und 'werden' $=$ 'zu teil werden'. Vgl. harjamma ize wairpip qens; ahd. iu scal sin heil; hhd. Ehre ward euch und Sieg, Gott sei Dank. Der Rest eines finalen Dativs rom Schema lat. receptui canere liegt vielleicht vor in ags. hie hine güde begyrdad 'sie rüsten ihn dem Kampfe, d. h. zum Kampfe'.

98. Doppelter Dativ. Bei einzelnen der den Dativ regierenden Verben war ihrer Bedeutung nach auch ein sächliches Objekt schon früh nicht ausgeschlossen, so z. B. bei tekan; vgl. auch das ags. Beispiel oben heofonum ästäg. Wie tekip imma kann ich auch sagen tekip wastjai oder wastjom 'das Kleid'. Und unter diesen Umständen ist dann ein doppelter Dativ möglich, der durch eine doppelte Ellipse des Akkusativ- und Genitivobjektes zu erklären ist, wie er vorliegt in got. has mis taitok wastjom? = "wer berührte mir (scil. das Kleid oder des Kleides und) diesem Kleide (scil. den Saum)?'. Andrerseits wäre auch angängig, das 'mir' in diesem Falle als Dativus commodi oder ethicus zu erklären (s. u.); auch auf diese Weise kommt nämlich ein doppelter Dativ zustande; ahd. thên wortun mir giloubi; ginādōt er uns thên sēton.

99. Dativus commodi und ethicus. Prinzipiell kann der Dativ zu jedem Verbum treten, wie wir das auch rom Akkusativ (und Genitiv) gesehen haben. Tritt er zu Verben, die für gewöhnlich absolut gebraucht werden, so reden wir von einem Dativ der loseren Verknüpfung, 


\section{$-85-$}

einem Dativ commodi oder incommodi; denn für gewöhnlich bedeutet dieser losere Dativ, daß die Verbaltätigkeit zum Nutzen oder Schaden jemandes erfolgt. Vgl. got. seinamma fraujin standip aippau driusip; ahd. scein uns der sterro; wehsit thir thaz kristes muas; nhd. euch blühen sechs liebliche Töchter.

Ist ein solcher loserer Dativ vom Personalpronomen gebildet, so redet man von einem Dativus ethicus. Im volkstümlichen Stile ist er sehr beliebt und hinterläßt oder bezweckt, namentlich in der 1. Person, den Eindruck einer sehr gemütlichen Anteilnahme. Vgl. für die 1. Person: ahd. ik mì dē ôdre wèt; mhd. ich stuont mir nehtint späte; im Volkslied: ich weiss mir einen anger breit; ich weiss mir ein blïmlein blaue; ich weiss mir eine müllerin und so oft. - Für die 2. Person: ahd. dū bist dir altèr Hün ummet spähēr; mhd. die minnet dir ein heiden; nhd. bei Lützen ritt er euch unter des Feuers Blitzen auf und nieder; nen Apfel schiesst der Vater dir vom Baum. - Für die 3. Person; denn auch gewisse Wendungen mit dem Dativ dieser Person wird man hierher ziehen dürfen, in denen das Reflexivum rein pleonastische Bedeutung hat: ahd. er sah imo thaz iämar; mhd. sō stunt ime üf der gude man; ich wil zu land usriten, sprach sich meister Hiltebrant.

100. Adnominaler Dativ. Der adnominale Dativ ist nichts Primäres und im Deutschen sehr selten. Er ist z. T. aus prädikativem Gebrauch zu erklären, vgl. § 17. Hierher gehören Verbindungen wie got. bropar Jakoba jah Juse; mhd. ein vorlouf allen; du widerstrìte viendes rāte; Schiller: den Fröhlichen ein Spott; Uhland: du teures Kind, nun Ehr und Liebe mir. Hier dient zur Erklärung überall die Ergänzung der Kopula.

Ein adnominaler Dativ aus Verschiebung im Satzverhältnis, wie er sich in andern indogermanischen 
Sprachen entwickelte, wäre auch im Deutschen leicht möglich gewesen, vgl. Beispiele wie ahd. $d \bar{u}$ wart demo Balderes volon sin vuoz birenkit; mhd. als si dō dem stolzen siniu bein hèt gekleit, wo der Dativ freilich noch zum Verbum gehört. Er ist indessen wohl immer als so vulgär empfunden worden, daß er in der Literatur, wie es scheint, nirgends auftaucht und wir ihn heute nur aus unserer vulgären Ungangssprache kennen, vgl. dem Vater sein Sohn ist gefallen u. a. m.

Aus prädikativem Gebrauch ist wiederum auch, wie beim Genitiv und Akkusativ, der Dativ beim Adjektivum entstanden; er wird vom zugrunde liegenden verbalen Begriff regiert und steht deshalb in Entsprechung zu jenen obengenannten Verben bei den Adjektiven, die 'lieb, hold, nah, nützlich usw.' und deren Gegenteile bedeuten. Beispiele erübrigen sich hier.

101. Der Dativ an Stelle des Lokativ. Die persönliche Funktion des Dativs erscheint deshalb so verwischt im Germanischen, weil hier der Dativ die Funktionen dreier anderer indogermanischer Kasus übernommen hat.

So vertritt er den alten Lokativ, der örtlich und zeitlich den Raum bezeichnet, in dem die Verbalhandlung vor sich geht. Ein alter Temporalis liegt vor in den adverbialen Wendungen got. pamma daga, wintrau, dagam iah nahtam, Damma frumistin daga; ahd. sārio thēn stuntōn, manageru zîti, dritten tage, morgane; mhd. nehten, wĩlen. Ein alter Lokalis liegt vielleicht vor bei kliban, ther gotes wizzōde kleib, ferner in den adverbialen Wendungen heime, allēn halbōn, mhd. manegen enden u. a. m.; vgl. § 21 . 102. Der Dativ an Stelle des Ablativ. Der Dativ vertritt ferner den alten Ablativ, der den Ausgangspunkt der Handlung bezeichnete. So steht der Dativ zunächst 
einmal beim Komparativ, got. frodozans sunum; anord. elde heitare 'heißer als Feuer'; ahd. hlüttrör leohte; wizero snēwe; bezzer sint dine spunne demo wine, s. § 21. [Vom Mhd. an mit Umschreibung: wizer danne snē.] - Er wird als ursprünglicher Ablativ bei Verben des "Trennens, Lösens' und dergl. anzusprechen sein; got. galausips is qenai; ferner vielleicht in ahd. fatere giboranan 'den aus dem Vater geborenen'.

103. Der reine Instrumental. Der Instrumentalis bezeichnet den Begriff, von dem die Verbalhandlung begleitet wird; damit kann einerseits ein persönlicher Begleiter, andrerseits eine Sache als Mittel oder Werkzeug gemeint sein. Noch in vielen seiner indogermanischen Gebrauchsweisen ist der Instrumental im Westgermanischen erhalten, freilich wohl nur in formelhaften Resten. So steht er komitativ: as. hwarf eft te Bethania brahtmu thiu mikilun; ahd. hlüttru muatu singit. Ferner als Mittel beim Verbum: as. he ni thorfte.. aftar thiu odaru wordu furđur gibioden; thoh ina Satanases féknea iungoron fïundes craftu habdin; ahd. nu scal mih swāsat chind swertu hauwan; cheisuringu gitān; goldo garo ziero. Schließlich als Instrumental des Maßes vor Komparativen, as. mikilu betera; ahd. liuzelu minnerun, michilu menigiron. Andere Arten alter Anwendungen des Instrumentalis lassen sich noch aus dem Angelsächsischen belegen.

Im Deutschen aber genügt der Instrumental in der Regel allein schon nicht mehr, sondern seine Funktion ist meist an die Präposition 'mit' geknüpft, die wiederum durch Verschiebung vom Verbum an das Nomen geraten ist. Vgl. ahd.... swertu hauwan, bretōn mit sinu billiu; mit drōstu, mit scazzu; mit furu brennen.

104. Der Dativ an Stelle des Instrumental. Wie aber im Plural im Germanischen allgemein, so ist im 
Gotischen schon früh auch im Singular der Dativ an Stelle des Instrumentalis getreten, in Deutschen dann der Dativ meist in Verbindung mit der vom reinen Instrumentalis ererbten Präposition 'mit'. Vgl. gotisch, komitativ und die Präposition noch beim Verbum: mipurrisup Xristau; mipinsandida imma bropar; as. habdun that barn mid im; ahd. hanton jah ouh ougön beginnent sie nan scouwōn; spenis mih mit dinēm wortun neben her frāgēn gistuont fôhèm wortum; der Dat. Sing. noch ohne Präposition: fuarun sēragemo muate; s. auch $\S 21$.

\section{Starkes und schwaches Adjektivum.}

105. Das schwache Adjektivum. Das Adjektivum in seiner schwachen Flexionsform wird bei attributivem Gebrauche in individualisierendem oder bestimmtem Sinne verwendet. Es steht deshalb z. B. immer, wenn ihm der bestimmte Artikel vorausgeht; got. sa liuba bropar; ahd. diz guata barn. Natürlich aber war es nicht an den bestimmten Artikel gebunden. Es kann auch individualisiert oder bestimmt werden ohne den bestimmten Artikel; vgl. got. Bartolomaiaus blinda; libains aivino; ags. gamela Scylfing; as. liebo drohtin; ahd. bi himilischin gote; ferner in zusammengesetzten Ortsnamen, vgl. in locum qui dicitur haohün steti; in villa langen thorphe, so Reichenbach, Lengenfeld, Altenburg. Ganz und gar bestimmt ist natürlich der Superlativ, der deshalb durchaus schwach flektierte; ferner der Vokativ und so tritt bei ihm das attributive Adjektivum zunächst in der schwachen Form auf, was sich in Plural in einigen altertümlichen Wendungen bis heute erhalten hat; ahd. liobo druhtin min; wibo scōnesta [doch auch schon stark heil magad ziari; mhd. lieber sun]; lieben Brüder, lieben Freunde. Ähnlich bei Segenswünschen, got. ossanna piupida sa qimanda; ahd. sāligo der pescouwot habēt; zu- 
weilen im Vokativ mit Artikel gimma thiu wiza, besonders im Mhd., meist jedoch ohne ihn: Königstochter jüngste. Prädikativ erscheint das Adjektivum nur selten schwach; die starke Form neben dem Artikel ist nur eine Ausnahme von der Regel.

106. Das starke A djektivum. Der starken Flexionsform des Adjektivums eignet, allerdings wohl erst aus dem Gegensatz zu der schwachen, ein gewisser unbestimmter oder genereller Sinn, wie sich aus seiner Verbindung mit dem unbestimmten Artikel und aus der fast ausschließlichen Verwendung in prädikativem Gebrauch ergibt. Auch der unbestimmte Artikel braucht natürlich nicht ausgedrückt zu sein. - Statt der flektierten Form konnte die unflektierte eintreten, im Got. zwar nur erst im Neutrum Nom., Akk. Sing., im Ahd. auch im Mask., Fem. Nom., Akk. Sing. und Nom., Akk. Plur. Neutrius. So attributiv besonders bei Voranstellung im Got. und Ahd.; got. gop waurstw; ahd. guot man; bei Nachstellung noch gern flektiert: krist guatēr. Im Mhd. breitete sich aber auch bei Nachstellung die flexionslose Form aus und zwar über alle Kasus, sogar wenn der Artikel voranging, diu heide rōt, von der linden breit; flektiert einen anger langen. Bei Voranstellung ist die flektierte Form besser bewahrt worden und herrscht heut wieder durchaus bis auf einige fast wie Kompositionen verstandene Reste: Jung Siegfried; lieb Kind; gut Freund. Im Mhd. und Frühnhd. freilich begegnet die unflektierte Form hier häufig im Nom. Sing. grōz jāmer neben grōzer jāmer und im Nom., Akk. Sing. Neutrius ein sĩdin hemde.

Auch in prädikativem Gebrauch hat sich die flexionslose Form alsbald eingestellt, ist aber doch wohl sekundär; im Ahd., Mhd. begegnet nicht eben selten noch der ältere, flektierte Gebrauch, besonders bei anderen Prädikaten als 
'sein' und 'werden'; ahd. thaz wĩg thaz ist sō hebigaz; sinan stuol liaz er italan; mhd. nides was er voller; ich weiz in wol sō küenen; alsō nazzer muoste ich von des münches tische scheiden.

Die Nominalformen des Verbums oder das Verbum infinitum.

107. Bedeutung und Funktion des Infinitivs. Die unter einander nicht verwandten Infinitive der indogermanischen Sprachen sind ihrem Ursprung nach nominale Formen. Im Germanischen gibt es nur éinen Infinitiv, von demselben Stamme gebildet wie das Präsens und daher mit der Bedeutung eines Infinitiv Praesentis ausgestattet, der seiner Form nach der Nominativ oder Akkusativ Neutrius eines Nomen actionis auf idg. *-(o)no ist. Einem urgerm. ${ }^{*}$ nimana $(m)$ entspricht got. niman, ahd.neman, mhd. nemen, nhd. nehmen eigentlich 'das Nehmen, die Nehmung'.

Die Funktion des Infinitivs ist im wesentlichen die nähere Bestimmung eines Verbum finitum, vgl. § 9. Er tritt wie ein Kasus zu einer Verbalform, er geht baden, er lehrt rechnen; er verfügt deshalb, wenigstens im Westgermanischen, auch über eine Flexion, die sogenannten Formen des Gerundiums oder des flektierten Infinitivs, ahd. fona minnu des anaplasannes, tragannes anst oder kann, so auch im Gotischen, mit Präpositionen versehen werden urrann du saian; mhd. äne sümen; der wolte riten üf stelen; durch klagen; ja er kann schließlich wiederum oder vielmehr immer noch rein substantivisch gebraucht werden, s. u. Das alles erklärt sich aus seinem nominalen Ursprung. Die adnominale Funktion des Infinitivs ist seiner verbalen gegenüber sekundär und erst aus prädikativem Gebrauche entstanden. Auch das stimmt wiederum zu seinem nominalen Ursprung; wir hatten dasselbe von der adnominalen 
Kasusfunktion gefunden. - Über die Konkurrenz, die dem Infinitiv mit Erfolg das Gerundium macht, vgl. § 9.

Die Bedeutung des Infinitivs ist im wesentlichen aktivisch. Wendungen, wie ich beginne (zu) reisen, ich gehe schwimmen, got. urrann (du) saian, in denen das Subjekt für Hauptrerbum und Infinitiv dasselbe ist, zeigen deutlich den aktiven Sinn des Infinitivs. Hat der Infinitiv ein anderes Subjekt als das Hauptrerbum, so kann es im Akkusativ oder Dativ auftreten und wir erhalten dann Erscheinungen, die man als Accusativus oder Dativus cum Infinitivo bezeichnen kann. Aber es ist auch ein Acc. c. Inf. möglich, wo der Akkusativ nicht das Subjekt, sondern das Objekt des Infinitivs ist. Es handelt sich dann also um einen Infinitiv transitiver Verben. Und dieser Infinitiv transitiver Verben verliert seine aktive Bedeutung und wird passivisch gefühlt im Acc. c. Inf. Das zeigt sich daran, daß, wenn gleichzeitig auch ein Subjekt da ist für den Infinitiv, man für dieses die Umschreibung mit der Präposition 'von' anwenden kann, was sonst nur beim reinen Passivum üblich ist. Statt ich liess die Soldaten eine Brücke schlagen kann man auch sagen ich liess von den Soldaten eine Brücke schlagen.

108. A ccusativus cum Infinitivo, vgl. § 10. Einen Acc. c. Inf. im Sinne des Lateinischen gibt es im Deutschen insofern nicht, als eine Konstruktion wie 'Caesar milites pontem facere iussit' nicht wörtlich wiedergegeben werden kann. Sobald also das Hauptrerbum keinen Akkusativ der Person regiert (befehlen, erlauben) und dieser Akkusativ (bier milites) unmöglich von der Rektion des Infinitivs abhängt (denn er ist dessen Subjekt), ist ein Satz wie C. befahl die Soldaten eine Brücke (zu) bauen im Deutschen seit je unmöglich. Wo etwa, wie im Ahd., ein solcher Satz dennoch erscheint, liegt Latinisnus vor. Der Acc. c. 


\section{$-92-$}

Inf. ist aber auch im Deutschen sofort möglich, sobald das Hauptverb unbeschränkt transitiv ist und also auch den Akkusativ einer Person regieren kann. Wie mhd. die porten vant er offen stên, ahd. ih irkanta thia kraft faran fona mir so nun auch ich fand ihn draussen stehn; frühnhd. des spiles kiennest du dich meister sin, ferner got. insandida ins merjan; gatawidedun anakumbjan allans; mhd. sin manheit tete si entwichen; nhd. ich höre den Redner spreehen; ahd. heiz mih queman, auch nū quedet ir mih wesan, er sih sagēt cot $\sin$ (se deum esse dicit), mhd. diu zaher diu $i c h \bar{e}$ üf sinem wange ligen sprach, wo quedan, sagèn, sprechen wie nennen, heissen gebraucht sind. Danach wird auch anord. kollopo vera hvalrétt mikenn 'sie sagten, es sei starkes Antreiben von Walen' nicht verwunderlich sein, und nach ich höre den Redner sprechen können auch Wendungen wie got. hausidedup ina siukan noch immer auf germanischer Echtheit beruhen. In allen diesen Beispielen hat der Infinitiv durchaus seine aktive Bedeutung.

In obigem lateinischen Beispiel ist 'milites' weder Objekt zu 'iussit' noch Objekt zu 'facere', sondern das in den Akkusativ getretene Subjekt des Infinitivs. Der Umstand aber, daß im Deutschen das Hauptverbum unbeschränkt transitiv sein muß, zeigt, daß der Akkusativ in allen diesen Fällen vom Hauptverb abhängt; der Akkusativ und der Infinitiv sind nicht auf einander angewiesen, jeder von beiden kann auch ohne den anderen bei dem Hauptverbum stehen (ich höre sprechen, ich höre den Redner); der Akkusativ ist Objekt des Hauptverbums und der Infinitiv nur dessen nähere Bestimmung. Die Konstruktion ist deshalb heute rein auch nur da noch möglich, wo nicht statt des Infinitivs das Gerundium eingetreten ist. - Es wird auch Niemand daran zweifeln, daß, wenn das 'Subjekt' des Infinitivs im Dativ steht, dieser nicht vom 
Infinitiv, sondern vom Hauptverb abhängt, vgl. got. gebun imma drigkan wein, galeikada jah mis meljan; ahd. guot ist uns hir zi wesanne; ich erlaube ihm zu gehen. Hierher auch mit Verschiebung des Abhängigkeitsverhältnisses der gotische 'Dativus cum Infinitivo', vgl. warp gaswiltan pamma unledin.

Ist der Infinitiv der eines transitiven Verbums, so kann er natürlich seinerseits wieder ein Objekt bei sich haben: ich sehe die Soldaten eine Brïcke schlagen oder ohne Objekt des Hauptrerbums: ich sehe eine Brücke schlagen. Dabei ist es natürlich völlig gleich, im zweiten Falle, ob das Hauptverbum transitiv oder intransitiv ist, vgl. ich befehle eine Brücke (zu) schlagen; nur ist heute diese Konstruktion wieder bloß möglich bei den Verben, die noch den reinen Infinitiv haben, also bei 'sehen, hören, machen, lehren, lassen, heißen'.

Hierher gehört nun das as. Beispiel (§ 10) thuo bādun thia liudi that word wendian; mhd. ich bat mich got genern (mit vertauschter Stellung der beiden Akkusative); ferner ahd. ir gisehet umbigeban fon here Hierusalem (videritis circumdari ab exercitu Hierusalem) "Jerusalem wird umgeben von einem Heer, wie ihr seht"; ik gihōrta dat seggen; sie sah druhtin iro bintan; mhd. muget ir nu wunder hoeren sagen; nhd. der den Gebieter lässt verachten; Homer lässt den Achill erschlagen; ich heisse ihn wählen (er wird gewählt); ich höre das Wort sprechen. Auch im Got. wäre garunnun lekinon fram imma (pata barn) möglich und vergliche sich unmittelbar dem ahd. ir gisehet umbigeban fon here Hierusalem. Diese Form des Acc. c. Inf. erinnert an den lat. Acc. c. Inf. Passivi 'Caesar pontem fieri iussit', ja sie wird auch von den alten Übersetzern zur Wiedergabe desselben verwendet. Trotzdem ist die deutsche Form nicht identisch mit der lateinischen, der Akk. ist 
im Deutschen nur Objekt des Infinitivs, er ist nicht notwendig, er kann auch fehlen und der Infinitiv steht nicht im Passivum. Wir verfügen zwar auch über einen Infinitiv Passivi, vgl. der den Gebieter lässt verachtet werden; ahd. ne läze sinen hals uberwunden werden fone geluste, aber dies ist eine sekundäre Ausdrucksweise. - Uns interessiert hier die Beobachtung, daß in allen diesen Beispielen der zweiten Art des sogenannten Acc. c. Inf. der aktive Infinitiv durchaus passivische Bedeutung hat.

109. Der adnominale Infinitiv. In seiner sekundären (s. o.) Verbindung mit dem Nomen ist der Infinitiv allmählich völlig vom Gerundium abgelöst worden, $d$. $h$ von dem, im Westgermanischen flektierten, Infinitiv mit der Präposition got. $d u$, ahd. $z u o$; vgl. nhd. die Pflicht zu helfen; got. hlauts du saljan, mel du bairan, aber noch gagrefts gameljan allana midjungard; es ist schwer darüber zu sprechen. Hier wird der Infinitiv aktivisch gefühlt. Passivisch wirkt der Infinitiv, wenn das Adjektivum, von dem er abhängt, sich auf ein Substantiv bezieht, also persönlich gebraucht ist, so daß dann dies Substantivum zwar Subjekt des Satzes, aber doch Objekt der Verbalhandlung des Infinitivs ist; der Brief ist schwer zu lesen; mhd. daz obez was êrlich, an ze sehenne zierlich; ahd. zi zellene ist iz lang; sìn gisiuni ist uns zi sehanne swär; got. uskiusan skulds ist fram paim sinistam 'er muß verworfen werden von

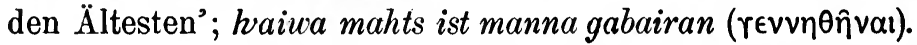
In den got. Beispielen steht noch der reine Infinitiv, deshalb erscheint der passivische Sinn hier viel deutlicher. 110. Erweiterungen im Gebrauch des Infinitivs. In seiner alten Natur begründet ist der substantivische Gebrauch des Infinitivs, der jedoch im Laufe der Zeit sich mehr und mehr ausgedehnt hat. Besitzt er ein Objekt, so erscheint dieses zwar schon sehr früh als attribu- 
tiver Genitiv, doch erscheint immer auch wieder die Rektion, die an Stelle des Infinitivs eine finite Verbalform verlangen würde, ahd. ih meino danchōn guotèn unde undanchön ubilēn; mhd. dā wart vil michel grïezen die lieben geste getān. - Beispiele für den substantivierten Infinitiv: got. ha ist pata us daupaim usstandan; ahd. lā din menden sin, lä dīn furhten sin; minnōn mēra ist thaz (diligere maius est); mhd. uns ist erloubet trüren und fröude gar benomen; tanzen unde singen zergāt mit sorgen gar; nhd. das Fiedeln, Schreien, Kegelspielen ist mir ein gar verhasster Klang.

Ein entgegengesetzter Zug sucht den Infinitir, der ja nun einmal ins Verbalsystem hineingeraten ist, enger in dieses zu verknüpfen; er macht zuweilen fast eine finite Verbalform aus ihm. So kann er in lebhafter Rede wie eine Aussageform funktionieren; es ist hier unter anderen ein gutes Beispiel aus Rosegger beigebracht worden: ich denk's es kommt die Wandlung. Niederknien, auf die Brust schlagen - machts dir einen Kracher und der Kronleuchter liegt auf dem Kirchenpflaster. Häufig ist die Vertretung einer Ausrufsform: auf diese Art dein Leben zu lassen, Götz, und so zu enden! und besonders die eines Imperativs: antreten!, aufstehen, hinlegen!; nicht wieder so lange lesen oben, Herr Kaplan!

111. Neue Infinitive. Ein Infinitiv Praesentis Passivi gebildet durch Umschreibung mit wesan (sin) und werdan (Partizip Prät. und Inf. dieser Hülfsverben) taucht vereinzelt schon im Got. auf; vgl. skal sunus mans uskusans fram sinistam wairban neben unserer oben genannten Konstruktion s. m. uskiusan skulds ist fr. s. Die Umschreibung mit wesan (sin) und werdan wird zunächst noch gleichwertig präsentisch gebraucht, vgl. ahd. gitoufit wesan (baptizari), firholan sin (celari); chiboran werdhan. Seit 
Ausgang des Ahd. wird die mit wesan oder $\sin$ (später worden sein) für die Vergangenheit des Passivs gebraucht. Noch Notker kommt mit dem Inf. Praes. Act. zur Bezeichnung der Vergangenheit des Aktivums aus; vgl. wer zwivelöt. Romanos iu wesen allero richo hērren 'quis nesciat R. olim rerum dominos fuisse'. Daneben aber gebraucht er schon den neugebildeten Infinitiv Praeteriti, vgl. zigen si mih pesmizzen habēn; nhd. dū muost in schiere vloren hän; do der kïnic Sigemunt wolde sin geriten.

112. Das Participium Praesentis. Auch die Partizipien sind nominaler Natur. Ist der Infinitiv ein Substantivum, so ist das Participium Praesentis ein vom Verbalstamm abgeleitetes Adjektivum; ist der Infinitiv ein Nomen actionis, so ist das Partizip ein Nomen agentis. Auch das Partizipium hat also eine Doppelfunktion, eine nominale und eine verbale.

Was seine nominale Funktion betrifft, so kann es wie jedes Adjektivum substantiviert werden. Es verliert dabei wiederum so wie der substantivierte Infinitiv die seinem Verbalstamm innewohnende Rektion und regiert den Genitiv; vgl. got. pans fijands galgins Xristaus (aber paim fijandam izuis); nhd. der Heiland seines Volkes. Die Bedeutung dieses Verbaladjektivums ist zunächst rein aktivisch. Der heilende Arzt und der eilende Bote sind der Arzt, welcher heilt und der Bote, der eilt. Das Subjekt der finiten Form ist das das Partizipium regierende Substantiv. Und so ist es auch beim substantivierten Partizip. Got. pai daupjandans $=$ of $\beta a \pi \tau i$ ¿ó $\mu \in v o$ hat nichts passivisches an sich, insofern daupjan (wie unser baden) neben der transitiven noch eine intransitive Bedeutung hat (intansitiv: ein Taufbad nehmen). Aber es erscheint auch ein Gebrauch, wo das regierende Substantivum eigentlich das Objekt der finiten Form wäre; und hier könnte man 
von passivischer Bedeutung des Partizipiums reden. Vgl. mit ringenden Händen (er ringt die Hände, die Hände werden gerungen); mhd. windende hende; eine klagende swoere (ich klage die sucere, klagen mhd. noch transitiv). Und vgl. ferner in noch viel freierem Gebrauch: ahd. vallandiu suht; mhd. minnende nōt, senende nōt; nhd. nachtschlafende Zeit, schwindelnde Höhe, melkende Kuh, sitzende Lebensart usw. Hier darf man aber wohl zur Erklärung überhaupt nicht vom Verbum ausgehen, nicht von transitiv oder intransitiv, Aktiv oder Passiv reden, sondern hier liegt wohl nichts vor als eine Erweiterung des nominaladjektivischen Gebrauchs; als reine Adjektiva, die hier auch mit ganz anderen Suffixen gebildet sein könnten (sitzig, melkig u. a.) sind hier die Partizipien aufzufassen. Bei einigen Wendungen wie mhd. alle mine lebenden tage, diz anesehende leit; nhd. essende und trinkende Ware könnte vielleicht allerdings auch ein gewisser Zusammenhang mit einer gerundiven Bedeutung einer Nebenform des deutschen Gerundiums vorliegen, die ihrerseits vielleicht mit der gerundiven Bedeutung des Partizipiums zusammenhängt, wie sie im Nordischen (indessen nur prädikativ) vorhanden ist; vgl. anord. eigi er bat tríanda 'nicht darf man das glauben', er pér pess ekke bipianda 'dir ist nicht darum zu bitten'; spätahd. ze chundande $=$ nuntianda, ce habende; mhd. daz līden ist swäre ze tragende; nhd. hochzuverehrender Herr.

Über den prädikativen Gebrauch des Participium Praesentis, dem es wie jedes andre Adjektivum unterliegt, s. o. §11. Hier wirkte nun indessen die besondre Beziehung zum Verbalstamm ein und führte in der Verbindung mit wesan und werdan zur Bildung zusammengesetzter Tempora. Vergangenheit: ahd. sō wārun sie unz an enti thaz lib leitenti; mhd. er was naht unde tac

Naumann, Deutsche Syntax. 
gedenkende; Lessing: ich war mir Sie hier nicht vermutend; ahd. thō ward mund sinēer sār sprechantēr; Luther: da ward das ganze Heer laufend und schrieen. - Futurum (im Präsens von 'werden'): got. jah stairrons himinis wairpand driusandeins; saurgandans wairpip; ahd. wirdist swïgenti; mhd. und werdent mir danne alle gebende die schulde.

113. Das Participium Praeteriti. Die Participia Praeteriti sind Verbaladjektiva, d. h. von Verbalwurzeln gebildete, dem Verbalsysteme eingegliederte Adjektiva. Sie sind dem Verbalsysteme eingegliedert worden, weil sie, auf ein Substantiv bezogen, von diesem nur etwas zeitweilig oder in besonderer Lage geltendes aussagten, nämlich daß es von einem bestimmten Vorgang betroffen wurde und dadurch in einen gewissen Zustand geriet, nicht aber sagten sie wie andere Adjektiva eine Eigenschaft von ihm aus, die sein Wesen betraf. Weil der Vorgang aber vollendet war, wurden sie Participia Praeteriti. Ihre stark nominale Natur zeigt sich indessen darin, daß sie nie teilhaftig sind der Rektion der finiten Verbalform, vgl. der Gesalbte des Herrn. Vom Participium Praesentis unterscheidet es sich namentlich dadurch, daß es je nach der Art des Verbums von vornherein entweder passivischen oder aktivischen Sinn hat. Es hat bei transitiven Verben einen passivischen Sinn (der gesendete Bote, ich sende den Boten, der Bote ist gesendet worden) und bei intransitiven Verben einen aktivischen (der gestorbene Mann, der Mann stirbt, der Mann ist gestorben = er hat dies aus sich selbst getan, nicht von andern erlitten); [bei fremdem Zutun benutzt man wohl scherzhaft die passivische Verwendung dieser aktivischen Form: er ist gegangen worden].

Eine Anzahl von Partizipien macht indessen eine Ausnahme von diesem passivischen Gebrauch der Transitiven. So schon got. drugkans = nhd. trunken (d. h. getrunken 
habend, nicht: getrunken worden); mhd. verswigen, ungezzen; ahd. gedienot, ein gedienter Soldat; eingebildet, belesen, ein studierter Herr; ungegessen, ungetrunken, ungebeichtet, ungefrühstückt ist er davon gegangen. Hier darf man zur Erklärung wiederum gar nicht vom Verbalbegriff ausgehen, sondern hier liegen reine Adjektiva vor. Es handelt sich hier wiederum um eine Frucht der nominal-adjektivischen Richtung.

Die verbale Richtung trug indessen auch ihre Früchte. Infolge seines passiven Charakters konnte das Partizip mit werdan zur Bildung des Praesens und des Praeteritum Passivi benutzt werden, mit wesan ( $\sin$ ) zur Bildung des Perfekt und des Plusquamperfekt Passivi. Das ist eine Folge des prädikativen Gebrauchs, dessen es wie jedes Adjektivum fähig ist. Auch in Beziehung auf ein Objekt konnte dies Partizipium prädikativ gebraucht werden, vgl. ich lasse die Tat ungerochen; mhd. si wil mir ungelōnet lān; ich tuon nāch iu gesant; ahd. nü habēt Uodalrīch firloran èrōno gilih. Einerseits entspringt hieraus die Bildung des Perfekt und Plusquamperfekt Aktivi durch Zusammensetzung des Partizipiums mit habèn, andrerseits beruht hierauf der absolute Gebrauch einiger solcher mit 'un-' negierter Partizipien, wie mhd. unverschuldet, unverscholt: er sprach an ir ère unverschuldet (ohne daß das verdient war); die mich hazzent unverscholt; ungevochten, ungedanket; nhd. unbeschadet, ungeachtet (vgl. § 11).

Aktivische Bedeutung hat das Participium Praeteriti bei den intransitiven Verben, geworden, gekommen, verblïht, geblüht, gesprungen usw. Es dient deshalb zur Bildung des Perfekt und Plusquamperfekt Aktivi in Zusammensetzung mit sin und mit habèn. Bei perfektiver Aktionsart, d. h. wenn das Subjekt durch die Handlung unter Abschluß des Vorgangs in einen gewissen Zustand gerät, mit sin; ich bin gevorden, du bist gekommen, sie ist ver- 
blïht. Bei imperfektiver oder durativer Aktionsart, d. h. wenn die Dauer eines Zustands oder der Verlauf eines Geschehens bezeichnet wird, mit habèn; sie hat geblïht, sie haben getanzt.

Nur bei den Intransitiven perfektiver Aktionsart kann das Partizipium (abgesehen von allen Transitiven) adjektivisch-attributiv verwendet werden; eine gewordene Welt, aber nicht eine geblühte Blume; und nur bei ihnen natürlich auch prädikativ. Auf der aktivischen Bedeutung der Partizipien intransitiver Verben beruht schließlich auch eine den Tempusunterschied nicht berücksichtigende und darum merkwürdige prädikative Verbindung mit kommen als Hülfsverbum; er kommt gegangen, geschlichen, geritten; kommt gesungen und gesprungen; eine Kugel kam geflogen; kommt ein Vöglein geflogen.

\section{Nominaler und verbaler Satzbau.}

114. Das Verbum finitum. Es gibt zweigliedrige Sätze, bei denen außer dem Subjekt wie natürlich, auch das Prädikat aus einer Nominalform besteht, wie Träume Schäume, Alle Mann an Bord; als eingliedriger Satz, bestehend aus nur éiner Nominalform, kann der Vokativ aufgefaßt werden. Daß es auch eingliedrige Sätze, bestehend aus éiner Verbalform, gibt, haben wir schon gesehen; die Impersonalia gehörten hierher, got. rignida. Auch absolut gebrauchte Imperative können als eingliedrige Sätze aus éiner Verbalform aufgefaßt werden. Man wird von einem nominalen und von einem verbalen Satzbau reden können.

Der normale Satz der indogermanischen Sprachen trägt aber einen gemischten Charakter, inden das Prädikat gewöhnlich eine finite Verbalform ist (§ 4-7). Die Schaffung des Verbum finitum wird mit Recht als eine 


\section{$-101-$}

der Hauptgeistestaten der indogermanischen Völker bezeichnet. Es besteht kein Zweifel darüber, daß der nominale Satzbau einen Sprachzustand darstellt, der bei weitem älter ist als der Satzbau gemischten Charakters. Zwar daß etwa der Stil einer großen Anzahl unserer Sprüchwörter wie Viel Feind viel Ehr, Viel Geschrei wenig Wolle, Alter Fuchs alte List, Roter Bart ungetreue Art u. a. m. noch in direktem Zusammenhang mit jener uralten Syntax des nominalen Satzes stünde, mag schier bezweifelt werden. Hier wie auch sonst in manchen sprachlichen Dingen liegt wohl eher immer wiederholte Urzeugung vor. Wohl aber ist bekannt, daß die Kinder zunächst in rein nominalen Sätzen zu reden beginnen und ferner, daß die Sprachen fast aller primitiven Völker überhaupt das Verbum finitum nicht kennen. Primitive Sprachen gebrauchen Gegenstandsbegriffe in Sätzen, in denen wir unbedingt ein Verbum finitum benötigen; sie sagen mein Auge für ich sehe, du mein binden für du bindest mich, sein Sitz für er sitzt darauf, mein Tragen den Stein für ich trage den Stein. - Schließlich hat sich das Verbum finitum überhaupt erst aus dem Nomen entwickelt mit Hülfe der Pronomina und anderer nicht immer deutlich erkennbarer Suffixe. Ursprünglich herrschte Identität zwischen Nominal- und Verbalstamm; aber die nominale Bedeutung eines *bhero-, *nemo- ist die primäre; *bhero-, *nemo- bezeichnen eher einen Zustand, ein Ding, eine Person als die Aktivität einer Handlung. Das aber ist das Wesen des Verbum finitum, die Aktivität der Handlung zu bezeichnen.

115. Beschreibender und erzählender Stil. Das Nomen bezeichnet einen Gegenstand, einen Zustand, eine handelnde Person; das Verbum ein Geschehen, das Handeln selber. Das Nomen ist der Träger der Beschreibung, das Verbum der der Erzählung. Wir können noch immer über 
einen vorwiegend nominalen und einen vorwiegend verbalen Satzbau verfügen. Wir können einen nominalen oder beschreibenden Stil von einem verbalen oder erzählenden unterscheiden. Nach ihren extremsten Spielarten werden wir sie auch den gelehrten und den dichterischen Stil nennen können. Der Gelehrte untersucht Dinge und hält Zustände fest, er operiert deshalb hauptsächlich mit dem Nomen im Stil seiner wissenschaftlichen Sprache; was er vom Verbum verwendet, ist im allgemeinen wenig mehr als das Hülfsverbum. Des Dichters Phantasie, die alles in lebendigem Werden erblickt, löst auch die Zustände in Erzählung auf und in ungleich höherem Grade bilden deshalb Verben das Gerüst seiner Rede. Man vergleiche einen Satz aus Wundt: In der Entwicklungsgeschichte der bildenden Kunst ist uns bereits eine Erscheinung entgegengetreten, die für die Stellung des Tieres innerhalb der primitiven Formen des Kultus eine wegweisende Bedeutung besitzt mit einem Satz aus dem Märchen: Der Frosch, als er die Zusage erhalten hatte, tauchte seinen Kopf unter, sank hinab und über ein Weilchen kam er wieder heraufgerudert; hatte die Kugel im Maul und warf sie ins Gras.

Bekannt sind die Klagen über die etwas schwierige und unklare Sprache unserer neueren Gesetzgebung. Sie beruhen auf der einigermaßen übertriebenen Anwendung des rein nominalen Stiles in dieser Sprache. Es wäre zu untersuchen, ob eine Nachahmung der Sprache des alten römischen Rechts vorliegt oder eine Übertragung von der Sprache der Rechtswissenschaft, wo natürlich der nominale Stil völlig berechtigt wäre. Man kann aber im Zweifel sein, ob der nominale Stil für die Sprache des Gesetzes am Platze ist. Schließlich stellt das Gesetz doch keinen Zustand dar, sondern mindestens zu einem Teile immer einen Vorgang, eine Begebenheit; (wenn einer das 
und das tut; wenn dies oder das geschieht). Die Schwierigkeit und Unklarheit unserer Gesetzessprache würde also auf einer Stilwidrigkeit beruhen, indem auf Bücher der Begebenheit die Sprache der Zuständlichkeit angewandt worden ist. Unsere alte germanische und deutsche Rechtssprache hielt sich von diesem Fehler durchaus frei. Man vergleiche einige Paragraphen aus dem Bürgerlichen Gesetzbuch mit einigen aus dem Schwabenspiegel. B. G. $\S 526$ (auch schon von anderer Seite zu diesem Zwecke zitiert): Soweit in Folge eines Mangels im Rechte oder eines Mangels der verschenkten Sache der Wert der Zuwendung die Höhe der zur Vollziehung der Auflage erforderlichen Aufwondungen nicht erreicht, ist der Beschenkte berechtigt, die Vollziehung der Auflage zu verweigern, bis der durch den Mangel entstandene Fehlbetrag ausgeglichen wird. Oder $\S 1975$ Die Haftung der Erben für die Nachlassverbindlichkeiten beschränkt sich auf den Nachlass, wenn eine Nachlasspflegschaft zum Zwecke der Befriedigung der Nachlassgläubiger angeordnet oder der Nachlasskonkur's eröffnet ist. Schwabenspiegel cap. 128 Nimet ein man eine witwen, diu gut hat, daz man mit dem pfluge buwet, und stirbet si und man sol daz gut wider geben, und ist es gesät und gebuwen: der man nimet den nuz mit rehte dar abe. - Cap. 137. Dienstman nement erbe und erbent als ander liute, di fri sint, nach allem lantrechte. Ez mag aber ir eigen niht gevallen uz ir herren gewalt, ob si niht erben hānt. Si enmugen ouch ir erbe niht verkoufen wan wider ir genoze.

Darauf beruht die Klarheit und ein großer Teil der Poesie des alten Rechtes, daß es das Verbum so häufig verwendet. Es geht oft genug geradezu in Erzählung über, und bekannt sind jene Glanzbeispiele aus dem alten Rechte, die zugleich Glanzbeispiele alter germanischer poetischer Prosa sind, aus dem Nordischen die berühmte Friedensformel 


\section{$-104-$}

aus der Graugans und aus den alten friesischen Rechtsquellen das Stück von den drei Hauptnöten in den Emsiger Texten.

\section{Genera Verbi.}

116. Die Funktionen der drei Genera. Die Genera verbi bezeichnen die verschiedenen Verhältnisse, in denen das Subjekt zur Verbalhandlung steht. Unterscheidet man nun zwischen bloß grammatischem und wirklich logischem Subjekt, dann sind das Aktivum (ich öffne die Türe) und das Medioreflexivum (die Türe öffnet sich) dadurch vom Passivum (die Türe wird geöffnet) getrennt, daß bei diesem das grammatische Subjekt nicht zugleich das logische ist. Im Passivum erscheint grammatisch als Subjekt der Begriff, der bei aktivischer Ausdrucksweise das Akkusativobjekt wäre, der oder das von der Verbaltätigkeit Betroffene. Man nennt das Passivum die Leideform des Subjekts oder sagt auch, daß es das objektive Erleiden einer Tätigkeit bezeichnet. Wir können für das Passivum die Gleichung ansetzen: Grammatisches Subjekt $=$ Objekt. Das logische Subjekt, der Täter, kann noch daneben ausgedrückt werden, muß es aber nicht, allerdings nun nie durch den Kasus des Subjekts, sondern durch got. fram, hd. von mit dem Dativ (seltener durch, got. Dairh); die Türe wird von mir geöffnet.

Demgegenüber sind beim Aktiv und Medioreflexiv logisches und grammatisches Subjekt immer identisch. Vom grammatischen Subjekt geht hier wirklich die Verbaltätigkeit aus. Der Unterschied zwischen diesen beiden Genera besteht nun nur darin, daß das Medioreflexivum diejenige Verbaltätigkeit bezeichnet, 'deren Schauplatz in der Sphäre des Subjektes liegt' und zwar durchaus, während die des Aktivums gewöhnlich außerhalb der Sphäre des Subjektes liegt. Mit andern Worten, das 
Medioreflexiv bezeichnet eine Verbaltätigkeit, an der das Subjekt persönlich interessiert ist, eine Handlung, die sich auf das Subjekt selbst (zurück-)bezieht. So besteht nun allerdings dergestalt eine gewisse Verwandtschaft mit dem Passivum, insofern auch beim Medioreflexiv das grammatische Subjekt. Objekt der Verbalhandlung ist. Übergänge sind zu verstehen, got. haitad $a=$ er nennt sich führt $\mathrm{zu}$ er wird genannt; in gewissem Sinn ist auch das Medioreflexiv eine Leideform, freilich nur eine Selbstleideform. Wir können das Medioreflexivum durch folgende Gleichung ausdrücken: Grammatisches Subjekt $=$ Objekt $=$ logisches Subjekt.

Die Gleichung des Aktivums aber lautet: Grammatisches Subjekt $=$ logisches Subjekt. Das Objekt ist fremd, liegt außen, kann natürlich auch, so bei den Intransitiven immer, ganz fehlen. Das Aktiv bezeichnet also im wesentlichen eine Handlung, die das Subjekt vornimmt (ich esse, komme, gebe). Dann aber kann es auch einen Zustand bezeichnen, in welchem das Subjekt sich befindet, zunächst wohl nur zufolge seines ihm eigenen Wesens, so bei vielen Intransitiven wie ich fliesse, wachse, blühe, bin, werde. Die Eigenschaft eines Dinges wird hier als seine Tätigkeit aufgefaßt. Hierin darf man wohl eine gewisse Verwandtschaft mit dem Medioreflexi vum bemerken. - Und drittens kann das Aktivum auch einen Zustand bezeichnen, in den das Subjekt gerät, aber, und das ist wesentlich, ohne fremden Einfluß gerät. Hierher gehört eine große Klasse intransitiver Verben von inchoativer Aktionsart, welche eben das Geraten in einen Zustand bedeutet, im Got. die Verben auf -nan, im Ahd. die Verben auf $-\bar{e} n$. Indem diese also einen Vorgang am (grammatischen) Subjekt bezeichnen, den dieses doch immerhin erleidet, besteht hier eine gewisse Annäherung an das Passivum, 
freilich mit dem Unterschied, daß dieses grammatische Subjekt zugleich das logische ist und die Verbaltätigkeit aus dem Wesen des grammatischen Subjektes selber sich ergibt. Nie könnte hier mit fram, von oder durch ein äußeres Subjekt der Verbalhandlung angefügt werden, wie das im reinen Passivum möglich ist, weil kein äußeres Subjekt hier vorhanden ist. Solche Verben sind: got. fullnan 'voll werden' (aber fulljan 'füllen'), aber nicht 'von einem gefüllt werden'; weihnan 'geheiligt werden', gablindnan 'blind werden'; ahd. haftēn 'festhängen' intr. (aber heften 'heften, binden' tr.); nazēn 'naß werden' (aber nezzen 'nässen'); altēn 'alt werden'; irheizèn, irkaltèn 'heiß, kalt werden'. Immerhin dienen diese Inchoativa schon bei Ulfilas und auch.im Ahd. öfters dazu, an Stelle eines Passivums des fremden Originals zu treten, got. gafullnoda

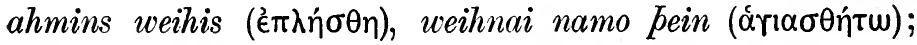
ahd. unde iz nahtēt 'ac nox funditur; grāwēn ih ze unzîte 'funduntur intempestivi cani'.

Dieses vielseitigste ist zugleich das älteste und ursprünglichste der drei Genera. Seiner Funktion will es eigentlich widersprechen, wenn auch die Impersonalia im Aktiv und zwar nur im Aktiv erscheinen, weil bei ihnen ja überhaupt kein Subjekt zum Ausdruck kommt. Hier wird offenbar durch das Aktivum nichts als die reine Verbaltätigkeit bezeichnet. Das Medioreflexiv wäre freilich seiner Natur nach noch mehr für die Impersonalia ausgeschlossen; eher würde sich für sie das Passivum eignen, bei dem allein von einem logischen Subjekt abgesehen werden kann. Aber die Impersonalia sind viel älter als das Passiv; es hatte ihnen zur Zeit ihrer Entstehung kein anderes Tempus als das Aktivum zur Verfügung gestanden.

117. Das Medioreflexivum. Auch das Medium ist alt und gehört zum indogermanischen Erbe; seine be- 
sondere Bedeutung war in besonderen Endungen ausgedrückt, die sich von denen des Aktivums unterschieden. Im Germanischen sind von diesen alten Formen nur noch die des Präsens und zwar nur noch im Gotischen vorhanden; aber diese Formen haben bereits (medio)passive Bedeutung angenommen. Da es sich ebenso wohl auch, vor dem völligen Aussterben dieser Formen, in den übrigen Dialekten verhielt, ist mit gemeingermanischer Neuerung das mit dem Medium ja fast identische Reflexivum an seine Stelle getreten. Wir können deshalb im Germanischen von einem Medioreflexivum sprechen. - Zunächst gibt es reine Mediatantum: got. skaman sik ( $\alpha i \sigma \times u ́ v \in \sigma \theta \alpha \iota)$; deutsch: sich schämen, sich beeilen, sich freuen. Ferner können zu Aktiven Medien gebildet werden: sich ankleiden, sich waschen, besonders für innere Vorgänge: sich zusammennehmen, sich sagen, sich ermuntern, sich einbilden (von uns als Mediumtantum empfunden, Goethe noch: wir bildeten ihr ein); anord. verjask 'sich wehren'. Vgl. got. bugjaina sis matins; nim pus bokos; anord. pau fundusk 'sie fanden sich'; peir setiask nipr 'sie setzen sich nieder'; ahd. zi hĩun er imo quenūn las; mhd. do gedāhten im die besten; nhd. Goethe: ich liebe mir den Müllerknecht; liebt er sich gar ïber die Massen ... Dativ und Akkusativ des Pronomens scheinen gleich alt zu sein, sie richteten sich wohl gemäß ihrer Funktion nach der Intensität des Selbstbetroffenwerdens; in Heliand überwiegt der Dativ. Ist der Dativ logisch ganz gut überhaupt entbehrlich (ich weiss mir ...), so liegt schon reiner Dativus ethicus vor.

118. Das Passivum. Das Passivum ist das jüngste und unvolkstümlichste der drei Genera; im Indogermanischen gab es noch kein Passivum, höchstens Medialformen, die infolge der Verwandtschaft der beiden Genera passiv gebraucht werden konnten. Diesen Zustand bewahrt 
uns im Germanischen das Gotische: poei usfulljanda in mela seinamma ( $\pi \lambda \eta \rho \omega \theta \dot{\eta} \sigma o v \tau \alpha)$; fraletaid, jah fraletanda

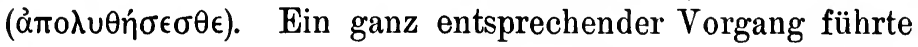
dann im Nordischen zur passiven Bedeutung des Reflexivums; spyriask 'erkundet werden'; skip buask 'die Schiffe werden gerüstet'. - Eine gemeingermanische Neuerung ist dann aber die Umschreibung durch wisan und werpan mit dem Participium Praeteriti. Im Gotischen gilt diese Umschreibung nur erst für die Vergangenheit. Und zwar wird die vollendete Handlung hauptsächlich wiedergegeben durch die Formen von wisan (ist, was); ist numans er ist genommen worden'. Für das erzählende.Präteritum gelten die Formen mit wairpan und wisan; haitans warp 'ėk $\lambda \hat{\eta} \theta \eta$ ';

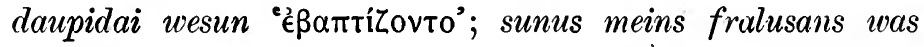
jah bigitans warp [aber im Präsens: haitada, und in $\mathrm{Zu}-$ sammensetzung mit dem Präsens von wairpan entsteht futurischer Sinn: wairpip numans 'er wird genommen werden'].

Im Nordischen hat die Umschreibung mit dem Präsens von vera 'sein' (und verda) präsentischen, die mit dem Präteritum präteritalen Sinn.

Im Deutschen gelten die Formen mit dem Präsens von werdan schließlich für das Praesens Passivi [nachdem anfangs mehr futurischer Sinn wie im Got. in ihnen gelegen hatte]; die Formen mit dem Präteritum von werdan gelten sowohl für das erzählende Präteritum wie für die vollendete Handlung. Abweichend vom Gotischen hat die Verbindung mit ist sehr oft präsentische (oder futurische) Bedeutung, ist giquetan 'dicitur', ist ginoman 'capitur' (sint geruorit 'commovebuntur'); aber schon von früh an hat diese Verbindung auch perfektische Bedeutung und die mit was dann plusquamperfektische (seit dem 13. Jahrh. mit - worden). 
119. Vermeidung des Passivums. Volkstümlicher Stil liebt die alte Syntax, liebt also noch immer das Aktivum mehr als das Passivum. Der gelehrte Stil, vor allem wieder der der modernen Rechtssprache, schwelgt im Passiv. Sogar die ahd. Übersetzer lieben im allgemeinen das Passivum nicht. Mittel der Vermeidung sind ihnen und uns noch heute 1) die 3. Person Pluralis aktivischer Tempora, vgl. dhazs dhanne sie inan chisähin dhoh sō chilaubidin 'ut dum videretur, crederetur'; 2) das zum Indefinit verblaßte Substantivum man, vgl. dār man poah pirgit 'ubi libri reconduntur'; bitet inti iu gibit man 'petitur et dabitur vobis'.

\section{Vorbemerkungen zu den Tempora.}

120. Aktionsarten. Die indogermanischen sogenannten Temporalstänme dienten in der Urzeit der Sprache überhaupt nicht zur Bezeichnung der Zeitstufen, denn die Verbalhandlung hat mit der Zeitstufe zunächst nichts zu tun, sondern sie dienten zur Bezeichnung der Aktionsarten, d. h. der Art und Weise wie die Handlung vor sich ging. Die Verbalform ist zwar zunächst zeitstufenlos, aber nie ohne eine bestimmte Aktionsart. Der Präsensstamm bezeichnete schlechthin die Dauer der völlig zeitlosen Handlung; der Aoriststamm bezeichnete die einfache Handlung; der Perfektstamm einen auf Grund von vorhergegangener Handlung erreichten Zustand. Um die Vergangenheit auszudrücken, hatte man nur die Mittel der Flexion und des Augments. Besonders in folgenden zwei wichtigen Aktionsarten kann die Handlung vor sich gehen: 1) in einer imperfektiven (durativen, kursiven) Aktionsart, die die Handlung in ihrem ununterbrochenen Verlaufe bezeichnet. Verben von imperfektiver Aktionsart sind: steigen, leben, liegen, schwitzen, lachen, streben, betteln, blicken, meinen und die große Mehrzahl der übrigen; 


\section{$-110-$}

2) in einer perfektiven (punktuellen) Aktionsart, die die Handlung im Hinblick auf den Moment ihrer Vollendung bezeichnet. Verben von perfektiver Aktionsart sind : finden, bringen, geben, nehmen, kommen, sterben, bersten, sagen (während 'reden' imperfektiv ist, 'sprechen' perfektive und imperfektive Aktionsart besitzt), werden, sein. Ein Mittel der Perfektierung nichtperfektiver Verben ist gemeingermanisch die Komposition, besonders die mit got. ga-, mhd. ge-; im Deutschen auch mit er-, ver-, entu. a. m. Vgl. got. Dahan 'schweigen' : gapahan 'verstummen', slepan 'schlafen': gaslepan 'entschlafen', haban 'besitzen': gahaban 'in Besitz bringen'; mhd. riten: errìten, ebenso volgen : er- oder ge-volgen 'einholen', bern 'tragen': gebern 'zu ende tragen, gebären'; nhd. blühen : verblühen, brennen: entbrennen, steigen: ersteigen u. a. $\mathrm{m}$.

121. Die Tempora des Germanischen. Von allen indogermanischen Temporalstämmen hat das Germanische nur 2 (3) bewahrt, den des Präsens und den des von Jacob Grimm so genannten Präteritums. Im Präteritum des starken Verbums sind Formen des idg. Perfekts vereinigt mit Formen des idg. Aorists; das Präteritum der schwachen Verben ist gebildet durch Zusammensetzung mit dem Aorist des Verbuns 'tun': *-dhom. Aber die Stämme des Futurums, Imperfektums, Plusquamperfektums fehlen völlig. Als dann die Bezeichnung der Zeitstufen im Fortschritt der idg. Sprachentwicklung wichtiger ward als die der Aktionsarten - sie erklärt sich aus einer Verschiebung des Standpunkts des Redenden, der zunächst die Handlung nur auf ihre Art ansah, sie dann aber nach ihrem zeitlichen Verhältnis zur lebendigen Gegenwart, aus der heraus er sprach, betrachtete - hat das Präsens die Funktion der Gegenwart überkommen, das germanische Präteritum die Funktion der Vergangenheit. So verhält 
es sich in allgemeinen. Noch aber gibt es Perfekta, "kann, weiß, mag' usw., die Gegenwartsbedeutung angenommen haben; noch kann man auch im Präsens vergangene Dinge erzählen, und noch können sowohl im Präsens wie im Präteritum Dinge ausgedrückt werden, die auf eine bestimmte Zeit nicht bezogen sind; auch läßt sich für das Präsens perfektiver Verben zunächst eine andre Bedeutung erwarten als für das Präsens imperfektiver Verben.

\section{Praesens und Praesenshistoricum.}

122. Das reine Präsens. Das Präsens hat also die Funktion überkommen, die Verbaltätigkeit der Gegenwart zu bezeichnen; der Hund bellt, d. h. eben jetzt höre ich ihn bellen. Sodann aber, nicht bezogen auf eine bestimmte Zeitstufe, bezeichnet das Präsens Verbaltätigkeiten von dauerndem Geltungswert, zeitlose Handlungen. Es ist deshalb das Tempus aller Beschreibung [der Hund bellt, d. h. er ist ein bellendes Tier], ferner immermehr auch das Tempus der Sentenzen und Sprüchwörter geworden; kein Mensch muss müssen; ahd. nöt nimet ten gewalt. 'Nehmen' ist zwar ein perfektives Verbum, aber es ist mit Recht bemerkt worden, daß im allgemeinen von den Verben imperfektiver Aktionsart das Präsens immer noch viel gebräuchlicher ist als von denen mit perfektiver Aktionsart. Eine Untersuchung der deutschen Sprüchwörter würde dies vermutlich bestätigen.

So erscheint namentlich bei den mhd. Epikern ein Präsens der zweiten Art sehr häufig, auch mitten in der Erzählung, bei der Benennung und Beschreibung von Gegenständen, wenn diese noch bestehen oder noch bestehend gedacht werden, und bei der Schilderung von allerlei Dingen und Personen, wo unsere Erzähler heute das Präteritum setzen oder aber das Präsens mit 'noch' 
verbinden würden; frühnhd. got danach pegan einen poumgarten pflanzen - da wuohs inne aller obeze wunne, dei wahsent da gnota in ieglichem manode; mhd. ein künec quam dar in daz lant, der was Cernoles genant, die liute in sinnem rīche die lebent sō tiuvelliche. Besonders gern bei heizen: ein degen, heizet Volknant, der kom ze Berne vür gerant; oder bei Angabe von Tages- und Jahreszeiten er lac bi dem gezile... unz an die vesperzit, sō diu sunne schatten. git. Zuweilen auch wird man sich dieses Präsens nur erklären können, wenn man sich vorstellt, daß dem mhd. Erzähler Bilder vorgeschwebt haben, die er beschreibt: Tantalus, des nōt ist ouch gestalt alsus, er swebet üf einem breiten se usw. Bildhaft und nicht fortschreitend ist auch ein gewisses rekapitulierendes Präsens bei den mhd. Epikern, das wie in einer Abbildung noch einmal dem Hörer oder Leser die Situation vor Augen führt, ehe die Handlung im Präteritum weitergeführt wird: Mōrolf ging wider in den walt, Salmāns gedenke wurden manigvalt. nū stāt er üf dem wäten plān und ist in grōzen sorgen, der ede'e kunig Salmān. Das konkrete Präsens stāt entspricht ganz einer Abbildung; daß auch das abstrakte in sorgen sin präsentisch erscheint, ist vermutlich schon ein weiterer Schritt in der Entwicklung. Man hat beobachtet, wie in altnord. Texten zu bildlichen Darstellungen das Präsens für konkrete Situationen erscheint, die man unmittelbar dargestellt sieht, das Präteritum für abstrakte, die man sich nur denken kann.

123. Präsensumschreibung. Das Präsens kann umschrieben werden durch das Particip Praesentis mit dem Indikativ Praesentis von 'sein'. Zweifellos kommt hierbei ganz besonders die durative Aktionsart zum Ausdruck; 'sein', an sich ja perfektiv, ist hier doch nur die Kopula, aber das Partizipium ist ein Adjektivum und bezeichnet 


\section{$-113-$}

also zeitlos eine dauernde Eigenschaft. Vgl. ahd. allero worolti ist er lib gebenti; mhd. als ich des beitende bin. Hierher gehört auch die jüngere Unschreibung mit 'in' und dem substantivierten Infinitiv (ist im Wachsen=wächst) und die etwas ältere, aber sehr volkstümliche mit 'tun' und dem Infinitiv; mhd. nü biten wir die muoter und ouch der muoter barn ... daz si uns tuon bewarn; nhd. wenns heut regnen tut. Diese Umschreibungen gelten freilich mutatis mutandis auch für andere Tempora, aber man wird ihnen auch da durativen Charakter nicht absprechen können.

124. Praesens historicum. Neben diesem reinen Präsens aber kennen wir im Nhd. ein Praesens historicum, das eine Erzählung beginnen und sie fortsetzen kann, indem es sie nicht unterbricht, sondern weiterführt und so in Tempus der Gegenwart Geschehnisse meldet, die der Vergangenheit angehören. Das Präsens hat die Funktion des Präteritums, sodaß der Hörer auch nicht einen Augenblick im Zweifel ist über die wirklichen Zeitverhältnisse. - Daß ein Praesens historicum überhaupt möglich ist, liegt letzten Endes zweifellos daran, daß die sogenannten Temporalstämme ursprünglich gar keine zeitliche Bedeutung hatten, mithin auch der Präsensstamm nicht; sonst wäre vielleicht dieser Wechsel der Tempora für immer unmöglich gewesen. Es wird daher wohl keine der idg. Sprachen nicht mindestens in dieser oder jener Stilart über ein Praesens hist. verfügen; keine von ihnen hat es natürlich auch erst in historischer Zeit entwickelt. Entgegen kommt der Verwendung des Präsens in der Erzählung auch in der Zeit fixierter Temporalverhältnisse und erleichtert hat den großen Wechsel offenbar die lebendige Phantasie des menschlichen. Geistes, die sich, was in der Vergangenheit gewesen ist, jederzeit in die Gegenwart zurückzaubern 
kann. Der lebendige Stil in allen Sprachen wird aus dem eigentlichen Tempus der Erzählung immer wieder in das Präsens fallen. Es fragt sich nur, ob auch die Literatursprache von dieser syntaktischen Möglichkeit Gebrauch macht. Die syntaktische Funktion des Praes. hist. haben wir verstanden und kennen sie; alles weitere ist lediglich wiederum Stilgeschichte.

Außer vom Nhd. (und Neuniederdeutschen, Reuter: as sei all rut sünd, dunn wutscht wat äwer den gang...) her kennen wir innerhalb des Germanischen das Praes. hist. vorzüglich aus dem Altnordischen. Zum altnord. Erzählungsstil gehört gradezu der fortwährende Wechsel zwischen Präsens und Präteritum; nu gerer hann svá ok bar 'nun tut er so und brachte’'; pá tók Haukr sveininn ok setr 'da nahm H. den Knaben und setzt ihn'. Ulfilas vermeidet das Praes. hist., auch wenn es im griech. Texte steht; offenbar vermeidet er damit die Umgangssprache, wie sich in diesem Zusammenhange vielleicht deutlicher erweist als irgendwie sonst. Einigemale aber läßt er es trotzdem stehn, und man wird diesen Fällen vielleicht besondere Beachtung schenken müssen; vgl. jah sai qimip

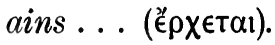

Daß das Praes. hist. im Ahd. fast garnicht vorkommt, nimmt bei der Natur der Schriftsteller dieser Zeit kaum wunder. Auch der deutsche epische Stil liebt es seiner Natur nach nicht. Es begegnet ebensowenig einerseits bei Otfrid, im Heliand und im Messias wie andrerseits im alten Hildebrandslied und in der gesamten mhd. epischen Poesie (mit verschwindenden Ausnahmen) wie schließlich in Hermann und Dorothea. Trotzdem war es selbstverständlich in der lebendigen Sprache vorhanden. Aus der gesamten ahd. Zeit verrät das, abgesehen von der rätselhaften Bedeutung des Präsens in den Versen der heber gāt in lîtun usw., ein ein- 
ziger Vers aus dem Ludwigslied: thō ni was iz burolang, fand her thia Northman. gode lob sagëda, her sihit thes her gerēda. Und vom 13. Jahrh. ab verraten es die Predigten, sobald sie in Erzählung übergehen: do daz nu sīn wirtinne hōrte, sō gāt si zuo Jakob und sait dem; und dō er daz also wider sich selber redet, sō stät er üf und kumt hinz sinem vater; nu hin balde und sich, wie ez gerāten habe dīn almuosen! und er gēt dar unde tuot den kasten üf. Ferner die Volksbücher, sofern sich nur ihre Verfasser dem Stil der Volkssprache nähern: und da er in die bachstuben kam, so fint er weder weck noch semlen; und do er also lag, so kumpt ein tierly, daz man nempt wisel. Und schließlich im Volkslied: es wolt ein megdlein wasser holen, aber die 2. Strophe: sie sicht sich hin, sie sicht sich um, sie meint sie wär alleine; Ein meidlein zu dem brunnen ging, aber dann: sie setzt ir krüglein neben sich; das ganze Lied: jetzt gang $i$ ans brünnele, trink aber net. Seit dem 16. Jahrh. scheint dann das Praes. hist. allgemein literaturfähig zu sein.

\section{Das Futurum.}

125. Das Präsens als Futurum. Zunächst genügte und genügt noch heute das Präsens an Stelle des verlornen Futurums zur Bezeichnung der zukünftigen Handlung;

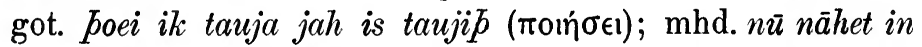
ir ungewin. Diese Möglichkeit beruht hauptsächlich darauf, daß das Präsens perfektiver Verben (bringe, komme, gebe) natürlicher Weise futurischen Sinn besitzt; so gibt got. wair $\not a$ griech. Łैoopal wieder, vgl. mhd. du wirst ein schœene wip; ahd. quement noh thio ziti. Der futurische Gebrauch des Präsens bei andern als perfektiven Verben ist sekundärer Natur. Entgegen kommt nun diesem Gebrauch die Komposition mit ga- (und andern Präpositionen), durch die eben nichtperfektive Verben perfektive Aktionsart 
erhielten. So genügt im Got. die $g a$-Komposition im Präsens zur Wiedergabe griechischer Futura: gup gasailvand

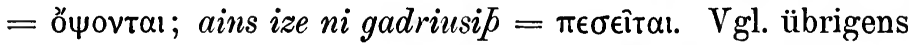
auch aus dem Deutschen: ahd. ih irstān after thiu; inti thiu quena Elysabeth gibirit thir sun (pariet); mhd. an dem ervert nu Parzivāl diu verholnen mare umben gräl; mir tuot ir scheiden für si wē, si gesehent einander nimmer mé.

126. Umschriebenes Futurum. Daneben treten nun von früh an mannigfache Umschreibungen auf, z. T. mit Rücksicht auf die Aktionsart, z. T. auch ohne sie. So ist im Got. die Umschreibung durch duginnan und haban mit dem Infinitiv imperfektiver Verben möglich; fagino

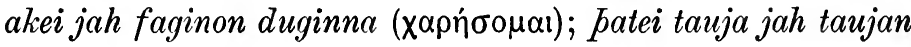

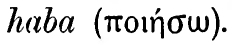

Im Westgermanischen hat sich, wie es scheint ohne Rücksicht auf die Aktionsart, die Unschreibung mit 'sollen' und 'wollen' (seltener 'dürfen, mögen, müssen') und dem Infinitiv verbreitet; die Umschreibung mit scal tauchte schon einmal in Got. auf, skulu und munu 'mögen, sollen' mit dem Infinitiv umschreiben das Futurum im Nordischen. Man ist unwillkürlich geneigt, einen Ausfluß der fatalistischen Weltanschauung in dieser Umschreibung mit sculan zu erblicken; jedenfalls scheint sie zunächst nur solche zukünftige Ereignisse zu betreffen, die ihren Ursprung außerhalb der menschlichen Psyche und des menschlichen Willens haben. Für die Ereignisse aber, die innerhalb dieser Sphäre entspringen, scheint zunächst die Umschreibung mit 'wollen' zu bestehn. Vgl. ahd. berga sculun swinan; daz hōrtih rahhōn ..., daz sculi der antichristo mit Eliase pāgan; nū scal mih swāsat chind swertu hauwan; aber andrerseits in minemo herzen wil ih iemer gehukken. Wendungen wie Luthers es will abend werden sind dann sekundär; der Weg zu ihnen führte über Wendungen wie 
mhd. uns wil schiere wol gelingen; ich wil weinen von dir $h \bar{a} n$. - In der Bildung des Infinitiv Futuri haben sich 'sollen' und 'wollen', übrigens mit deutlicher Bewahrung des alten Unterschieds, lebendig erhalten; vgl. er scheint sein Haus verkaufen zu wollen, aber das Haus scheint verkauft werden zu sollen.

Speziell im Hochdeutschen hatte die Umschreibung mit 'werden' und dem Participium Praesentis größere Zukunft, an dessen Stelle jedoch seit mhd. Zeit der Infinitiv tritt, hauptsächlich wohl in Analogie nach dem Gebrauch bei den übrigen Hilfsverben; mhd. ich woene ir werdent mir es jehen. Diese Umschreibung mit 'werden' und dem Partizip ging offenbar von Verben imperfektiver Aktionsart aus, die durch die Verbindung mit dem Präsens des perfektiven werden futurischen Sinn erhielten; so erscheint sie denn schon im Got. saurgandans wairpip $=\lambda u \pi \eta \theta \eta \dot{\sigma} \sigma \epsilon \theta \epsilon$; ferner ahd. wirdist swīgēnti; mhd. jā wirt ir dienende vil manic woetlicher man.

\section{Die Tempora der Vergangenheit.}

127. Präsensbedeutung des Präteritums. Für die Bedeutung des germanischen Präteritums scheint sein Perfektelement ausschlaggebend gewesen zu sein. - Besitzt das Präsens perfektiver Verben futurischen Sinn, so kann ihr Perfektum leicht präsentischen Sinn erhalten; so ist ich weiss $=i$ ch habe erblickt (zu lat. video). Daher begegnet in der älteren Sprache das Präteritum in Sätzen allgemeingültigen Inhalts, der auf 'wiederholter Erfahrung oder Wahrnehmung' beruht, ungilonot ni bileib, ther gotes wizzōde kleib; 'bleiben' war früher perfektiv gemeint, ein Endergebnis ausdrückend, 'kleben' konnte perfektiv gebraucht werden, aber von hier aus konnte sich der Gebrauch wohl auch auf Imperfektiva ausdehnen. Bei perfektiven auch 
in Glück- und Segenswünschen: kesah in got; wol im wart, der vil gereit (= redet) und weiz er rehte, waz er seit.

128. Das Tempus der Erzählung. Der Tenpusstamm des erreichten Zustandes, gebildet von Verben imperfektiver Aktionsart, mußte zunächst einmal eine Unterbrechung der ununterbrochen fortdauernden Handlung bezeichnen, nach welcher sodann eine andre Handlung einsetzen kounte; ich stieg, nun liege ich; ich stieg, dann lag ich, nun meine ich... So ist das Präteritum zum Tempus der Erzählung geworden; got. urrann gagrefts fram kaisara Augustau; ahd. sunufatarungo iro saro rihtun, garutun se iro güdhamun, gurtun sih iro swert ana; mhd. ez wuohs in Burgonden ein edel magedin; nhd. der Knabe kam, der König rief.

129. Das Präteritum als Perfektum. Aber noch immer konnte und kann das Präteritum auch weiter als Perfektum fungieren; got. usiddja unhulpo 'ist entwichen'; ahd. ik gihorta dat seggen, dat gafregin ih mit frahim, daz hörtih rahhōn; mhd. hoert, waz man ime riet; nhd... gab mir ein Gott zu sagen, was ich leide. Heute gilt das besonders für die norddeutschen Idiome, ich machte gestern bei ihm Besuch.

Aber auch das (zunächst ja verlorne und noch nicht wieder neugebildete) Plusquamperfekt konnte in der älteren Sprache durch das Präteritum ersetzt werden und kann es noch heute; got. ataugida Mariin af Dizaiei uswarp sibun unhulpons; ahd. want er do ar arme wuntane bouga, sō imu se der chuning gap; mhd. daz ouch ir ie alsō gar diu armuot oberhant gewan, daz weste lützel ieman; Schiller: er selbst vertraute mir, was ich zwar längst... schon in Erfahrung brachte.

130. Das neue Perfekt. Bei den West- und Nordgermanen ging indessen, fast erst in literarischer Zeit (8.Jahrh.), 
die Sprache daran, ein neues Perfekt (und Plusquamperfekt) zur Bezeichnung der vollendeten und mit ihrem Resultat in die Gegenwart fortwirkenden Handlung zu bilden. Sie benützte dazu das Participium Praeteriti, das infolge seiner Bedeutung, ein Resultat, einen vollendeten Vorgang anzuzeigen, vorzüglich geeignet war, in Verbindung mit 'sein' oder 'haben'. Und zwar unterscheiden sich hierin, vgl. $\S 113$, die transitiven von den intransitiven Verben.

Als Perfektum gilt es jedoch, abgesehen von der völlig reinen Literatursprache, nur in den norddeutschen Mundarten, die freilich lieber hier das Präteritum brauchen (s. o.). In Oberdeutschland und oft auch, absichtlich oder unabsichtlich, bei den oberdeutschen Erzählern, wenn sie der Lautform nach die Schriftsprache schreiben, fungiert das neue Perfektum ganz und gar als Tempus der Erzählung an Stelle des geradezu ausgestorbenen Präteritums. Ein Beispiel solcher Anwendung bereits bei Otfrid (IV $15,55)$ er habēt in thār gizaltan drōst managfaltan mitten in der Erzählung, umgeben von Präterita.

131. Die Bildung bei den Transitiven. Auch mit Beziehung auf ein Objekt konnte hier das Particip. Praet. prädikativ gebraucht werden; vgl. ich lasse die Tat ungerochen. Wie das Vulgärlat.-Romanische hat darum auch das Germanische zu der fast selbstrerständlichen Umschreibung mit habèn (ahd. auch eigan) gegriffen; denn diese Verbindung sagt eine vom Subjekt am Objekt vollendete Handlung aus. Auf das Objekt bezogen muß das Partizip in Kongruenz mit diesem flektiert werden. So entspricht denn genau der lat.-roman. Wendung nunc habet Uodalricus honores perditos die ahd. sie eigun mir ginomanan liobon druhtīn minan. Die flektierte Form erhielt sich jedoch nicht lange angesichts einer gewiß sehr häufigen Ellipse des Objekts; so griff das Deutsche zur flexions- 
losen, das Nordische zur neutralen Form; ahd. then tod habet funtan thiu hella ioh firsluntan; anord. fader hans hefer fat moelt 'sein Vater hat es gesagt'; ... at fader hennar hefbe hann á braut reket 'daß ihr Vater ihn weggejagt hätte'.

132. Die Bildung bei den Intransitiven. Hier unterscheidet sich wiederum die Perfektbildung der Perfektiva von der der Imperfektiva.

Nur bei den perfektiven Intransitiven kann, wie wir sagten $§ 113$, das Particip. Praet. prädikativ gebraucht werden, natürlich aber nur in Beziehung auf das Subjekt (intransitiv!). Mit der Kopula 'sein' verbunden mußte es dann seiner Natur nach von dem Subjekt ein Resultat, einen erreichten Zustand aussagen. So war auch diese Verbindung ein vortrefflicher Perfektersatz. Alle perfektiven Intransitiva bildeten also ihr Perfektum mit 'sein'; auch hier natürlich zuerst flektiert: ahd. er ist bilizbanēr ('bleiben' ursprünglich perfektiv, s. o.); anord. ek em komenn; ferner unflektiert ahd. nū ist er queman herasun.

Bei den imperfektiven Intransitiven, deren Particip. Praet. nicht prädikativ gebraucht werden kann, war zunächst natürlich keine der beiden neuen Perfektbildungen möglich; hier mußte vollauf das Präteritum genügen. Seit Ausgang der ahd. Zeit, im As. wie es scheint schon eher, bilden sie es nun wie die Transitiva mit 'haben'. Man kann nur annehmen, daß diese Bildungsweise von den Transitiven auf sie übertragen worden ist, nachdem bei diesen mit Ellipse des Objekts die flexionslose und also formell scheinbar nicht mehr prädikative Form sich durchgesetzt hatte.

Dies sind zweifellos die ursprünglichen Verhältnisse, die in den meisten Fällen wohl noch heute gelten; wir sagen ich habe gestritten, gejammert, gesündigt, geprahlt, ge- 
lärmt, gewinselt usw., dagegen ich bin geworden, gekommen, gestorben, geborsten, geschmolzen, komponiert ich bin genesen, verdorben, entronnen, geraten; er hat geklungen aber er ist verklungen, es hat geblitzt aber der Gedanke ist aufgeblitzt. Doch finden sich mannigfache Abweichungen älterer Sprachperioden von jüngeren, Unterschiede unter den Mundarten und der Mundarten wiederum von der Schriftsprache; mhd. mir ist getroumet, ich hän gevolget; frühnhd. es hat geraten, gelungen; nundartlich er hat gewesen, gestorben, ist gestanden, hat gegangen usw. Zum Teil erklären sie sich wohl aus unsicher gewordenem Sprachgefühl, zum größeren Teil jedoch aus veränderter Auffassung über die usuelle Aktionsart eines Verbums. Eine sehr große Anzahl von Verben kann nämlich von vornherein sowohl perfektiv als auch imperfektiv gebraucht werden, je nachdem ob sie das Eintreten oder die Andauer eines Zustandes bezeichnen, vgl. mhd. was gelegen und hät gelegen, ist gesezzen und hät gesezzen, was gestanden und het gestanden, nhd. ich bin (nieder)gekniet und ich habe gekniet; ich bin ans andere Ufer geschwommen aber ich habe mein Teil geschwommen; er ist auf den Baum geklettert aber er hat den ganzen Tag geklettert, ebenso bei reiten, fahren, gehen, wandern, laufen, waten, fliegen, rudern, segeln, ferner bei keimen, wachsen, spriessen, gären, schwinden u. a. m.

\section{Die Modi.}

133. Der Indikativ. Im Indikativ geben wir die reine Aussage wieder, ganz gleich ob diese nun Wirkliches oder nur Vorgestelltes enthalten mag. So kann, wie wir sahen, der Indikativ des Präsens für das Futurum, also eine Vorstellung, verwendet werden. Der Indikativ kann ferner in Vertretung anderer Modi erscheinen, im Präsens an Stelle eines Imperativs, vgl. mhd. ir ezzent, ïbel hüt! 
(Erec 6524); Schiller: du übernimmst die spanschen Regimenter; im Präteritum an Stelle des Irrealis in Bedingungssätzen, vgl. mhd. vorht er den widerslac ('hätte er ihn gefürchtet'), sō het er sis vil wol erlān; Schiller: warf er das Schwert von sich, er war verloren. Ähnlich kann er im Nhd. in allen Tempora bei bloßer Annahme von Tatsachen stehen; angenommen, er kommt; gesetzt, er kam, er ist gekommen. Hier hat sich der Indikativ auf Kosten des Konjunktivs ausgebreitet, wie er es auch in fast allen Arten der Nebensätze, sogar in indirekter Rede und Frage (er sagt, er kommt; er fragt, wer kommt) getan hat; er stand früher nur in der Mehrzahl der Relativsätze (nicht in den verallgemeinernden), der Kausalsätze, in Folgesätzen, die keine beabsichtigte Folge ausdrücken und in Bedingungssätzen (ahd. fliuhit er in then sē, thār giduit er imo wē).

Aber der Gegensatz zu den anderen Modi verlieh dem Indikativ sekundär die Bedeutung eines Modus der Realität. Und so haben jene Vertretungen des Imperativs und des Irrealis einen sehr bestimmten rhetorischen Zweck, indem der Redende das eine Mal den Inhalt seines Befehles schon als sich eben vollziehende Tatsache, das andere Mal Bedingung (und Folge) in der Lebhaftigkeit der Erzählung bereits als vollzogene Tatsache erblickt.

134. Der Imperativ. Für Forderung und Aufforderung gebrauchen wir den Imperativ, wenn das Gebot unmittelbar ausgeführt werden soll. Da sein Formenbestand verkümmert ist, tritt der infolge seiner Wunschbedeutung verwandte Konjunktir Praesentis ein und zwar in der 3. Person schon vorn Gotischen ab, obgleich hier die echte Imperativform noch vorhanden ist; got. liultjai liuhap izwar; ahd. themo si iamer heili; im Plural: nū frewên sih es alle; Schiller: gehn einige und zünden Reisholz an. Auch für die 1. Plural. (Adhortativ) ist alsbald der 


\section{$-123-$}

Konjunktiv eingetreten; ahd. singēm (älter noch singamēs); mhd. nü binden $\bar{u} f$ die helme. Die Umschreibung mit lasst uns scheint besonders im Niederd. verbreitet gewesen und in die Schriftsprache hauptsächlich durch Luther eingeführt worden zu sein. Für die 2. Person gelten die alten Imperativformen, im Got. findet sich hier der Konjunktiv bei der für alle Fälle geltenden dauernden Vorschrift (bata waurkjaif du meinai gamundai); auch im Ahd. wird er hier beobachtet. Für die 1. Sing. gilt natürlich der Konjunktiv.

Der Imperativ kann im Deutschen umschrieben werden durch 'müssen, sollen, wollen, mögen $=$ können' mit dem Infinitiv; mhd. got müeze iuch bewarn; ahd. bimidan thu ni wolless; 'du sollst nicht töten, vgl. anord. nu skaltu vera.. 'nun sollst du sein..'; ahd. hiar mag ev lernēn; nhd. $d u$ kannst gehen. - Selten erscheint er und wohl nur in der älteren Sprache in Nebensätzen; as. êwa gebiudid, that thu man ni slah; mhd. ich sage dir rehte, wie du tuo. Aber noch heute kann der Imperativ einen konditionalen oder konzessiven Nebensatz vertreten; ahd. stig nidar, wir gilouben thir sār; leset allo buah thio sin, ni findit ir..; Goethe: verliere was, er wird es bringen.

135. Der Konjunktiv Praesentis. Konjunktiv und Optativ sind im Germanischen in eine Form zusammengefallen, die formell der Optativ übernommen hat. Der idg. Konjunktiv ging verloren. Wir nennen die Form hier Konjunktiv.

Der Konjunktiv Praesentis hat im Hauptsatz im Verlaufe der Sprachentwicklung an Ausdehnung eingebüßt. Als Optativ fanden wir ihn dienend zur Ergänzung des Imperativs und als reine Wunschform finden wir ihn ferner bei Erfüllbarkeit im Präsens bis heute; got. qimai fiudinassus peins $=$ dein Reich komme. - In der älteren 
Sprache stand der Konjunktiv als Dubitativus in Fragesätzen, um einen Zweifel auszudrücken; got. ha qipau?; du hamma galeipaima?; ahd. noch bei Notker waz tuoien wirs bruodera?. Dann trat der Indikativ dafür ein, erentuell umschrieben mit 'sollen' und 'wollen' oder der Konjunktiv Praeteriti. - Als Potentialis steht er in der älteren Sprache, um eine bloße Vorstellung oder Möglichkeit zu bezeichnen; jah jabai qebjau, batei ni kunnjau ina, sijau galeiks izwis liugnja 'ich würde sein'; ahd. der sī doh nu argōsto ōstarliuto 'wäre'. Hier ist er hauptsächlich vom Konjunktiv Praeteriti abgelöst worden.

136. Der Konjunktiv Praeteriti. Der Konjunktiv Praeteriti bezeichnet vornehmlich die Irrealität in der Aussage, in der Bedingung wie im Wunsch. Er kann auch mit 'müssen, sollen, wollen' umschrieben werden. Vgl. got. jabai allis Mose galaubidedeip, ga-bau-laubidedeip mis; ahd. genuoge getrunchin gerno; guat wāri imo, thaz giboran $n \bar{i}$ wäri ther man; mhd. uns waere wirtes nōt, der uns noch hiute goebe sin bröt; - got. wainei ('utinam') pivdanodedeip; ahd. wolti got, erwundīn dise zìte; mhd. ouwē, gescehe ich si under kranze; müeste ich noch geleben; nhd. o dass sie ewig grïnen bliebe. Noch in Mhd. kann der Konjunktiv Praeteriti hier neben der Irrealität zugleich die Vergangenheit ausdrücken, wo wir uns im Nhd. mit dem Konjunktiv des umschriebenen Plusquamperfektums behelfen; mhd. scehe ez niht her Hartmuot kann auch heißen 'hätte er es nicht gesehen'. Schon früh kann der Konjunktiv Praeteriti aber in dubitativer und potentialer Bedeutung an Stelle des Konjunktiv Praesentis treten, mit völliger Aufgabe seines Tempuscharakters. Vgl. ahd. scolti er sin krist guatēr?; mhd. war möhte ich nü geriten?; nhd. wärs möglich, könnt ich nicht mehr, wie ich wollte?; mhd. sō miltes vürsten hōhzìt möhte noch den armen niht gewerren. 
Zur Bezeichnung des Potentialis in der Vergangenheit haben wir dann seit mhd. Zeit wiederum zum Konjunktiv des umschriebenen Plusquamperfekts gegriffen; mhd. ich hetez baz gelazen $\bar{e}$.

Über die Konjunktive in Nebensätzen, wo sie die ältere Sprache in großer Ausdehnung kannte, von der Regelung des Tempus durch die Zeitenfolge in der älteren Sprache, sowie über die Einschränkung beider Konjunktive durch den Indikativ im jüngeren Sprachgebrauch und des Konjunktiv Praesentis durch den Konjunktiv Praeteriti haben wir schon oben das wichtigste in Kürze gesagt; vgl. $§ 56$; $57 ; 133 ; 134$. 


$$
\text { . }
$$




\section{Aus dem Verlag von}

\section{Karl J. Trübner in Straßburg}

\section{$\operatorname{mcmxv}$}

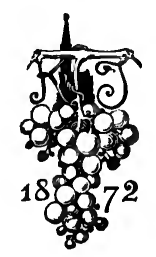

Durch die meisten Buchhandlungen des In- und Auslandes zu beziehen. 


\title{
Abriss \\ der deutschen Grammatik
}

\author{
von \\ Hans Schulz
}

Privatdozent an der Universität Freiburg i. Br.

(Trübners Philologische Bibliothek Band 1.)

80. VII, 135 S. 1914. Geh. 16 2.20, geb. th 2.70.

Das Buch faßt in ganz kurzen Zügen, unter Benutzung und Anführung der hauptsächlichsten Literatur, die zum Studieren der deutschen Grammatik gehörigen Forschungsgebiete zusammen.

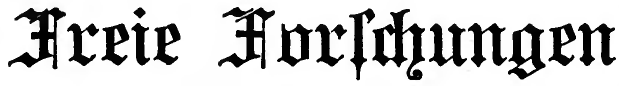

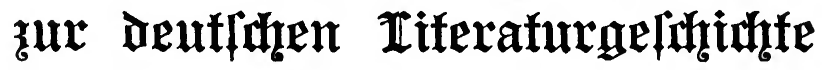

\section{Seraug̨gegeben von}

\section{Fram}

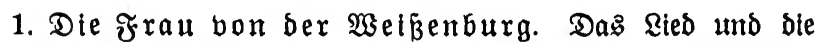

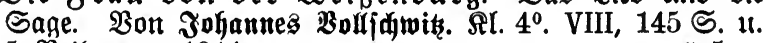
5 Beilagen. 1914.

A 5.-

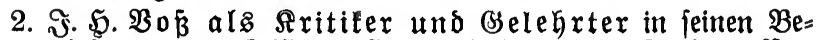

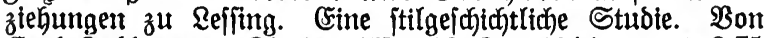

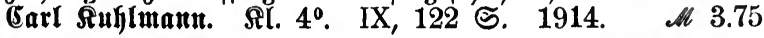

3. Wieland und das Drama. Bon Dr. Emilie Marx. Rl. $4^{0}$. VII, 136 S. $1914 . \quad \mu$

4. (5). Ch. Ridtenbergs Stellung zur beutfalen Rite=

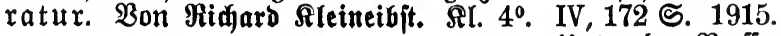
unter ber $\mathfrak{B r e f f e . ~}$

Verlag von KARL J. TRÜBNER in Straßburg und Berlin 


\section{Deutfides \\ FremDwörterbud}

$\mathfrak{F a n s} \mathfrak{i o n} \mathfrak{S} \mathfrak{d u l} \mathfrak{z}$

Pribatbozent an ber $\mathfrak{u n i v e r j i t a ̈ t ~ f r e t b u r g ~} i$. $\mathfrak{B r}$.

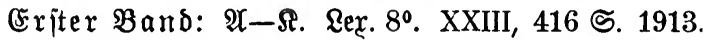

Bebeftet $M$ 8.20, in Retnmand gebumben $M$ 9.-.

Der II. Band: $\mathfrak{\Omega}-3$ wiro in etwa $5-6$ Rieferungen von je 5 Bogen

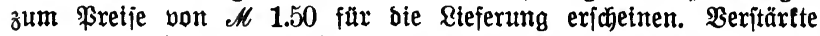
Rieferungen werben entiprechend böber beredfnet.

Das Werk versucht zum ersten Male eine lexikalische Behandlung der in unsere Sprache aufgenommenen Fremdwörter nach den Grundsätzen der modernen Wortforschung. Der Verfasser hat es sich zur Aufgabe gemacht, für jedes Wort die Quelle und die Zeit der Entlehnung zu ermitteln, seinen ursprünglichen Geltungsbereich festzustellen und unter Darlegung des historischen Belegmaterials seine Entwicklung im deutschen Sprachgebrauch zu veranschaulichen. Besonderer Wert wurde darauf gelegt, die lebende und allgemein gebräuchliche Sprache zu fassen und eingehend $z u$ behandeln.

„Das lang ersehnte geschichtliche Fremdwörterbuch tritt endlich in Erscheinung, nicht im Zusammenarbeiten mehrerer, nicht als Ertrag einer langen Lebensarbeit, sondern dank der Tatkraft, dem mutigen Zugreifen eines jugendfrischen Mannes. Schulz will allerdings nicht ein Seitenstück zum Deutschen Wörterbuch bieten, seine Arbeit ist vielmehr auf ein einbändiges Werk berechnet. Es sollen nur die wirklich lebendigen Fremdwörter behandelt werden und nur die, die der allgemein gebräuchlichen Sprache angehören; Veraltetes, wie das große Heer der technischen Ausdrücke, scheidet also aus. Was Schulz innerhalb dieser Grenzen geleistet hat, ist ganz vortrefflich. Auswahl, Anordnung, Darstellung sind durchaus zweckentsprechend und geschickt; musterhafte Knappheit verbindet sich mit großem Reichtum ... Die Ausstattung des Buches ist durchaus erfreulich. Hoffentlich liegt das Ganze recht bald vollendet vor uns."

Prof. Dr. O. Behaghel in Literaturblatt für germanische und romanische Philologie XXII. Fahrgang IQII, Nr.I.

Verlag von KARL J. TRÜBNER in Straßburg und Berlin 
Socben erschien :

\title{
Eftymologifdhes Ssörferbud Der Deuffiden $\mathfrak{S p r a d b e}$
}

\author{
vont

\section{Friedrid Rluge}

orb. Profefjor ber beutjđen Sprađje an ber untberfität frreiburg $i$. Br.

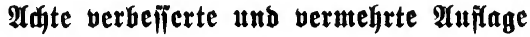

Lex. 80. XVI, 515 S. 1915. Sebeftet $\mathscr{M} 10$. -, in Reintwand geb. AN 11.40, in Salbfranz geb. N 12.50

Das Werk behauptet nunmehr drei Jahrzehnte lang seinen hervorragenden Platz innerhalb der deutschen Sprachwissenschaft. Für den Fachmann wie für den Laien ist es ein unentbehrliches Nachschlagebuch geworden. Die Rätsel, die in den Worten der Muttersprache verborgen liegen, klärt der knappe Band von etwa 30 Bogen allseitig und überzeugend auf. Der Verfasser hat in der wissenschaftlichen Durchdringung der deutschen Sprach- und Wortgeschichte stets seine Lebensaufgabe gesehen und bemüht sich auch diesmal wieder den Fortschritten auf dem Gebiet der Lexikographie und Etymologie gerecht zu werden. Der große Erfolg des Werkes ist der beste Beweis dafür, daß der Verfasser mit seinem Buch für das Verständnis der Muttersprache dem deutschen Volk ein Bildungsmittel ersten Ranges geschaffen hat.

Verlag von KARL J. TRÜBNER in Straßburg und Berlin 


\section{DEUTSCHE GRAMMATIK}

GOTISCH, ALT-, MITTEL- UND NEUHOCHDEUTSCH VON

\section{W. WILMANNS}

Professor der deutschen Sprache u. Literatur a. d. Universität Bonn.

Erste Abteilung: Dritte verbesserte Auflage. Gr. $8^{0}$. 32 Bogen. 191 I.

$\mathscr{M}$ 9.-, in Lwd. geb. $\mathscr{M}$ 10.-, in Halbfranz geb. $\mathscr{M} 11.50$ Lautlehre.

Zweite Abteilung: Zweite Auflage. Gr. $8^{0}$. XVI, 67 I S. 1899. Anastatischer Neudruck 191 I.

$\mathscr{M}_{12.50}$, in Lwd. geb. $\mathscr{M}$ 1 3.50, in Halbfranz geb. $\mathscr{M}_{15}$. Wortbildung.

Dritte Abteilung: Erste Hälfte: Erste und zweite Auflage. Gr. $8^{0}$. X, 315 S. 1906.

$\mathscr{M}$ 6. - , in Lwd. geb. $\mathscr{M}$ 7.-, in Halbfranz geb. $\mathscr{M}$ 8.-

- - Z Zweite Hälfte: Erste und zweite Auflage.

Gr. 80. VIII, S. 317-772. 1909 .

$\mathscr{M}$ 9.-, in Lwd. geb. $\mathscr{M}$ Io.-, in Halbfranz geb. $\mathscr{M}$ I I.Flexion:

(Verbum, Nomen und Pronomen).

„... Es ist sehr erfreulich, dass wir nun ein Buch haben werden, welches wir mit gutem Gewissen demjenigen empfehlen können, der sich in das Studium der deutschen Sprachgeschichte einarbeiten will, ohne die Möglichkeit $\mathrm{zu}$ haben, eine gute Vorlesung über deutsche Grammatik zu hören: in Wilmanns wird er hierzu einen zuverlässigen, auf der Höhe der jetzigen Forschung stehenden Führer finden. Aber auch dem Studierenden, der schon deutsche Grammatik gehört hat, wird das Buch gute Dienste leisten zur Wiederholung und zur Ergänzung der etwa in der Vorlesung zu kurz gekommenen Partien. Doch auch der Fachmann darf die Grammatik von $W$. nicht unberücksichtigt lassen. Denn alle in Betracht kommenden Fragen sind hier mit selbständigem Urteil und unter voller Beherrschung der Literatur erörtert ..." Literarisches Centralblatt 1893, Nr.40.

Verlag von KARL J. TRÜBNER in Straßburg und Berlin 


\section{GRUNDRISS}

DER

\section{GERMANISCHEN PHILOLOGIE}

UNTER MITWIRKUNG ZAHLREICHER FACHGENOSSEN HERAUSGEGEBEN VON

\section{HERMANN PAUL}

ord. Professor der deutschen Philologie an der Universität München.

DRITTE VERBESSERTE UND VERMEHRTE AUFLAGE

Von der neuen Auflage des Grundrisses sind bis jetzt die folgenden Bände erschienen:

I. Die Elemente des Gotischen. Eine erste Einführung in die deutsche Sprachwissenschaft. Von Friedrich Kluge. Gr. $8^{\circ}$. VIII, I33 S. I91I.

Geheftet $\mathscr{M} 2.25$, in Leinwand gebunden $\mathscr{M}$ 3.-.

2. Urgermanisch. Vorgeschichte der altgermanischen Dialekte. Von Friedrich Kluge. Gr. $8^{\circ}$. XI, 289 S. I9I3.

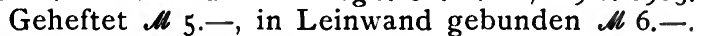

3. Geschichte der deutschen Sprache. Von Otto Behaghel. Gr. $8^{\circ}$. IX, 354 S. 1911 . Mit einer Karte.

Geheftet $\mathscr{6}$ 6.-, in Leinwand gebunden $\mathscr{M}$ 7.-

4. Geschichte der nordischen Sprachen besonders in altnordischer Zeit. Von Adolf Noreen. Gr. $8^{0}$. VII, 239 S. 1913.

Geheftet $M 4.50$, in Leinwand gebunden $\mathscr{H} 5.50$.

5. Grundriß des germanischen Rechts. Von Karl von Amira. Gr. $8^{\circ}$. XII, 302 S. 1913.

Geheftet $\mu_{5}$.- , in Leinwand gebunden $\mathscr{M}$ 6.-. Unter der Presse

Historische Syntax der englischen Sprache von E. Einenkel. Ca. 12 Bogen.

In Vorbereitung:

Geschichte der mittelhochdeutschen Literatur. Von F. Vogt.

Ausführliche Prospekte stehen zur Verfügung!

Verlag von KARL J. TRÜBNER in Straßburg und Berlin 


\section{Wörterbuch-Bibliothek.}

Wörterbud Der Deut/d)en \&aufmanns(plad)e. Auf geschichtlichen Grundlagen. Mit einer systematischen Einleitung. Von Alfred Schirmer. Lex. $8^{\circ}$. LI, $218 \mathrm{~S}$. 1911.

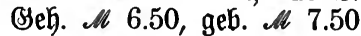

Die Drut/d)e Drudker(prad)e. Bon Dr. Seinxid Rlenz. $8^{\circ}$. XV, 128 S. 1900 . Beh. M 2.50 , geb. M 3.50 Sdplagwörterbud. Bon Dtto Radendorf. $8^{0}$. XXIV, 365 S. 1906. Sseh. 4 6.-, in Reinmand geb. M 7.-

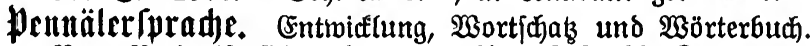

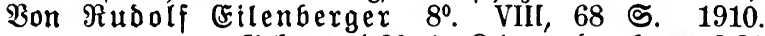
(seh. $M 1.80$, in Reintwand geb. 22.30 Sđclten-Wörterbud). Die Beruf $\bar{s}=$, bejonders Şandwerfer=

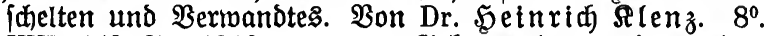

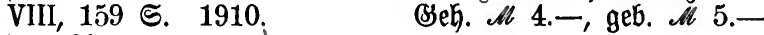
Rotwelld. Duellen und Wortidats ber (sauner= ipradie und ber berwandten Beheimipraden. Bon Friedrta Rluge. I. Rotwelifies Duellenbud). Br. $8^{0}$. XVI, 495 ธ. 1901.

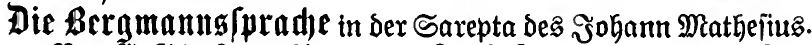
Bon E. \& öpfert. $8^{0}$. IV, 107 S. 1902.

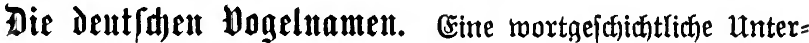
juffung. Bon Sugo Suolahtt. Bsr. $8^{0}$. XXXIII, 540 S. 1909. (seb). M 16.-, geb. $\mathscr{M}$ 17.-

Siebrnlürgi(d)-(äd)fi(d)eg Wörterbud). Mit Benützung der Sammlungen Johann Wolffs herausgegeben vom Ausschuß des Vereins für siebenbürgische Landeskunde.

Erster Band: 1.-4. Lieferung. Bearbeitet von Adolf Schullerus. Lex. $8^{0}$. Je 10 Bogen. 1908/13. Je $\mathscr{M} 4$.$\mathrm{Z}$ weiter Band: 1.-3. Lieferung. Bearbeitet von Friedrich Hofstädter, Georg Keintzel und Adolf Schullerus. Lex. $8^{\circ}$. Je 10 Bogen 1911/12. Je $\mathscr{M}$ 4.-

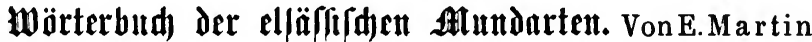
und H. Li enhart. I. Band: Lex. $8^{\circ}$. XVI, 800 S. 1899. Geh. $\mathscr{M} 20 .-$, in Halbfranz geb. $\mathscr{M} 23.50$ II. Band: Mit einem alphabet. Wörterverzeichnis und einer Mundartenkarte von Hans Lienhart. Lex. $8^{\circ}$. IV, 1160 S. 1907.

Geh. $M$ 32.-, in Halbfranz geb. $M$ 35.-

Verlag von KARL J. TRÜBNER in Straßburg und Berlin 


\section{REALLEXIKON DER GERMANISCHEN ALTERTUMSKUNDE}

Unter Mitwirkung zahlreicher Fachgelehrten herausgegeben von

\section{Johannes Hoops}

ord. Professor an der Universität Heidelberg.

Erster Band. A-E: Lex. $8^{0}$. XVII, 642 S. 1911-13. Mit 62 Abbildungen und 47 Tafeln.

Geheftet $\mathscr{N} 21 .-$, in Halbfranz geb. $N 24 .-$

Zweiter Band. F-J: Lex. $8^{0}$. XII, 630 S. 1913-15. Mit 29 Abbildungen and 37 Tafeln.

Geheftet $\mathscr{N}$ 20.-, in Halbfranz geb. $\mathscr{N}$ 23.-

Dritter Band, 1. Lieferung: Kacheln-Latris. Lex. $8^{0}$. S. 1-128, mit 7 Tafeln und 6 Abbildungen im Text. 1915. $M 5 .-$

$D^{A S}$ REALLEXIKON gibt eine von Spezialforschern bearbeitete lexikalische Gesam tdarstellung der Kultur der germanischen Völker bis etwa zum Ende des ersten Jahrtausends. Es werden alle diejenigen Tatsachen behandelt, die nicht bloß für die betreffende Einzelwissenschaft von Interesse, sondern auch für die verwandten Disziplinen wissenswert und belangreich sind.

Die Publikation des Werkes erfolgt in Lieferungen mit zahlreichen Tafeln und Textabbildungen. - Der Subskriptionspreis beträgt 5 Mark für jede Lieferung von ca. 8-10 Bogen nebst Tafeln und Abbildungen. Verstärkte Lieferungen werden entsprechend höher berechnet. Der Verlag behält sich jedoch das Recht vor, später für neuhinzutretende Bezieher den Preis zu erhöhen.

Das ganze Werk ist auf 4 Bände von zusammen 140 Bogen Lex. $8^{0}$ berechnet.

Verlag von KARL J. TRÜBNER in Straßburg und Berlin 


\section{Neuere Werke.}

Henrich, Anton, Die lyrischen Dichtungen Jakob Baldes. Quellen und Forschungen zur Culturgeschichte der germanischen Völker. 122. Heft. $8^{\circ}$. IX, 233 S. 1915. Scholl, Dr. Klaus, Die Mundarten des Kreises Ottweiler. Untersuchungen auf lautphysiologischer und sprachgeschichtlicher Grundlage. 80. X, 157 S. 1913. Sdramm, J̛rib, Shlagmorte ber $\mathfrak{A}$ lamodezeit. Bei= heft zu Band 15 der Zeitjurift für beutjhe Wort= forjatung. Mit 3 Tafeln in Lidytorutúf. $8^{0}$. III, 120 S. 1914.

A 5.50 .

Schwarz, Dr. K., Das intervokalische -gim Fränkischen. Sprachgeschichtliche Untersuchungen. Mit 3 Karten und 4 Skizzen im Text. 80. VIII, 134 S. $1914 . \quad$ N 5.Tappolet, Ernst, Die Alemannischen Lehnwörter in den Mundarten der französischen Schweiz. Kulturhistorisch-linguistische Untersuchung. Erster Teil: Gr. 8 ${ }^{0}$. III, 104 S. 1914. Mit einer Karte.

Torrens, R. K., and Herbert Parker, English Idiomatic and Slang Expressions done into German. KI. 80. XII, 119 S. 1914.

Geheftet $\mathscr{N} 2.25$, kartoniert $\mathscr{N} 2.50$.

Untersuchungen zur Deutschen Sprachgeschichte. Herausgegeben von Rudolf Henning. Heft 5: Das Reichenauer Glossar Rf nebst seinen näheren Verwandten Bib. 9 und Bib. 12. Von Dr. Robert Brans. Gr. 80. IV, 119 S. 1914. M 3.Buftmann, Rubolf, $\mathfrak{B a l t h e r ~ v o n ~ b e r ~} \mathfrak{B}$ ogelweide. Mit 3 Tafeln. $\mathfrak{R l} .8^{0}$. III, 102 S. 1913. Sekeftet $\mathscr{M} 2 .-$, fartoniert $\mathscr{N} 2.40$.

Verlag von KARL J. TRÜBNER in Straßburg und Berlin 


$$
,
$$

$$
-
$$


.

$=$ 


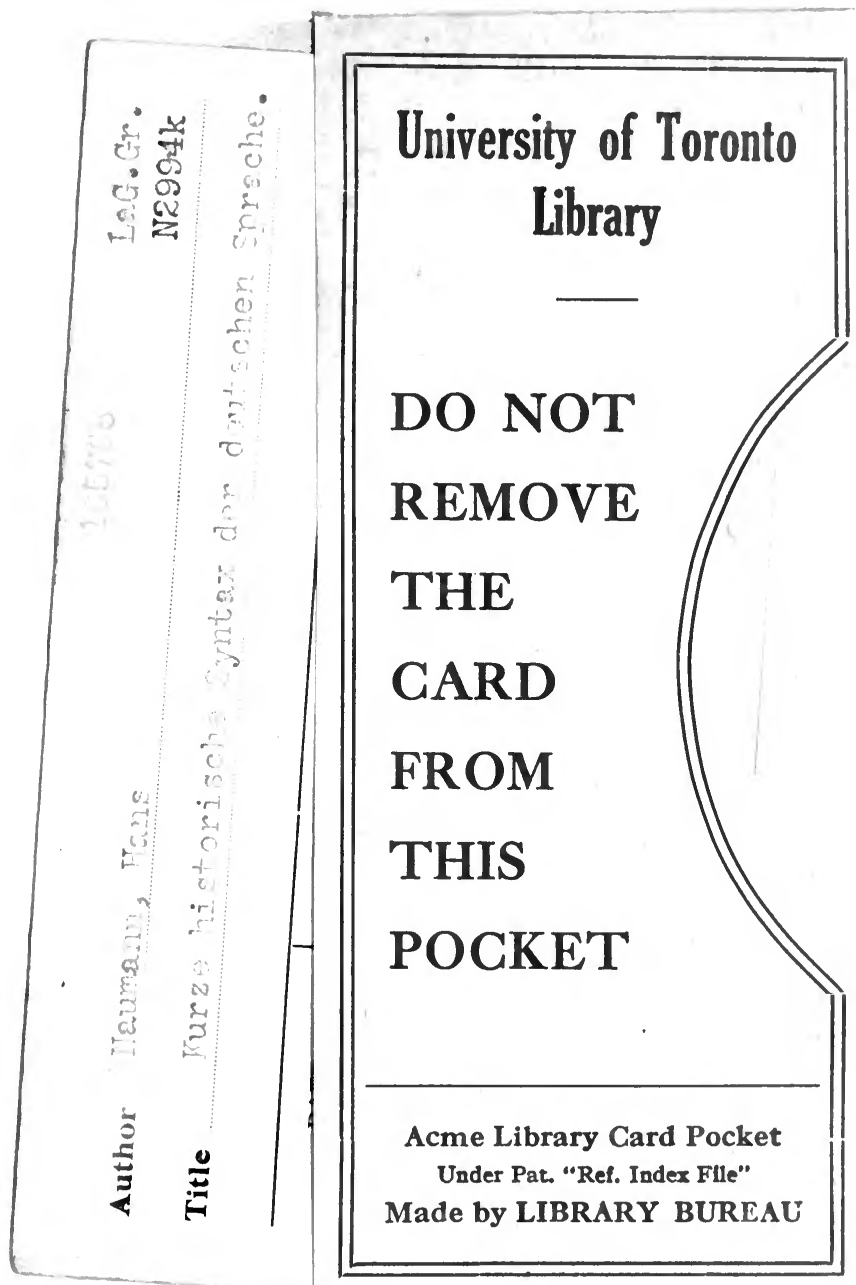




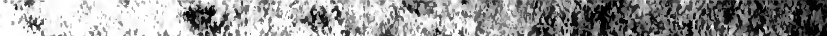

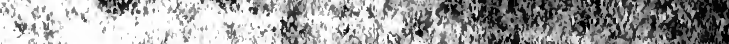

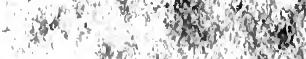

(4)

nis

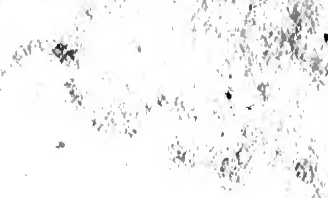

30
$x$
0
4

Nom

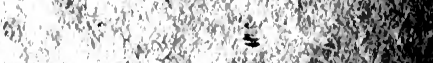

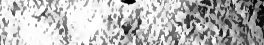

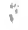

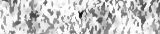
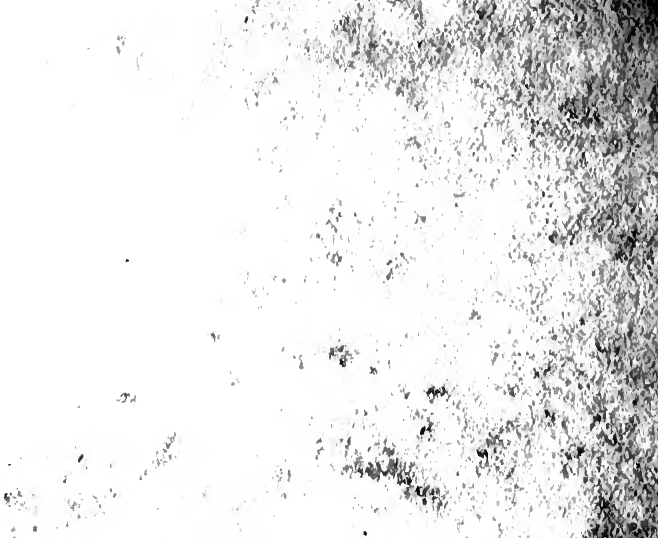

$\operatorname{moval}^{4}$
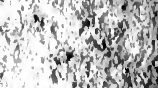

is 20
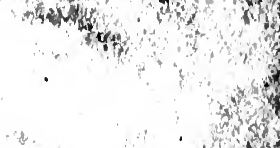

thes

(n)

a d o

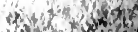

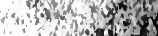
(n)

C.N1 and on $-2+24$ $3 \times$ $\therefore \quad n+m$ 10. and and and is ond a d tom th on

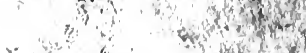

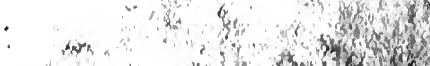

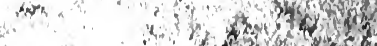
$\rightarrow$ t and

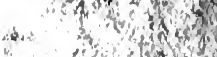
3930 , the a Noth 